(اختيار نوع الجنين ( الاصطفاء الجنسي )

اختيار نوع الجنين ( الاصطفاء الجنسي )

بين متطلبات الحاجة ودواعي الرضا بالمشيئة

\title{
دراسة فقهية مقارنة
}

د ـ ـ خالا محمد حسين إبر اهيم

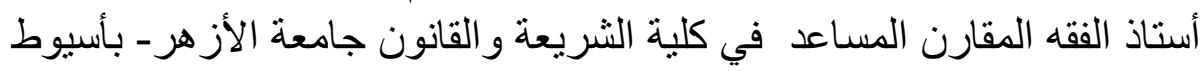

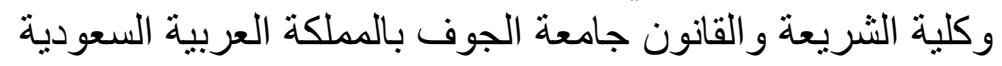

\section{مقدمة}

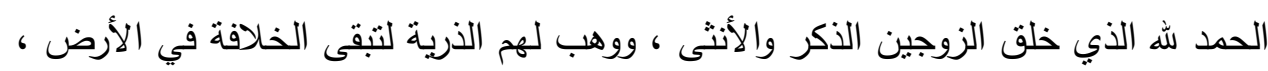

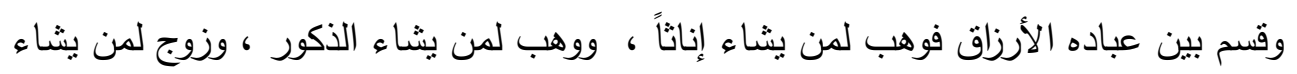

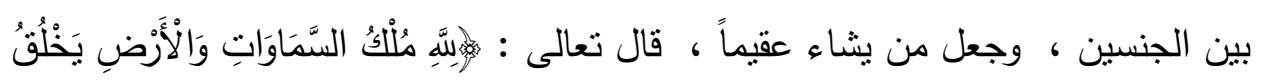

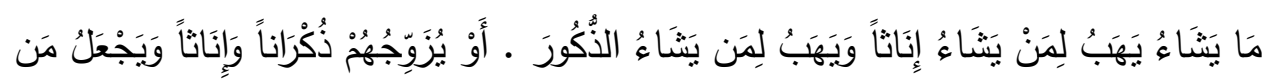

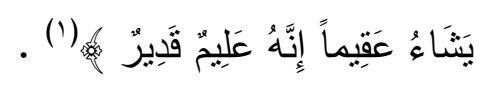

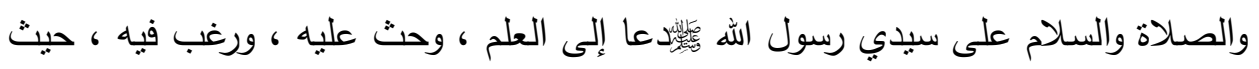

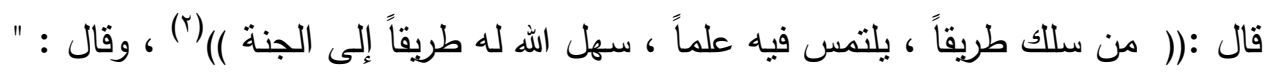

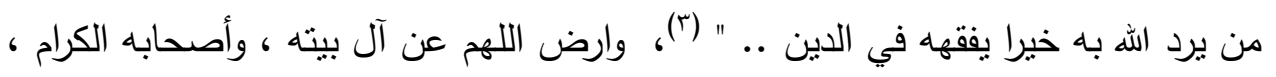
ومن تبعهم بإحسان إلى يوم الدين ، وبعد ....

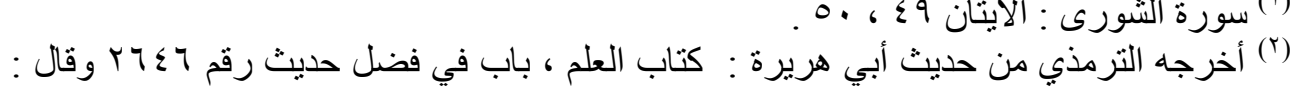

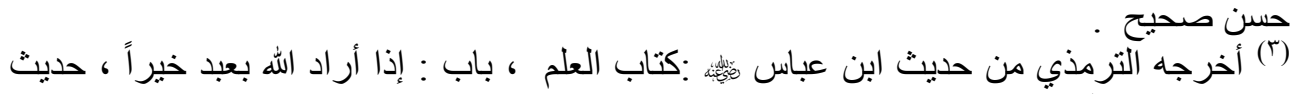

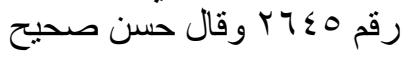


د / خالا محمد حسين إبراهيم

فقد أثرت الاكتشـافات العلميـة الحديثة على جميع مناحي الحياة في الوقت الحاضر تأثيراً بالغاً ، وأفرزت العديد من القضايا والنوازل الجديدة التي لم تكن معروفة من قبل ، والذي

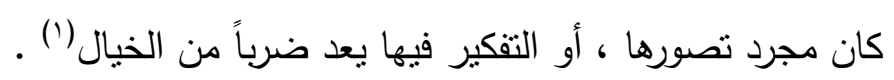

ومن هذه النوازل الجديدة التي أفرزهـا التقدم العلمي في مجال الطب ، والهندسـة الوراثيـة

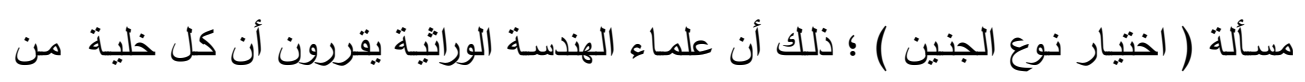

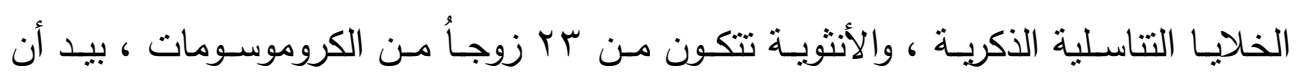
الكروموسومات الانثويـة متشـابهة وتحمل الرمز (xx ) ، وعند انقسام هذه الخلية تحمل كل خلية منقسمة المورث (x) ) أما الرجل فإن خليته الأساسية تحمل كروموسومين مختلفين

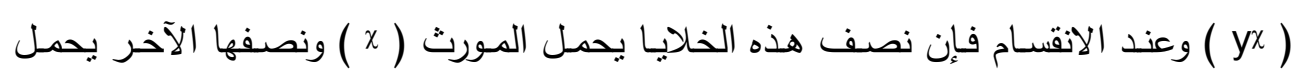
المورث ( y ) ، فإذا التقى الحيوان المنوي الذي يحمل الخلية (x ) مع خلية المرأة التي هي

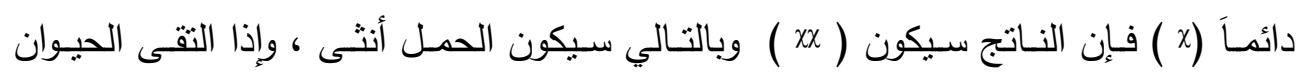
المنوي الذي يحمل الخليـة (y ) مـع خليـة المرأة التي هي (x) فإن الناتج سيكون (xy)

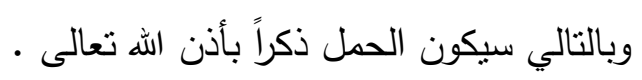
وقد تمكن العلماء في الآونـة الاخيرة من فصل الكروموسومات الذكرية ( y ) في السائل المنوي عن الكروموسومات الانثوية(x ) ، وهو ما يعرف بغربلة السائل المنوي ، فإذا كان

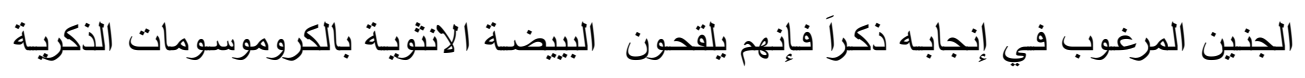
ف (y ) فإذا قدر الله تعالى لهذا التلقيح أن يتم جاء الجنين ذكراً بإذن الله تعالى ، وإذا كان الجنين المرغوب في إنجابه أنثى فإنهم يلقحون البييضـة بالكروموسومات الذكرية ( x ) ، فإذا ما قدر الله تعالى لهذا التلقيح أن يتم جاء الجنين أنثى بإذن الله تعالى .

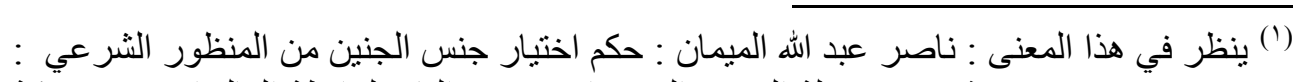

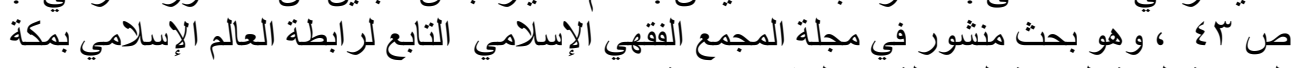

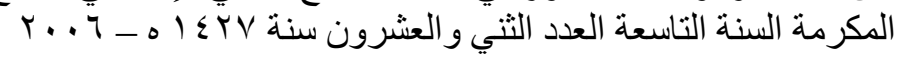

or. مجلة بحوث كلية الآداب 
اختيار نوع الجنين ( الاصطفاء الجنسي )

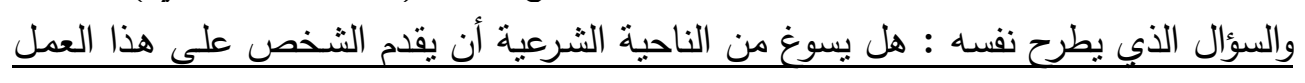

، ويتخير نـوع الجنين الذي يريد لأي سبب من الأسباب ؟ هذا مـا سيحاول هذا البحث

$$
\text { أهداف البحث : الإجابة عنه . }
$$

ويهدف هذا البحث إلى تحقيق الاهداف الآتية :

ا - بيان حقيقة اختيار نوع الجنين ؛ وذلك لأن بيان حقيقة الثـيء أمر ضروري لفهـه ، وتصوره ، ومن ثم الحكم عليه .

r - بيان الطرق التي يمكن أن يلجأ إلبها لاختيار نوع الجنين سواء أكانت هذه الطرق ، طبيعية ، أو مخبرية ، حنى يمكن توضيح الحكم الثرعي لهذه العملية . r - توضيح آراء العلماء المعاصرين في هذه العملية بشتى صورها .

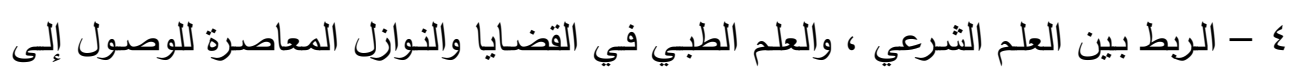
قواعد وقوانين تحكم العمل الطبي تكون منسجمة مع أحكام الثريعة الإسلامية .

\section{منهج البحث :}

لم تقتصر هذه الدراسـة على طريقة واحدة من طرائق البحث ، ولا على منهج واحد من مناهجه ، وإنما اعتمد البحث فيها على عدة مناهج : 1 - المنهج الاستقرائي ، وذلك بتتبع جزئيات البحث في مظانها المختلفة ، والتوليف بين هذه الجزئيات وصولاً إلى الحكم الصحيح في المسألة محل البحث . . r - المنهج الاستتباطي : وذلك مـن خـلال الوقوف على وجـه دلالـة النصـوص ، وأقوال العلماء في المسألة محل البحث . r - المنهج المقارن ، وذلك من خلال المقارنـة بين الأقوال المختلفة في المسألة ، وذكر أدلتهم ، ومناقثنة هذه الأدلة ، ثم ترجيح ما قوي دليه دونما تعصب لرأي من الآراء . 
و يشتمل هذا البحث على تمهيد ، وفصلين، تسبقهما مقدمة ، وتليهما خاتمة ، علاوة على

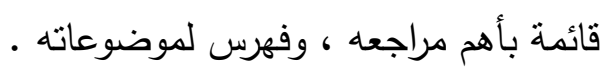

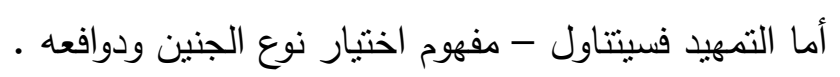

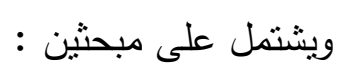

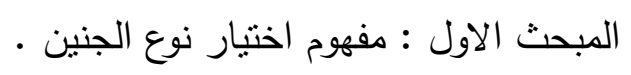

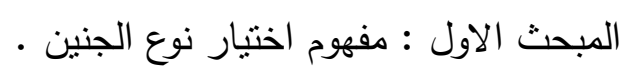
الفصل الأول - الوسائل القديمة لاختيار نوع الجنين وحكمها الثرعي.

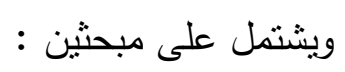
المبحث الأول - الوسائل القديمة لاختيار نوع الجنين .

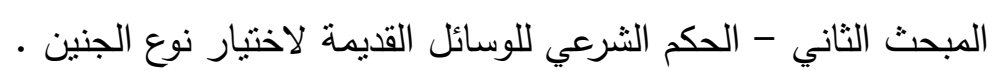
الفصل الثاني -الأساليب الحديثة لاختيار نوع الجنين وحكمها الثرعي .

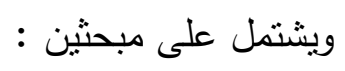
المبحث الأول - الوسائل الطبيعية لاختيار نوع الجنين وحكمها الثرعي • المبحث الثاني - الوسائل المعملية لاختيار نوع الجنين وحكمها الثرعي • و الله - تعالى - أسأل أن يعصمنا من الزلل ، ويوفقنا في القول والعمل . 
اختيار نوع الجنين ( الاصطفاء الجنسي )

$$
\begin{aligned}
& \text { تمهيد } \\
& \text { بيان مفهوم اختيار نوع الجنين ودوافعه } \\
& \text { ويشتمل على مبحثين : } \\
& \text { المبحث الأول - مفهوم اختيار نوع الجنين - } \\
& \text { المبحث الثاني - دوافع اختيار نوع الجنين } \\
& \text { المبحث الاول } \\
& \text { مفهوم اختيار نوع الجنين }
\end{aligned}
$$

لكي يستبين مفهوم عملية اختبار نوع الجنين لابد من بيان المعنى الإفرادي لهذه العملية ، ثم بيان التعريف الاصطلاحي( اللقبي ) لها ، وذللك في مطلبينعلى النحو التالي : المطلب الأول

\section{المعنى الإقرادي لاختيار نوع الجنين}

إن الناظر في مفردات عملية ( اختيار نوع الجنين ) يجد أنها تتركب من ثلاث مفردات هي

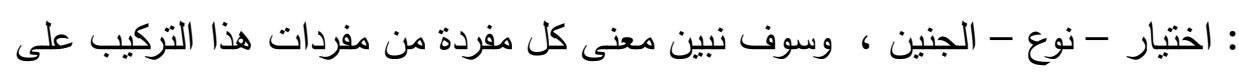

حدة ؛ ضرورة أن فهم معنى الثيء يتوقف على فهم ما تركب منه ، وذللك فيما يأني :

$$
\text { أولا - معنى ( اختيار ) : معنى الاختيار في اللغة : }
$$

الاختيار: مصدر الفعل : اختار ، يقال : اخترت الثيء ، وتخيرته : انتقيته ، والاسم :

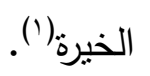

والاختيار : بمعنى الاصطفاء ، والتفضيل ، يقال : اختار فلاناً ، أي : اصطفاه ، وانتقاه ،

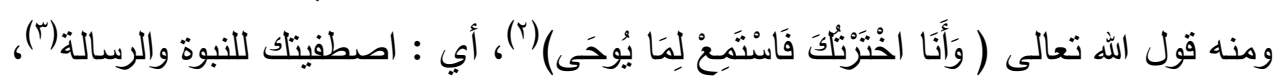

(1) المخصص لابن سيده ؟ / بـ الناثنر : دار إحياء التراث العربي - بيوت ، الطبعة الأولى سنة

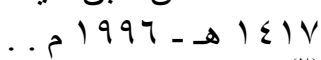

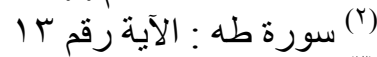

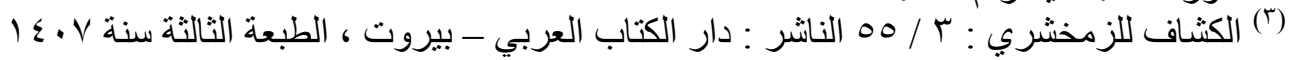

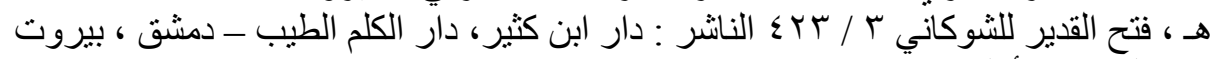

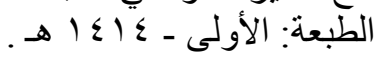

مجلة بحوث كلية الآداب 
واخترته على غيره : فضلته عليه ، وخيره بين شيئين ، أي فوض إليه إليه الخيار فيهما(')،

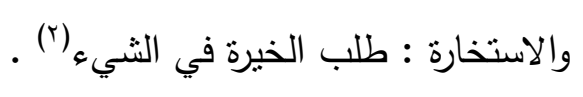

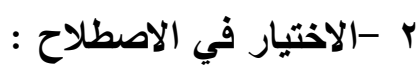

ولا يخرج معنى الاختيار في اصطلاح الفقهاء عن المعاني اللغوية السابقة ، فهو يعني

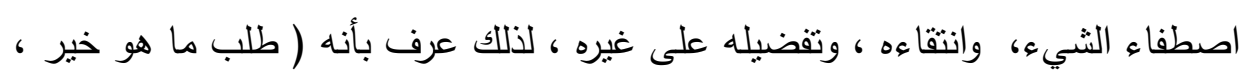

$$
\begin{aligned}
& \text { وفعله ) (r) } \\
& \text { ثانياً - معنى ( نوع ) : } \\
& 1 \text { - معنى النوع في اللغة : }
\end{aligned}
$$

النوع في اللغة الصنف من كل شيء ، ويجمع على أنواع ، سواء قل أو كثر ، وهو أخص

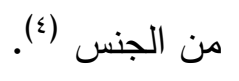

\section{r}

والنوع عند المناطقة هو ( كلي مقول على واحد ، أو كثثرين متققين في الحقائق في جواب ما هو (م)

(') مختار الصحاح : ص 99 المكتبة العصرية - الدار النموذجية ، صيدا - بيروت ، الطبعة

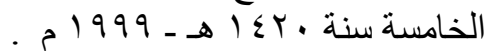

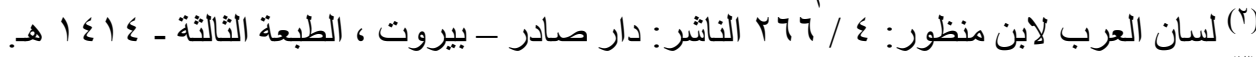

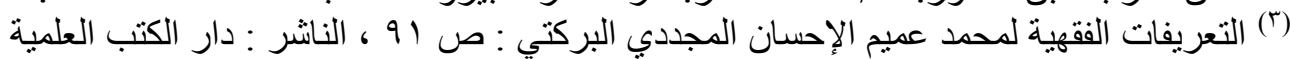

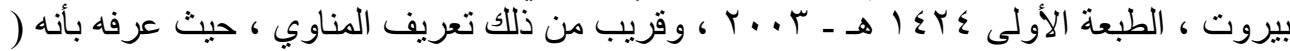

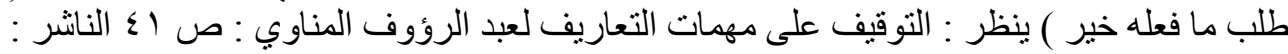

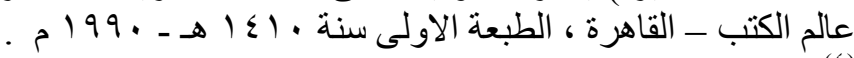

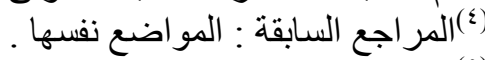

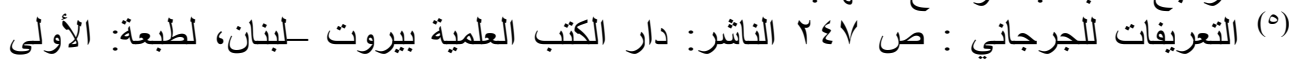

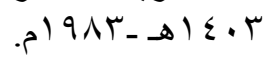

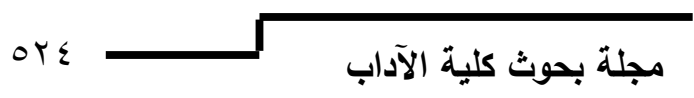


اختيار نوع الجنين ( الاصطفاء الجنسي )

شرح التعريف :

فقوله : ( كلي) جنس في التعريف ، وقوله : ( والمقول على واحد ) إثارة إلى النوع المنحصر في الثخص، وقوله : ( على كثيرين) ليدخل النوع المتعدد الأشخاص، وقوله: ( متفقين في الحقائق) يخرج الجنس؛ فإنه مقول على كثيرين مختلفين في الحقائق، وقوله: ( في جواب ما هو ) يخرج الثلاثة الباقية : الفصل، والخاصة، والعرض العام؛ لأنها لا تقال في جواب: ما هو (') .

r - تعريف النوع عند الأصوليين والققهاء :

أما عند الاصوليين والفقهاء فيعرف النوع بأنه ( كلي مقول على كثيرين متفقين في الأغراض ، دون الحقائق ، كالرجل ، والمرأة ) (؟) ، بخلاف الجنس عندهم فهو عباره عن ( كلي مقول على كثيرين مختلفين في الأغراض دون الحقائق )، كالإنسـان فإنـه يطلق على كثيـرين مختلفين في الأغراض ؛ لأنه يندرج تحته رجل ، وامرأة ، والغرض من خلقة الرجل مختلف عن الغرض من خلقة المرأة(r). ولما كان كل من الرجل ، والمرأة أنواعاُ عند الاصوليين والفقهاء آثرنا التعبير في عنوان هذه الدراسة ب ( اختيار نوع الجنين ) ولم نعبر ب ( اختيار جنس الجنين ) كما فعل كثير من

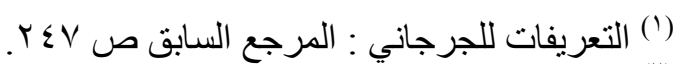

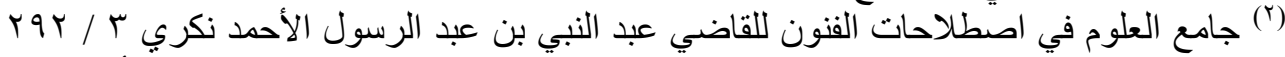

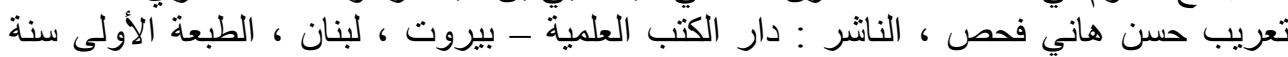

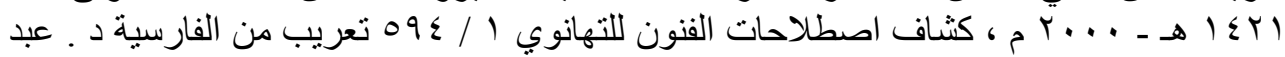

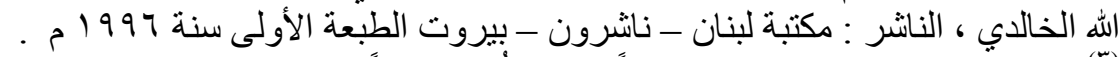

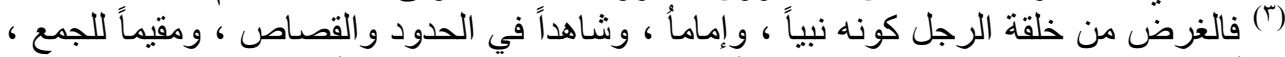

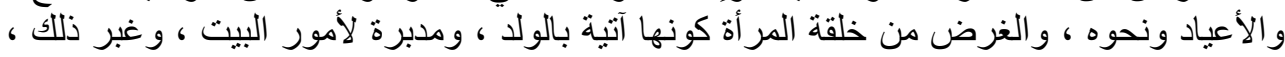

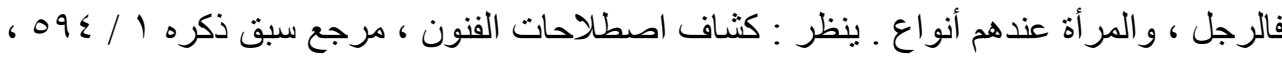




\section{د / خالد محمد حسين إبرا هيم}

الباحثين ؛ على أسـاس أن الجنين إما أن يكون ذكراً ، وإمـا أن يكون انثى ، وهو في كلتا

الحالتين نوع ، وليس جنساً (')

$$
1 \text { - ثالثاً - معنى ( الجنين ): }
$$

أصل مادة الجنين مأخوذ من الاستتار، يقال : جنّ الثيءَ يجُنّه جَنّا: ستره ، وكل شَـيْه

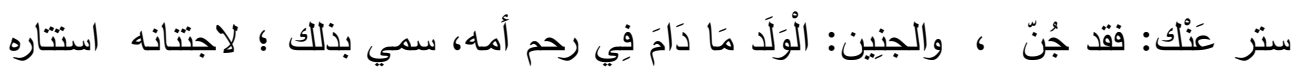

$$
\text { فِيهِ، وَيجمع على أجنَّة، وأَجْنُن (r). }
$$

ولا يخرج المعنى الاصطلاحي للجنين عند الفقهاء عن معناه عند أهل اللغة الذي هو: الحمل حال استتاره في بطن أمه (r) .

ولكن هذا هو المراد بالجنين في اصطلاح الفقهاءمنحيث العموم، وأما من حيث الخصوص ليطن

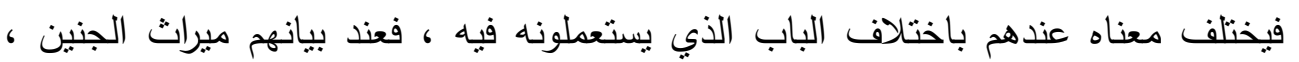

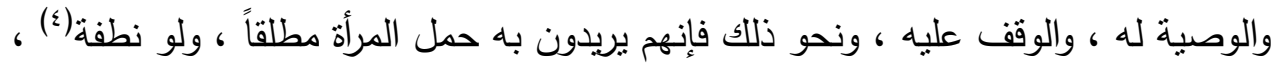

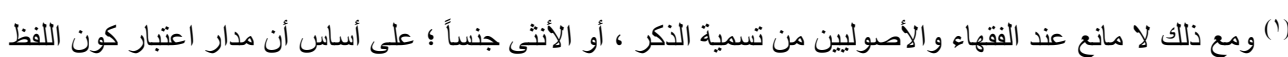

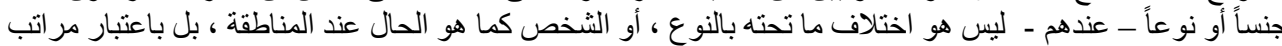

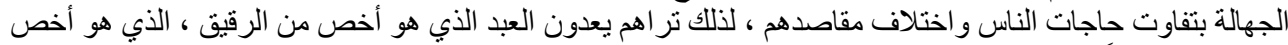

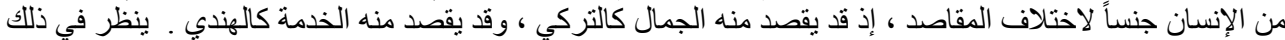

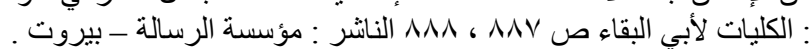

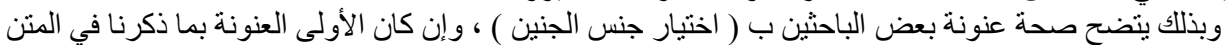

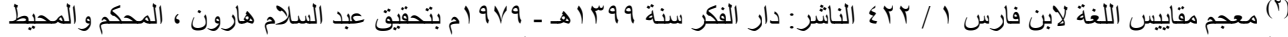

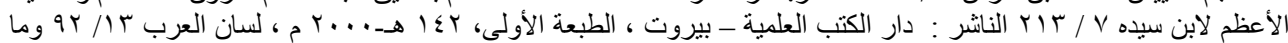

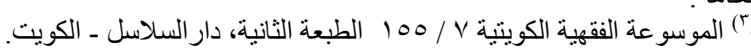

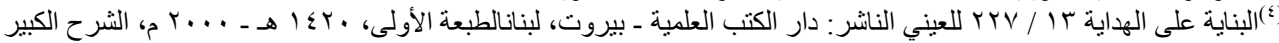

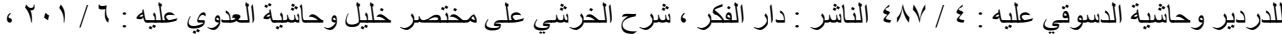

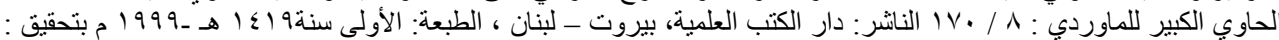

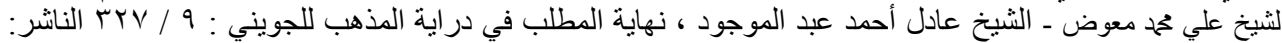

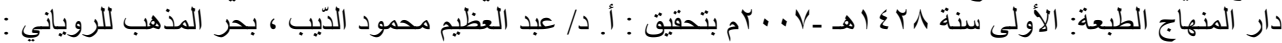

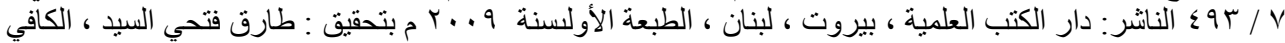

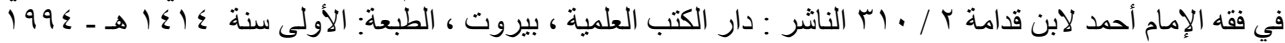

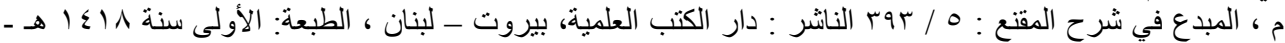




\section{اختيار نوع الجنين ( الاصطفاء الجنسي ) (أ)}

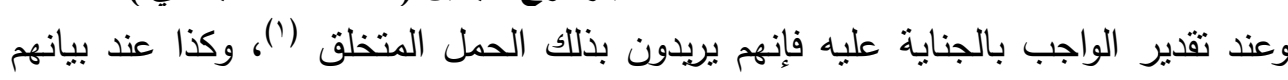
انقضاء العدة بإسقاطه(r) ، وعند تقريرهم حرمة إسقاطه فإنهم يريدون به الحمل الذي نفخ فيه

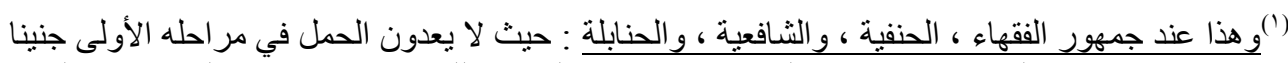

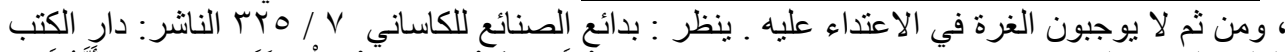

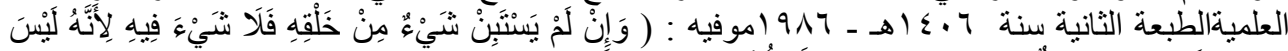

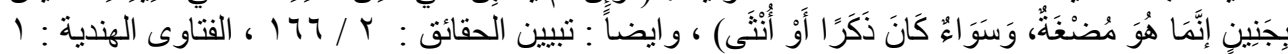

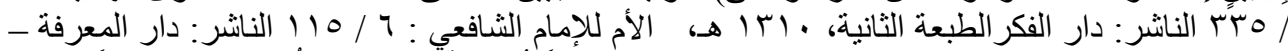

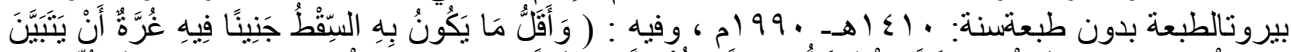

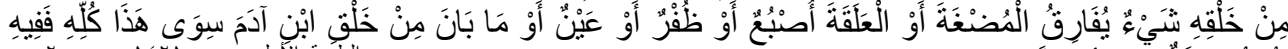

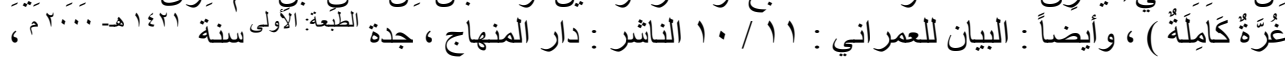

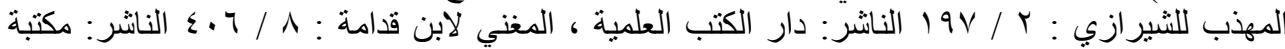

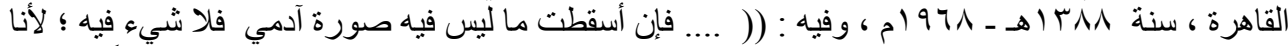

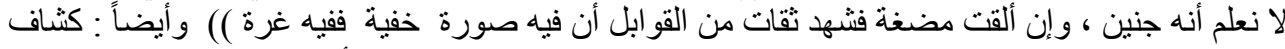

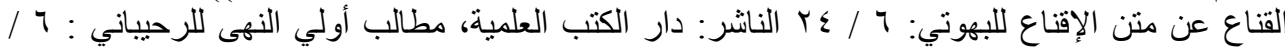

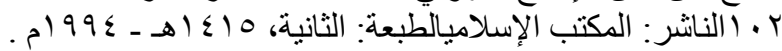

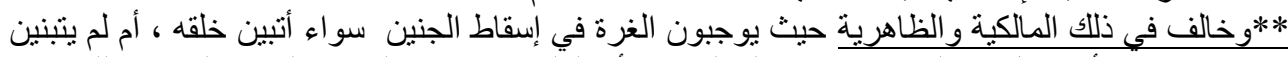

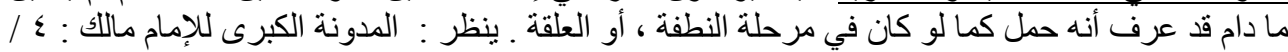

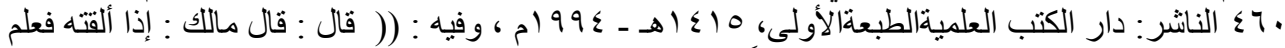

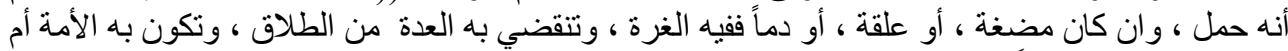

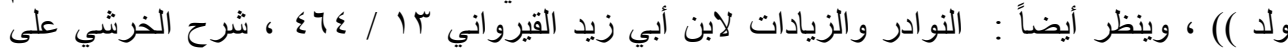

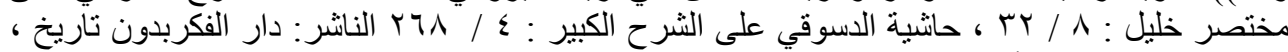

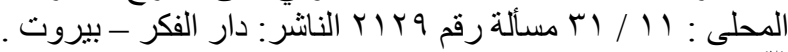

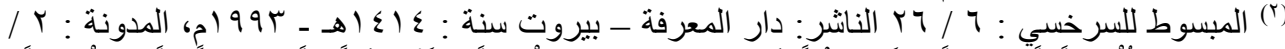

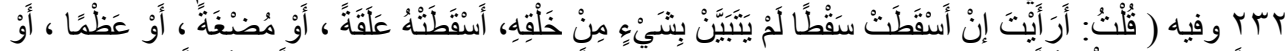

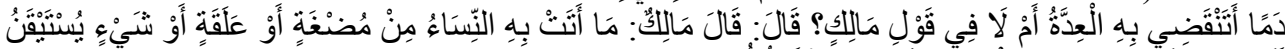

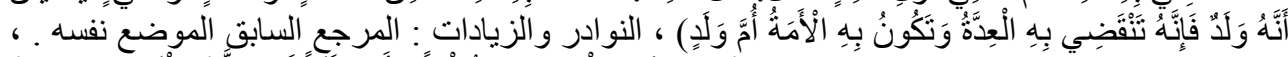

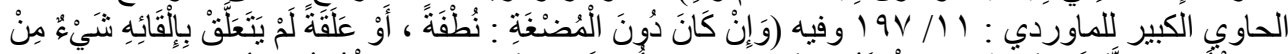

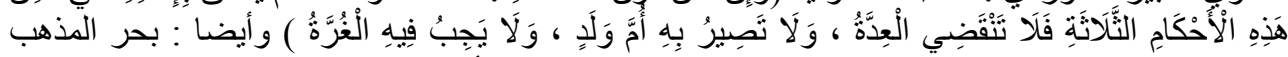

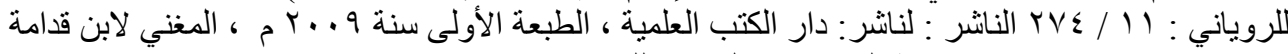

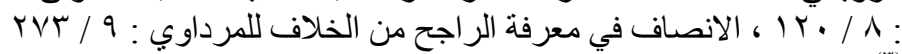

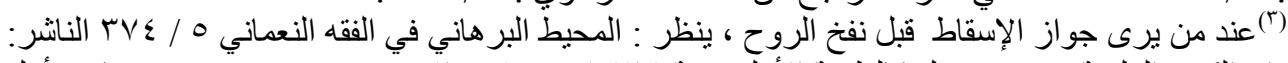

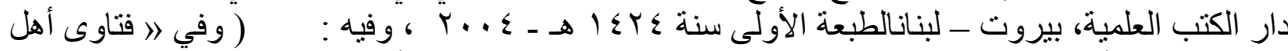

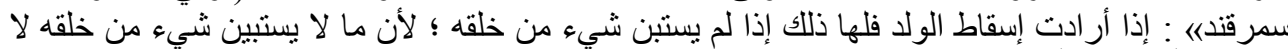

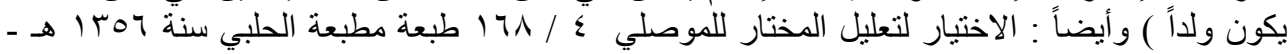

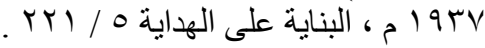


د / خالد محمد حسين إبراهيم

وكذا في مسألة شق بطن الأم المنتوفاة لإخراجه عند تحقق حياته(').

" ب-تعريف الجنين في الطب :

يطلق بعض علماء الأجنة الجنين على البييضة المخصبة بعد انغراسها في جدار الرحم ،

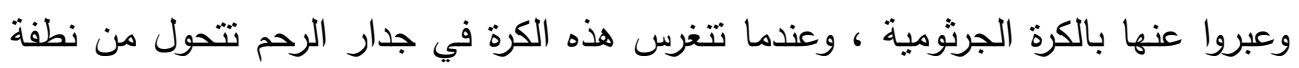

الأمشاج إلى علقة ، و هي المرحلة الجديدة لها في الحياة الجنينية ، أب:مرحلة العلقة (؟) . وعرفه بعضهم بأنه : الجنين أثناء فترة تخلقه في بطن أمه ، وتنتغرق هذه الفترة في

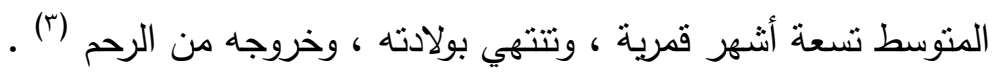

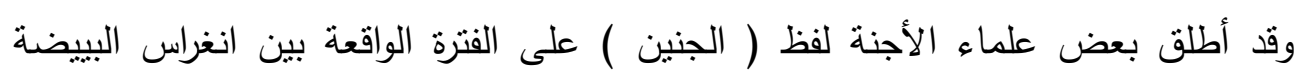
الملقحة في جدار الرحم، إلى نهاية الأسبوع الثامن ، ثم يطلقون عليه بعد ذلك اسم( حميل )

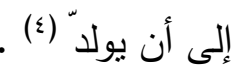

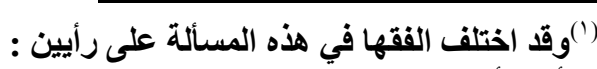

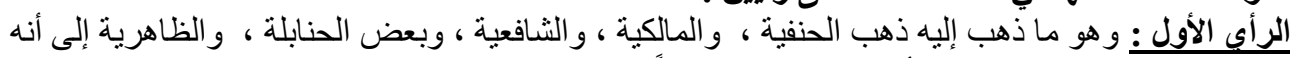

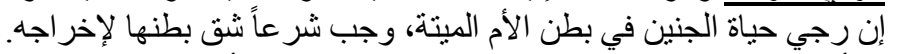

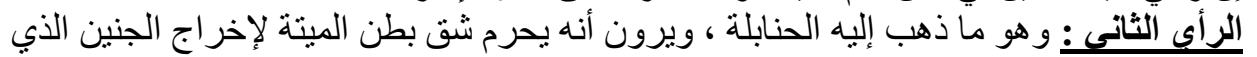

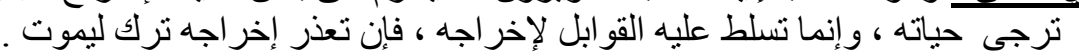

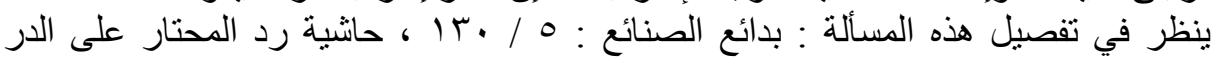

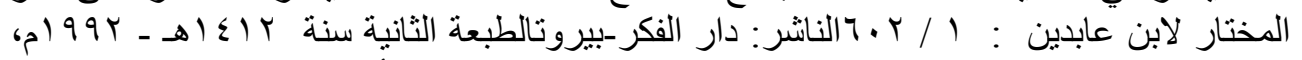

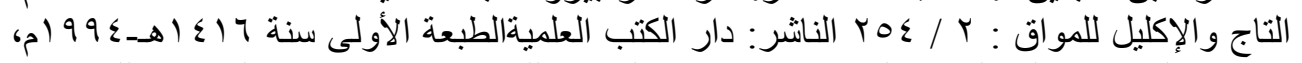

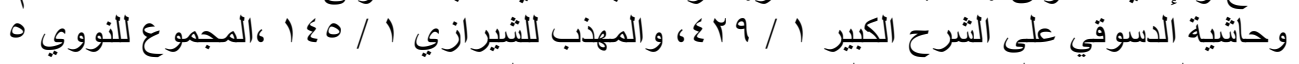

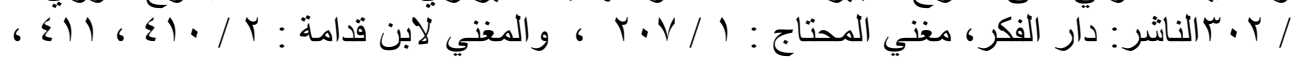

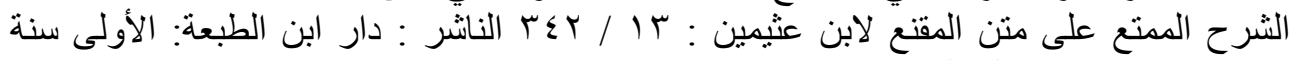

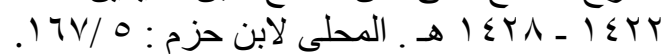

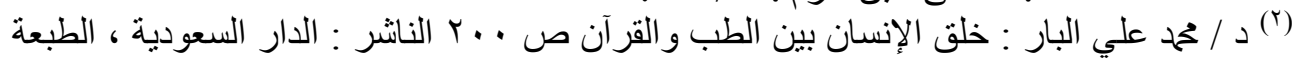

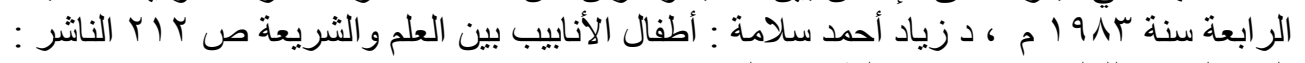

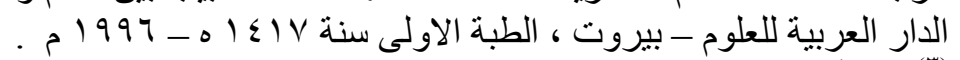

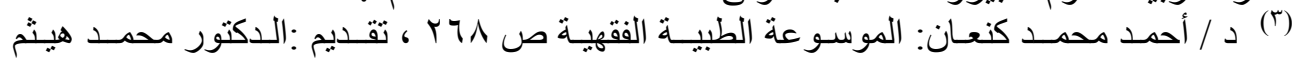

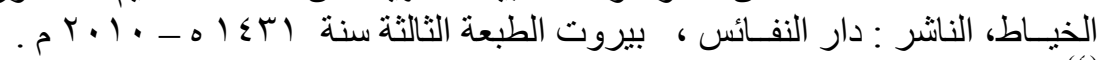

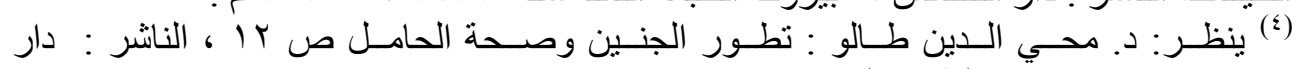

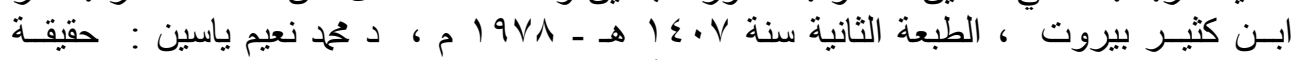

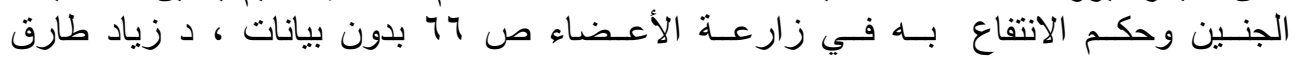

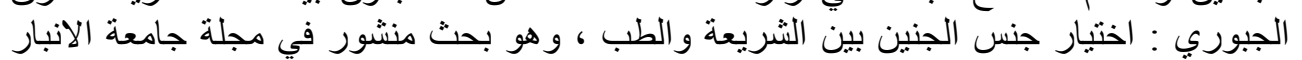

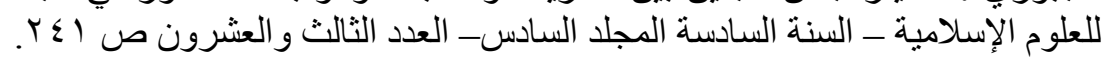

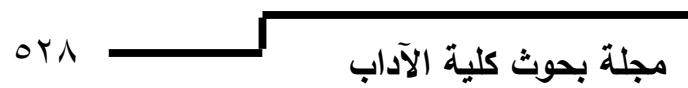




\section{اختيار نوع الجنين ( الاصطفاء الجنسي )}

ع - التعريف المناسب لموضوع البحث :

ولما كان موضوع بحثنا هو حكم اختبار نوع الجنين ، وكان هذا الاختيار ، أو الانتقاء- في الغالب - يحدث خارج الرحم ، بمناسبة عمليات التلقيح الاصطناعي الخارجي - ثم يعاد زرع البييضة في الرحم مخصبة بالنوع المرادمن الكروموسومات الذكرية ، أو الأنثوية للحيوان المنوي - على ما سيأتي - كان الأنسب - في بحثنا - تعريف الجنين بأنه: (البييضة الملقحة من لحظة التلقيح حتى بدء عملية الولادة ) (')وهذا التعريف يشمل ما إذا كانتهذه البييضة الملقحة، أو ( اللقيحة) موجودة داخل الرحم، أو خارجة عنه لَمَّا تُخرس فيه بعد ، بيد أنها إن كانت موجودة داخله ، مستقرة فيه ، فهي جنين حقيقة ؛ على أساس أن الجنين مشتق لغة من الاجتتان ، وهو الاستتار ، ولا يكون كذلك إلا إذا كان في رحم أمه (؟) ، وإن كانت لا نزال خارجه، فإنه وإن كان تسميتها جنيناً فيه بعض التجاوز - كما برى البعض (r)ــكونها لما تصل بعد إلى الرحم (๕)، إلا أنه يجوز تسميتها جنيناً من باب المجاز باعتبار ما سيكون إذا ما توافرت إرادة الله تعالى (ْ).

(1) ـ ـ فوزية عبد الستار : شرح قانون العقوبات القسم الخاص ص 9 اء الناشر : دار النهضة

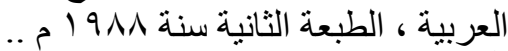

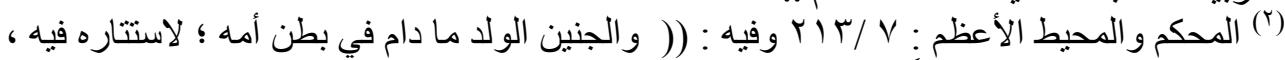

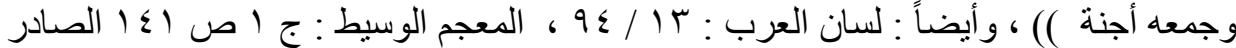

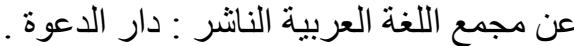

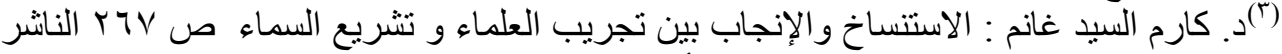

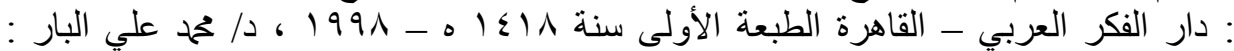

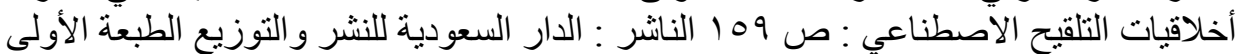

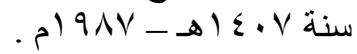

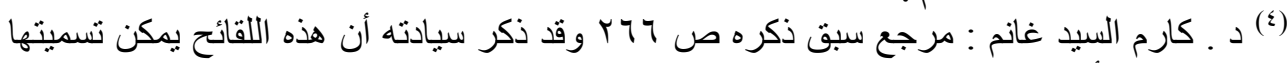

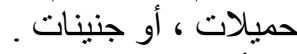

(0) ـ ـ أسماء فتحي عبد العزيز شحاتة : الحكم الشرعي في إسقاط العدد الز ائد من الأجنة الملقحة صناعياً وهو بحث منشور في السجل العلمي لمؤتمر الفقه الإسلامي الثاني - قضايا طبية

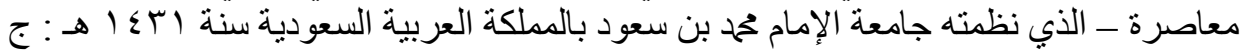


د / خالا محمه حسين إبرا هيم

$$
\text { المطلب الثاني }
$$

\section{التعريف الاصطلاحي( اللقبي ) لاختيار نوع الجنين}

\section{عدم تعرض الفقهاء القدامى لتعريف عملية اختيار نوع الجنين :}

لم يتعرض الققهاء القدامى لتعريف عملية اختيار نوع الجنين ؛ نظراً لكون العملية - في صورها الحديثة - لم تكن معروفة عندهم ، وإن كانت قد عُرِفت بعضًالوصفات التي يمكن أن تساعد في ذلك - على نحو ما سيأتي - إلا إنهم لم يتعرضوا لتعريف هذه الفكرة ؛ نظراً

$$
\text { لوضوحها عندهم ، وعدم حاجتها إلى بيان (') . }
$$

\section{تصدي الباحثين المعاصرين لتعريف عملية اختيار نوع الجنين :}

وعلى الرغم من ذلك فقد تصدى بعض الباحثين المعاصرين لعملية اختيار نوع الجنين ، فعرفها بعضهم بأنها: ( ما يقوم بها الإنسان من الأعمال والإجراءات التي يهدف من خلالها إلى اختيار ذكورة الجنين ، أو أنوثته ) (r) وعرفها البعض الآخر بأنها : ( تدخل الإنسان

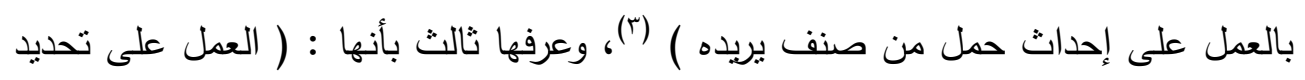

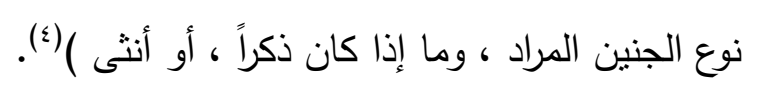

ولعل أفضل هذه التعريفات وأوضحها لعملية|ختيار نوع الجنين هو ما عرفها به البعض البه

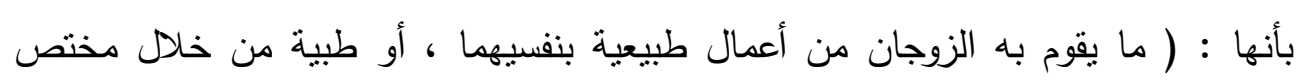

(') د. خالد بن زيد الوذيناني : اختيار جنس الجنين ، و هو بحث منشور في السجل العلمي لمؤتمر

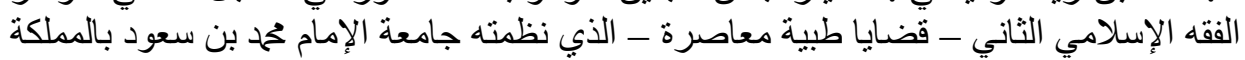

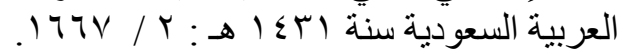

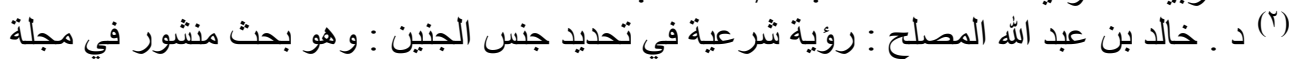

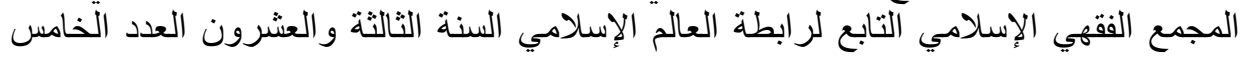

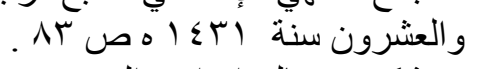

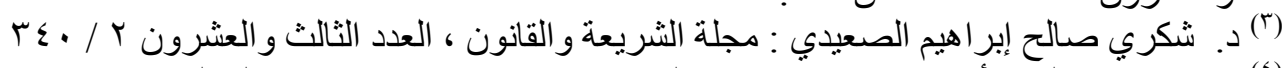

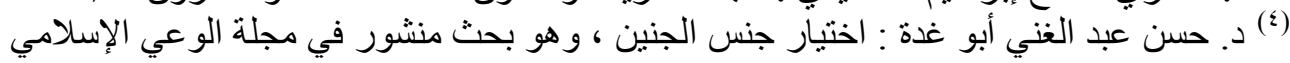

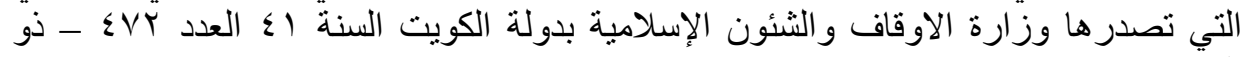

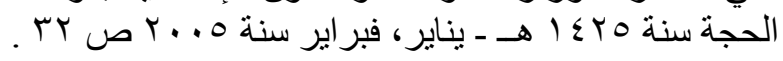




\section{(اختيار نوع الجنين ( الاصطفاء الجنسي )}

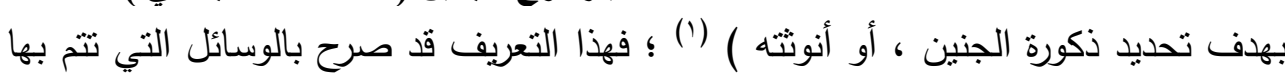

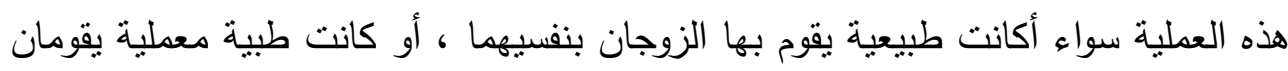
بها عن طريق لجوئهما إلى الدختصين من الأطباء في هذا الدجال .

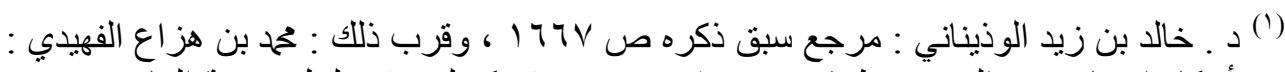

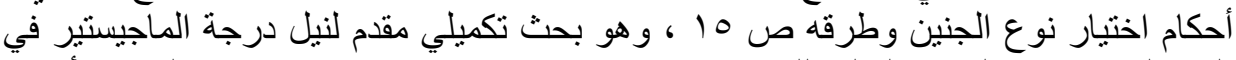

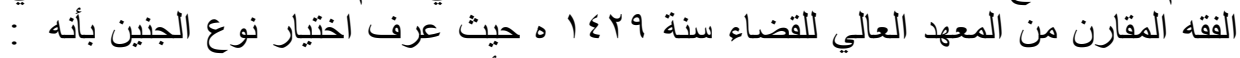

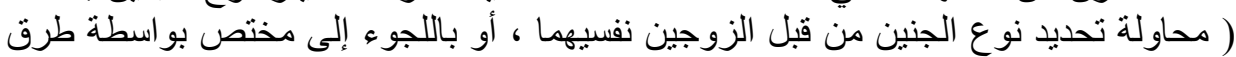
معينة تعين على تحديد ذللك ) . من نال 


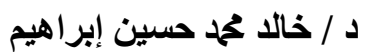

\section{المبحث الثاني \\ دوافع اختيار نوع الجنين}

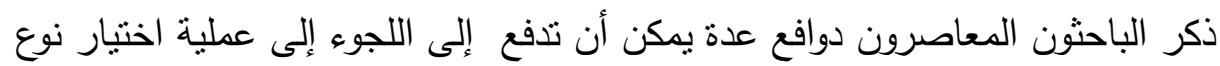
الجنين ، وهذه الدوافع يمكن تقسيمها إلى دوافع خاصة ، ودوافع عامة :

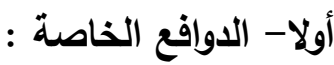

ويقصد بها الدوافع الفردية التي تلجأ إليها الأسرة من تلقاء نفسها ، مراعية في ذلك ظروفها الخاصة ، دونما توجيه من السلطة العامة ، ولعل أهم هذه الدوافع الخاصة ما يأني :

$$
\text { ا } 1
$$

وهي دوافع يقصد منها الوقاية من بعض الأمراض الوراثية التي قد تصيب نوعاً معيناً ؛ إذ

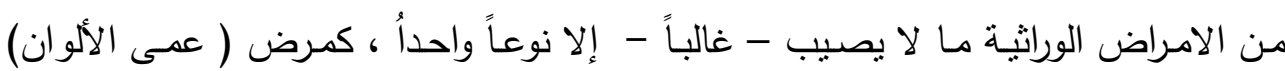

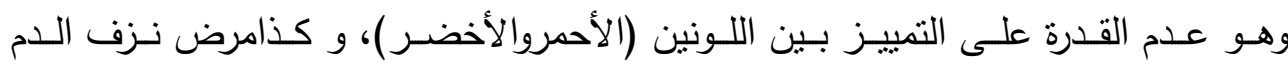

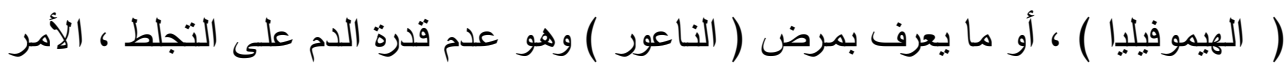

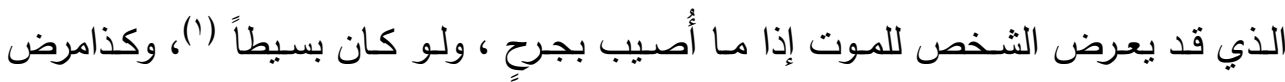

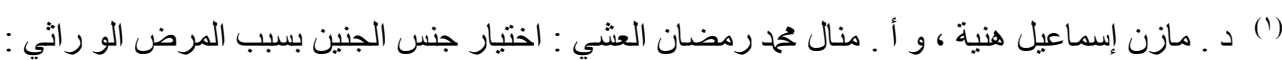

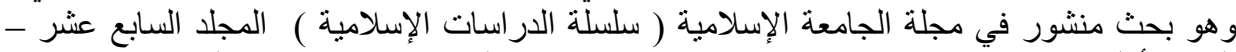

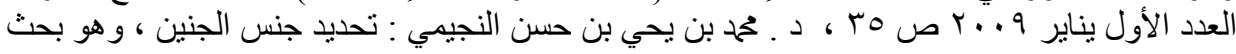
منشور في مجلة المجمع الفقهي الإسلامي التي تصدر عن رابطة العالم الإسلامي ، الدورة الثامنة عشرة ومن الطريف أن هذا المرض ينتقل عن طريق الإناث ، ولا يصيب إلا الذكور ، أي أن المرأة تحمل

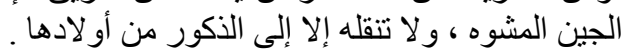

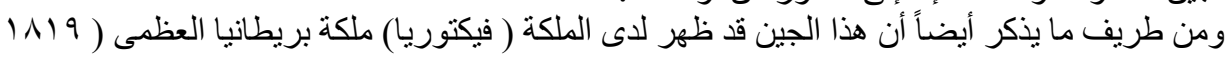

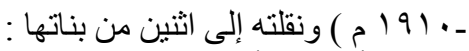

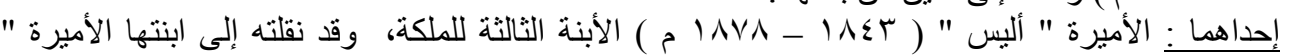

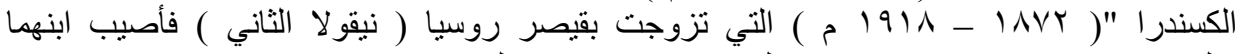

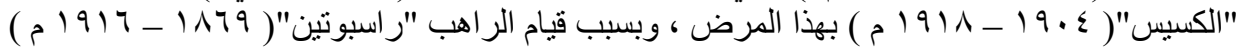

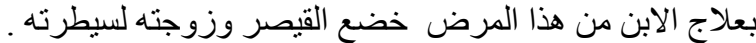

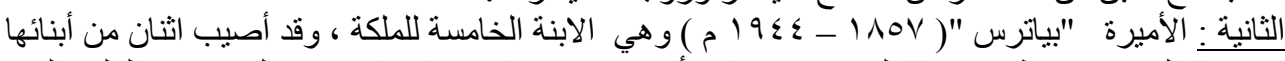

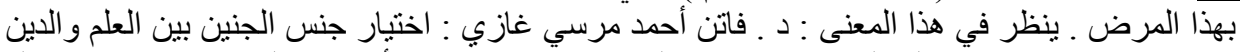

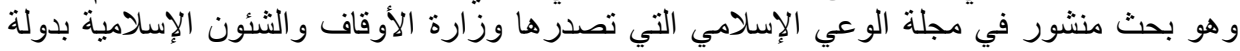

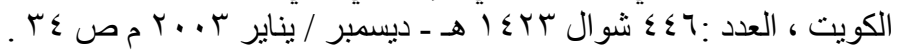

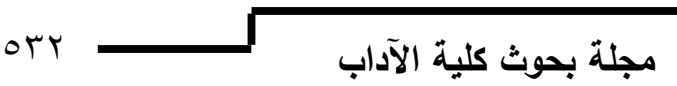




\section{اختيار نوع الجنين ( الاصطفاء الجنسي )}

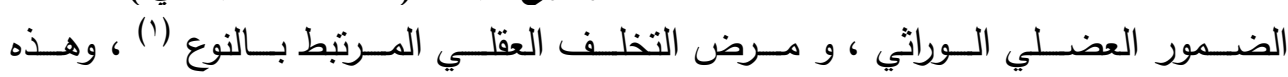
الامراضتصيب الذكور أكثر من إصابتها للإناث ، لذلك يسعى الوالدان في مثل هذه الحالات إلى اختيار النوع الذي هو مظنة السلامة من هذه الأمراض ، وهو الأنثى في معظم الحالات r

وهي تللك الدوافع التي يتم فيها اختيار نوع الجنين بسبب رغبة الوالدين في الحصول على

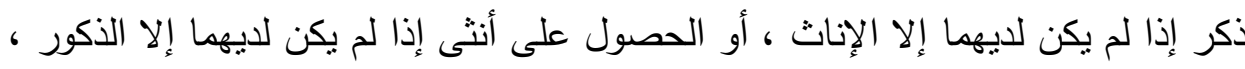

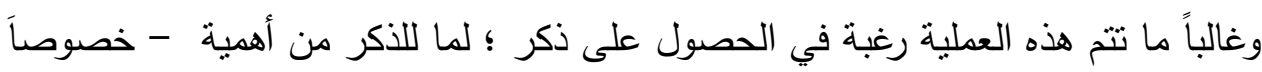
عند العرب -ـكونه يحمل اسم أبيه ، أو يساعده في العمل ، أو ربما كان هذا الاختيار راجعاً

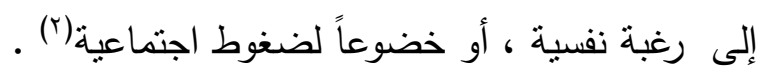

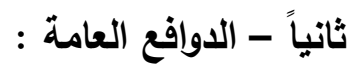

ويقصد بها تلك الدوافع التي يلجأ اليها الناس بإيعاز من السلطة العامـة ، وتأخذ شكل السياسة للدولة ، وأهم هذه الدوافع ما يأني : ا 1 - الدوافع السياسية والعسكرية :

فقد توجد بعض الظـروف السياسـية ، أو العسكرية التـي تلجـأ فيهـا الدولـة الـى توجيـه

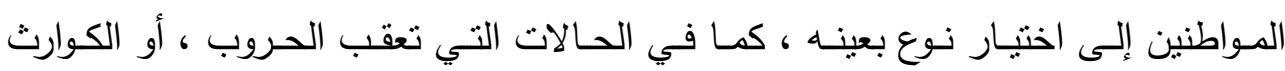
الطبيعية حيث يفقد فيها عدد كبير من الذكور ، ففي هذه الحالات ومثيلاتها قد تعمد الدولة

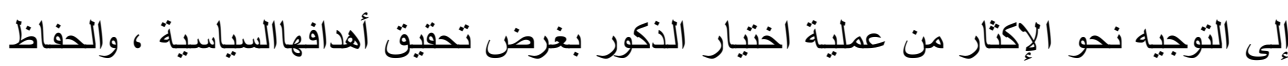
على أمنها ، وكيانها العسكري .

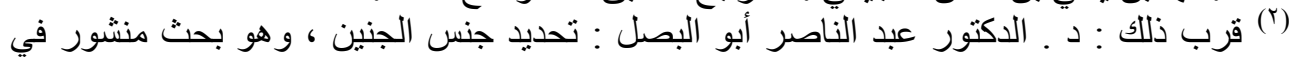

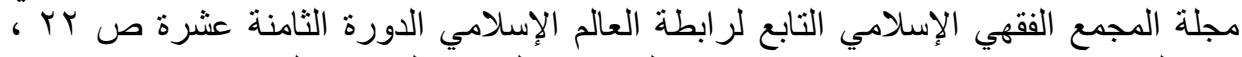

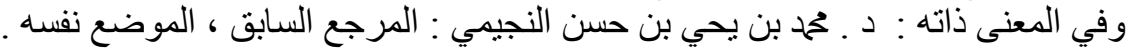


د / خالا تحمل حسين إبراهيم

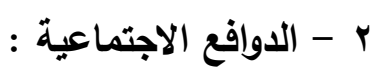

كما قد يكون اللجوء إلى اختيار نوع معين بدوافع اجتماعية ، كما في حالة انتشار ظاهرة

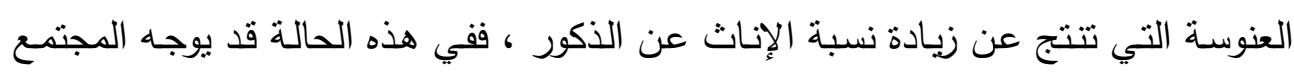

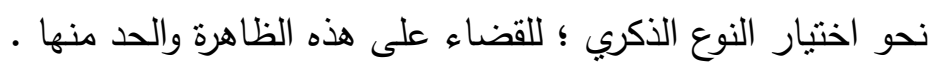

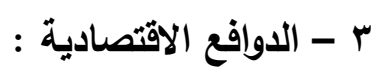
كما قد يكون اللجوء إلى هذه الوسيلة بدوافع اقتصادية عامة ، كما لو كانت الدولة تعاني من قلة الموارد البشرية اللازمة للتتمية الاقتصادية فإنها في هذه الحالة قد تلجأ إلى توجيه الوالدين نحو اختيار نوع الذكور؛ على أساس ان الذكور هم القوة المنتجة(').

(') قرب ذللك : د ـ فهـ سعد الرشيدي : اختيار جنس الجنين بالوسائل الطبيعية والمخبرية ـ دراسة

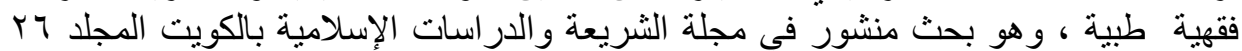

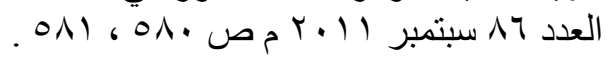

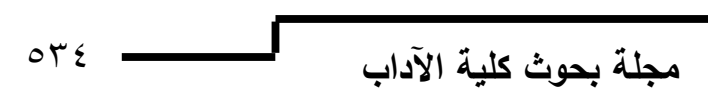


اختيار نوع الجنين ( الاصطفاء الجنسي )

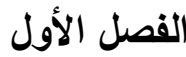

الوسائل القيمة لاختيار نوع الجنين وحكمها الثرعي الأي

ويشتمل على مبحثين

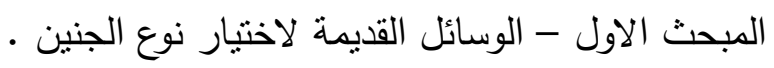

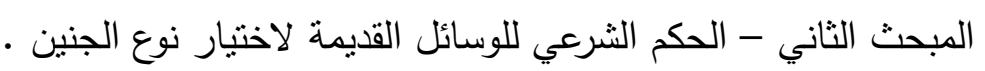

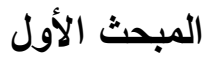

\section{الوسائل القيمة لاختيار نوع الجنين}

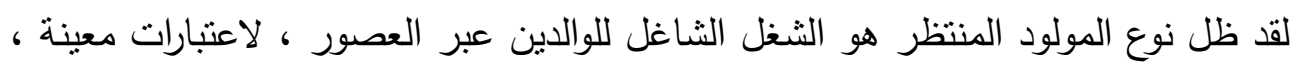
بعضها تحكمه الطبيعة والفطرة البشرية ، والأخرى العادات المتوارثة (') .

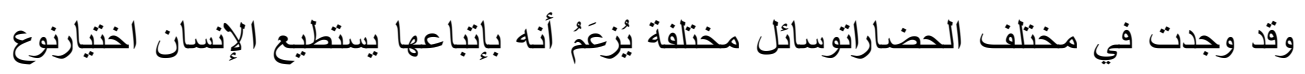

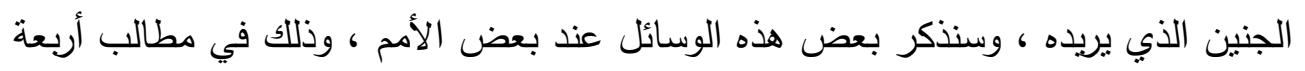

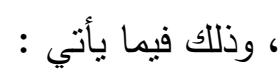
المطلب الأول - اختيار نوع الجنين عند اليونان .

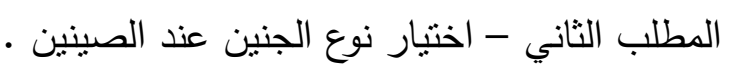

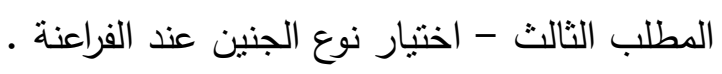

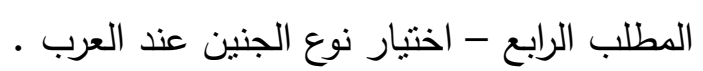

http://www.layyous.com/ar : موقع الدكتور نجيب ليوس على الرابط التالي (1) 


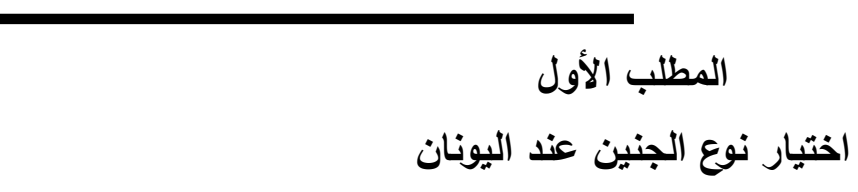

د الا محمل حسين إبرا هيم

لقد وجدت بعض المحاولات من قبل اليونانيين لاختيار نوع الجنين ، فقد ذكر الطبيب

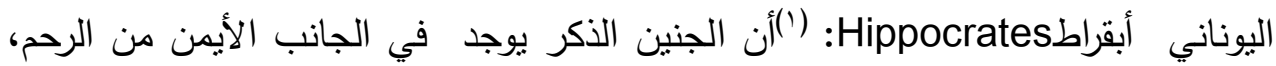
أما الجنين الأنثى فيوجد في الجانب الأبسر منه، وكان اليونانيون يعتقدون أن رحم المرأة

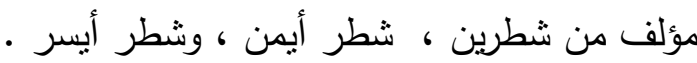

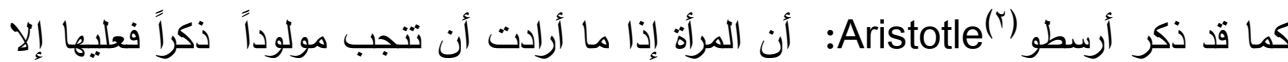
أن تضطجع على جانبها الأيمن بعد الجماع ، وتقكر بأن يكون المولود الذي ينتج عن هذا

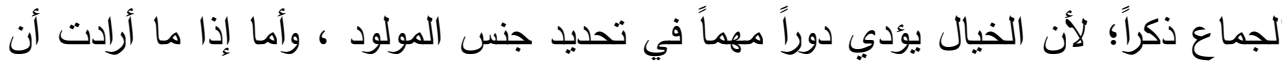
تتجب أنثى، فعليها أن تضطجع على جانبها الأيسر بعد الجماع ، وتقكر في إنجاب أنثى

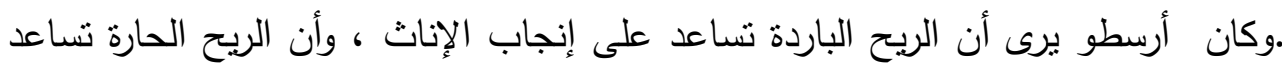
على إنجاب الذكور، كما كان يرى - أيضاً - أن النظر باتجاه الجنوب بساعد على إنجاب

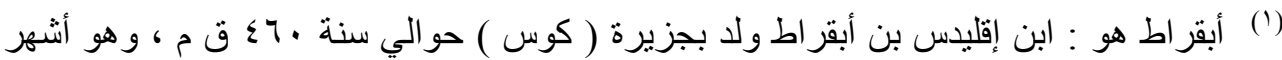

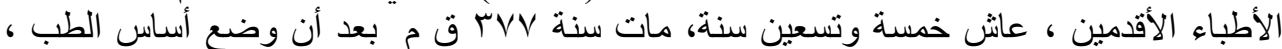

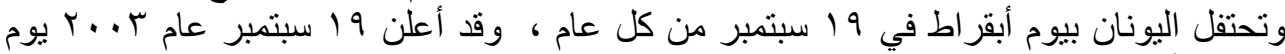

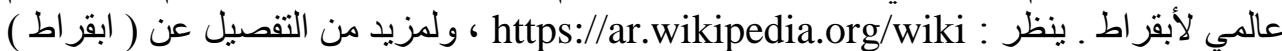

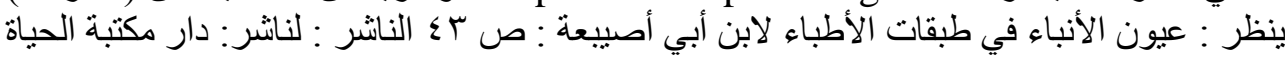

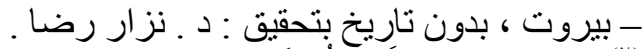

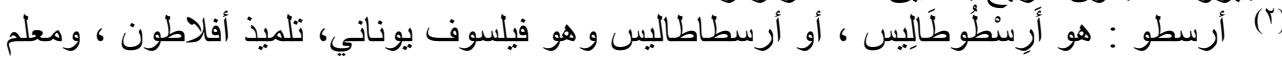

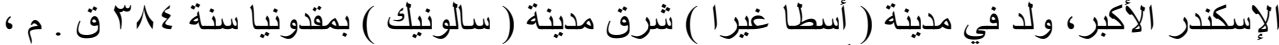

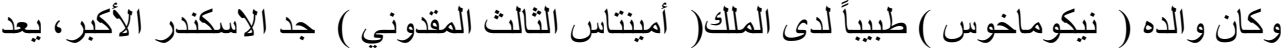

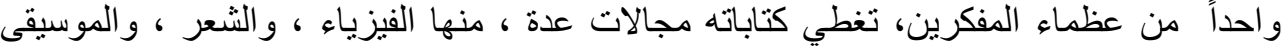

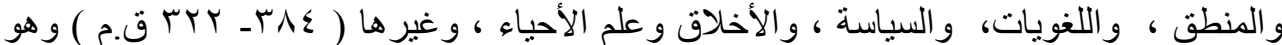

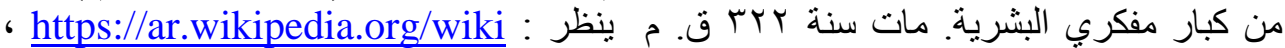

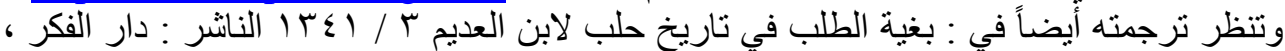

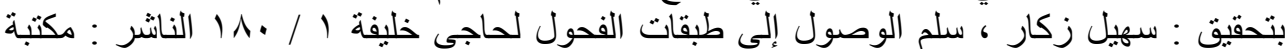

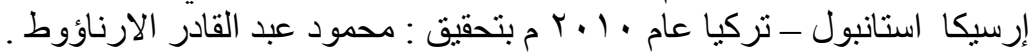


اختيار نوع الجنين ( الاصطفاء الجنسي )

الإناث ، و كان ينصح الرجال الراغبين في إنجاب مولود ذكربربط الخصية اليسرى(') ' ل

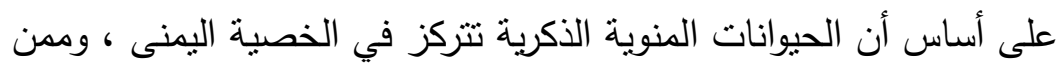

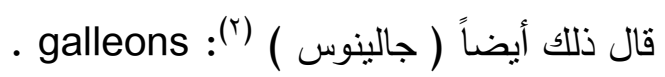

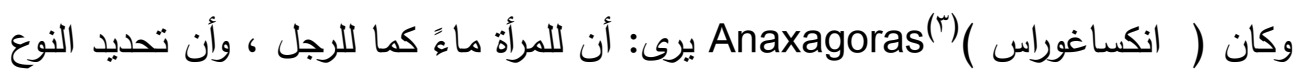

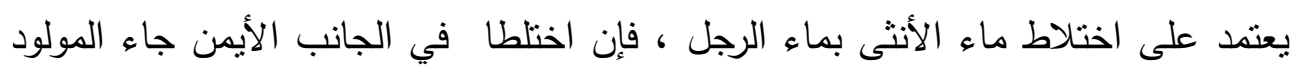

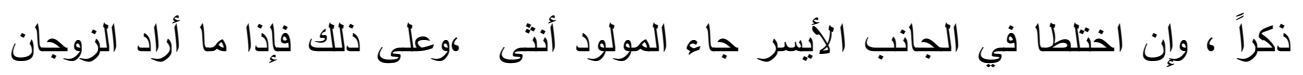
الحصول على مولود ذكر فعليهما الإضجاع على الجانب الأيمن أثناء الجماع، وإذا ما أرادا

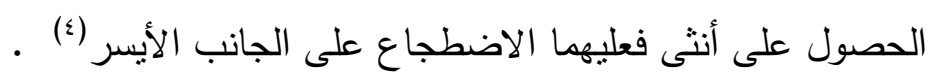
ولا شك أن هذه الطرق لا تعدوا أن تكون مجرد اجتهادات ، بيد أنها لا تعد صحيحة من عن الته الناحية العلمية (0).

(') ـ ـأكمل عبد الحكيم : جنس المولود الاختيار و التبعات ، وهو مقال منشور في جريدة الاتحاد

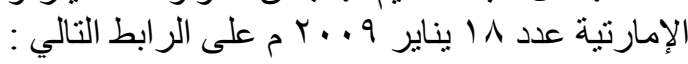
https://www.alittihad.ae/WejhatArticle/42649

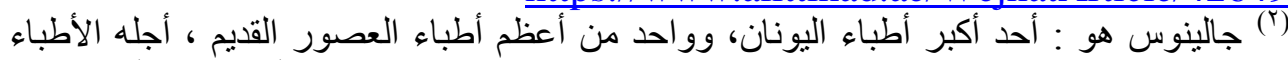

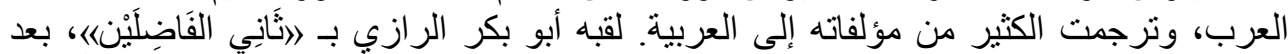

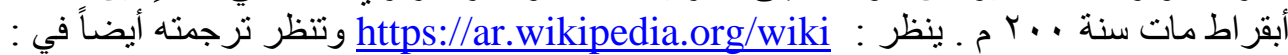

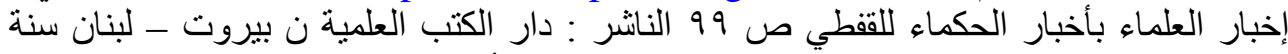

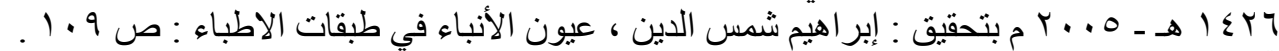

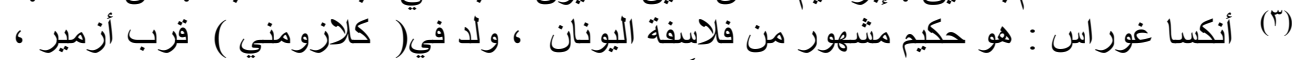

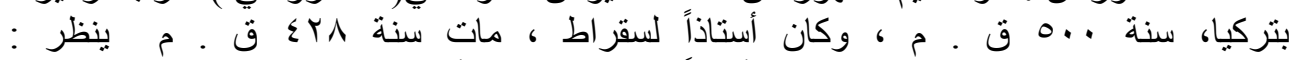

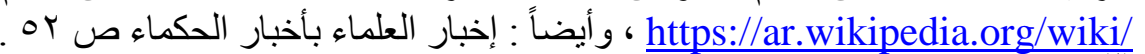

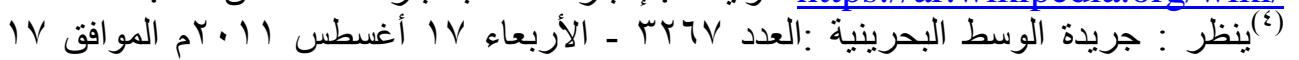

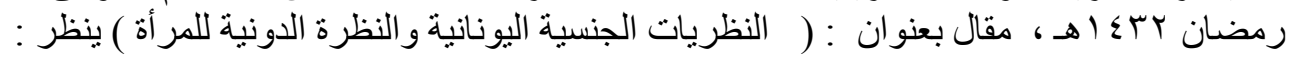
http://www.alwasatnews.com/news/584023.html

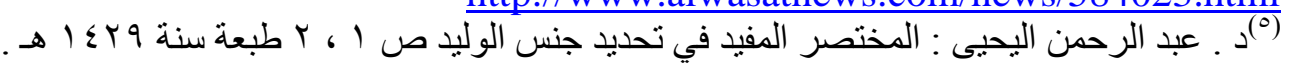




\section{المطلب الثاني \\ اختيار نوع الجنين عن الصينيين:}

د الا محمد حسين إبراهيم

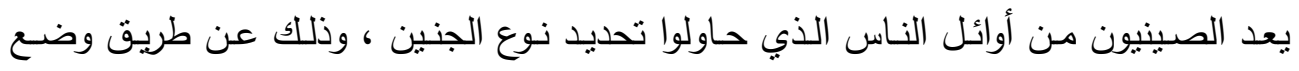

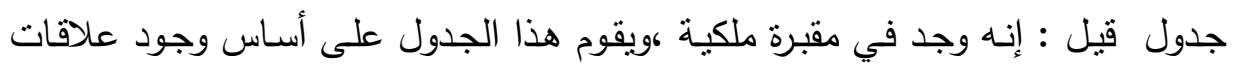

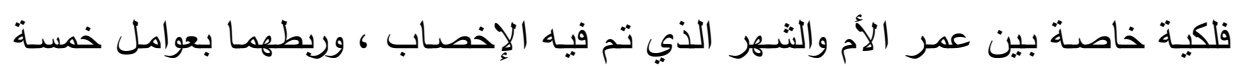

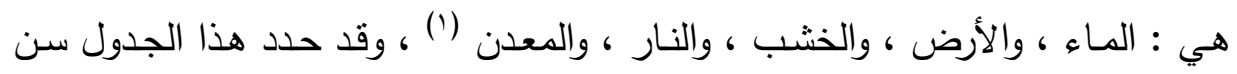

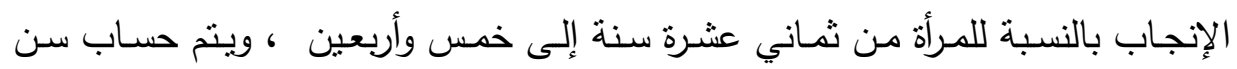

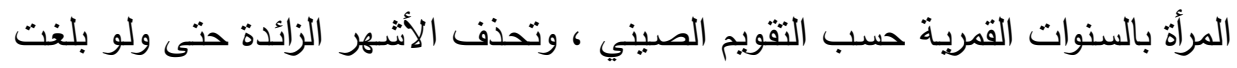

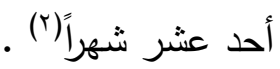
بيد أن هذه الطريقة لا ترنكز على أساس علمي يعتد به(") .

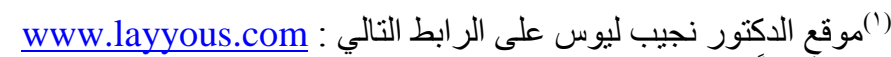

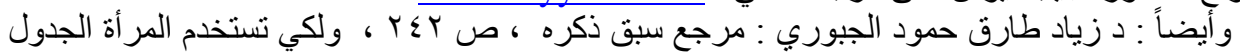

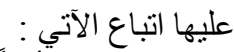
1

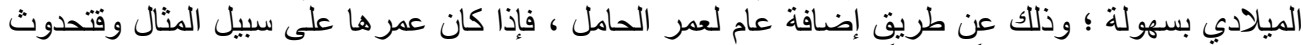

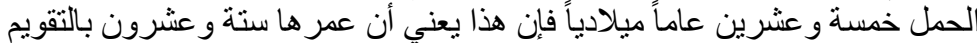
الصيني أي عن طريق إضافة عام اللعمر بالتاريخ الميلادي.

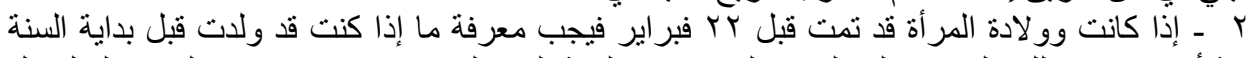

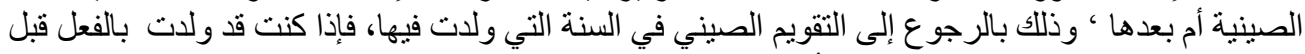

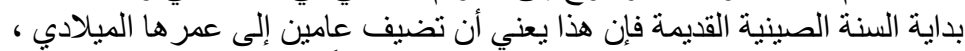

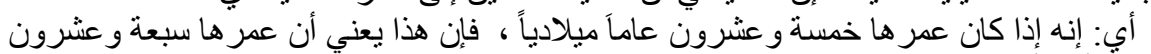

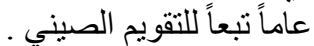

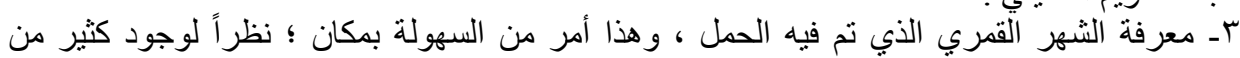

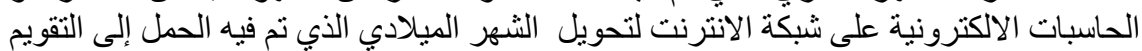

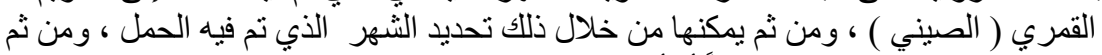

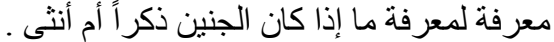

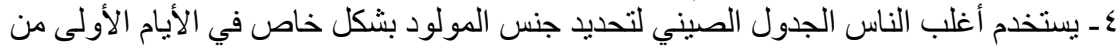

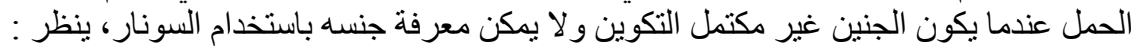
كيف تستخدم الجدول الصيني في تحديد جنس الجنين ، و هو مقال على موقع سيدني نت على على الر ابط التئ

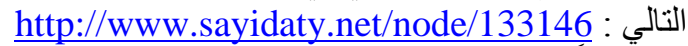

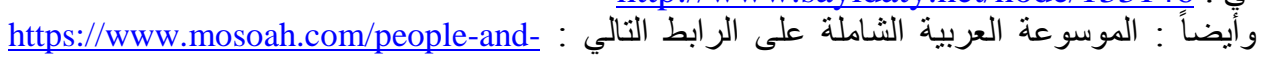
society/womens-interests/chinese-table (ז) ـ ـ عبد اللطيف ياسين : ولد أم بنت وهل يمكن اختبار الجنس المر غوب ، مطبعة دار العلم للطباعة

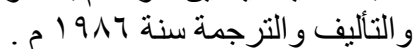

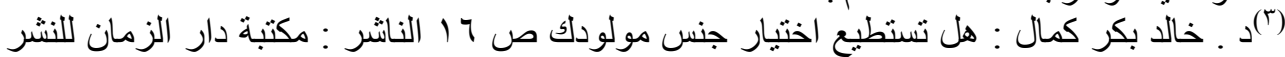

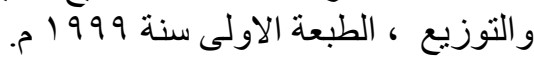

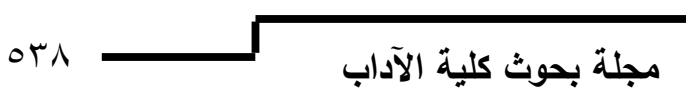


اختيار نوع الجنين ( الاصطفاء الجنسي )

وهذه صورة من الجدول الصيني :

\begin{tabular}{|c|c|c|c|c|c|c|c|c|c|c|c|c|c|}
\hline Age & 1 & 2 & 3 & 4 & & & & & & & & 11 & \\
\hline 18 & $\mathrm{G}$ & B & $\mathrm{G}$ & B & E & & & 3 & B & & B & B & B \\
\hline 19 & B & G & B & G & $C$ & & & B & B & B & B & $\mathrm{G}$ & $\mathrm{G}$ \\
\hline 20 & $\mathrm{G}$ & B & $\mathrm{G}$ & B & $\mathrm{E}$ & & & $B$ & B & B & $\mathrm{G}$ & B & B \\
\hline 21 & B & $\mathrm{G}$ & $\mathrm{G}$ & $\mathrm{G}$ & $C$ & & & $G$ & $\mathrm{G}$ & $\mathrm{G}$ & $\mathrm{G}$ & $\mathrm{G}$ & $\mathrm{G}$ \\
\hline 22 & $\mathrm{G}$ & B & B & $\mathrm{G}$ & E & & 3 & $\mathrm{G}$ & B & $\mathrm{G}$ & $\mathrm{G}$ & $\mathrm{G}$ & $\mathrm{G}$ \\
\hline 23 & B & B & $\mathrm{G}$ & B & 7 & & $\mathrm{~s}$ & 3 & $\mathrm{G}$ & B & B & B & $\mathrm{G}$ \\
\hline 24 & B & $\mathrm{G}$ & B & B & & & 3 & 3 & $\mathrm{G}$ & $\mathrm{G}$ & $\mathrm{G}$ & $\mathrm{G}$ & B \\
\hline 25 & $\mathrm{G}$ & B & B & $\mathrm{G}$ & & & & $\mathrm{G}$ & B & B & B & B & B \\
\hline 26 & B & G & B & G & I & & j & 3 & $\mathrm{G}$ & $\mathrm{G}$ & $\mathrm{G}$ & $\mathrm{G}$ & $\mathrm{G}$ \\
\hline 27 & $\bar{G}$ & $\mathrm{~B}$ & $\overline{\mathrm{G}}$ & $\mathrm{B}$ & & & i & 3 & B & B & B & $\mathrm{G}$ & B \\
\hline 28 & B & G & B & $\mathrm{G}$ & C & & & 3 & B & B & B & $\mathrm{G}$ & $\mathrm{G}$ \\
\hline 29 & $\mathrm{G}$ & B & $\mathrm{G}$ & $\mathrm{G}$ & $\mathrm{I}$ & & & $B$ & B & B & $\mathrm{G}$ & $\mathrm{G}$ & $\mathrm{G}$ \\
\hline 30 & B & $\mathrm{G}$ & $\mathrm{G}$ & $\mathrm{G}$ & & & & $\mathrm{G}$ & $\mathrm{G}$ & $\mathrm{G}$ & $\mathrm{G}$ & B & B \\
\hline 31 & B & $\mathrm{G}$ & B & G & & & & $\mathrm{G}$ & G & $\mathrm{G}$ & $\mathrm{G}$ & $\mathrm{G}$ & B \\
\hline 32 & B & $\mathrm{G}$ & $\mathrm{G}$ & G & C & & & $G$ & $\mathrm{G}$ & $\mathrm{G}$ & $\mathrm{G}$ & $\mathrm{G}$ & B \\
\hline 33 & $\mathrm{G}$ & B & $\bar{G}$ & B & C & & & $\begin{array}{l}G \\
\end{array}$ & B & $\mathrm{G}$ & $\mathrm{G}$ & $\mathrm{G}$ & $\mathrm{G}$ \\
\hline 34 & B & $\bar{G}$ & B & $\mathrm{G}$ & C & & & $\vec{G}$ & $\mathrm{G}$ & $\mathrm{G}$ & $\mathrm{G}$ & B & B \\
\hline 35 & B & B & $\overline{\mathrm{G}}$ & $\bar{B}$ & 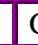 & & & $\vec{G}$ & B & $\mathrm{G}$ & $\mathrm{G}$ & $\mathrm{G}$ & B \\
\hline 36 & $\mathrm{G}$ & B & B & C & $\mathrm{I}$ & & & $\mathrm{G}$ & $\mathrm{G}$ & B & B & B & B \\
\hline 37 & B & G & B & B & & & & $\mathrm{G}$ & B & $\mathrm{G}$ & B & $\mathrm{G}$ & B \\
\hline 38 & $\mathrm{G}$ & B & $\mathrm{G}$ & B & & & & 3 & $\mathrm{G}$ & B & $\mathrm{G}$ & B & $\mathrm{G}$ \\
\hline 39 & B & $\overline{\mathrm{G}}$ & $B$ & B & I & & & $\mathrm{G}$ & $\mathrm{B}$ & $\mathrm{G}$ & B & $\mathrm{G}$ & B \\
\hline 40 & $\mathrm{G}$ & B & $\mathrm{G}$ & B & & & & 3 & $\mathrm{G}$ & B & $\mathrm{G}$ & B & $\mathrm{G}$ \\
\hline 41 & $\bar{B}$ & $\overline{\mathrm{G}}$ & $\overline{\mathrm{B}}$ & $\bar{C}$ & & & & 3 & $\mathrm{~B}$ & $\overline{\mathrm{G}}$ & B & $\mathrm{G}$ & B \\
\hline 42 & $\mathrm{G}$ & B & $\mathrm{G}$ & B & & & & $\mathrm{G}$ & B & B & $\mathrm{G}$ & B & $\mathrm{G}$ \\
\hline 43 & B & $\mathrm{G}$ & B & C & I & & & 3 & $\mathrm{G}$ & B & B & B & B \\
\hline 44 & B & B & $\overline{\mathrm{G}}$ & $\bar{B}$ & I & & & $G$ & B & $\mathrm{G}$ & B & $\mathrm{G}$ & $\mathrm{G}$ \\
\hline 45 & $\overline{\mathrm{G}}$ & B & B & G & & & & 3 & $\mathrm{G}$ & B & & B & B \\
\hline
\end{tabular}

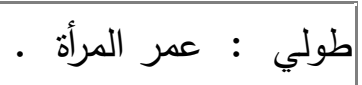
عرضي : الشهر الذي حدث فيه الإخصاب . 


\section{المطلب الثالث \\ اختيار نوع الجنين عند الفراعنة}

على الرغم من تقدم علم الطب عند الفراعنة ، إلا أنهم لم يؤثر عنهم - فيما أعلم - طريقة

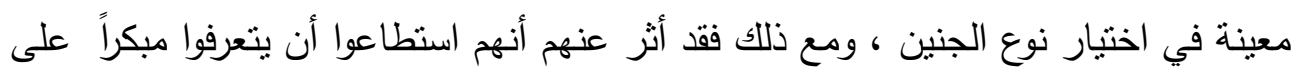
نوع الجنين في بطن الأم منذ ما يربو على خمسة آلاف عام ، وذللك عن طريق فكرة بسيطة ، وهو أن يؤخذ بول المرأة ، ويصب في إناعين منفصلين ، يوضع في أحدهما حفنةٌ

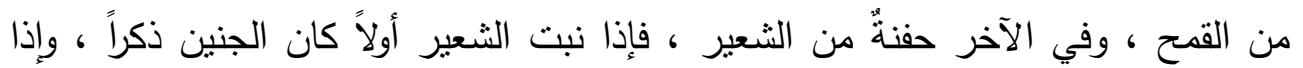

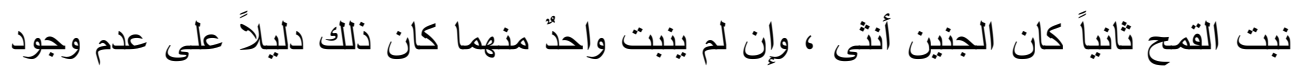
حمل (')

\section{المطلب الرابع \\ اختيار نوع الجنين عند العرب}

كان العرب - ولا يزالون - يؤثرون إنجاب البنين على البنات ، وكان معظمهفي الجاهلية يكره البنات كراهة شديدة ، فكان الواحد منهم إذا بشر بأنثى تغير وجهه ، وأسود غماً ، وحزناً

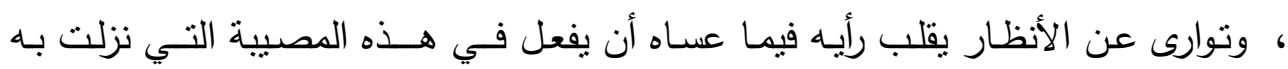

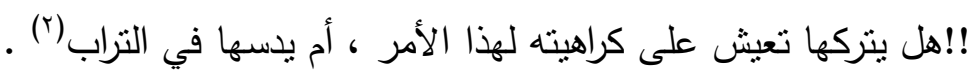

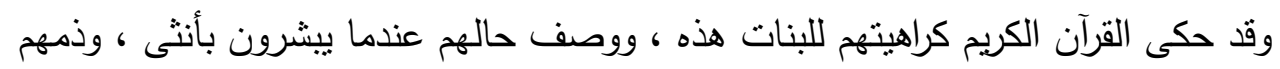

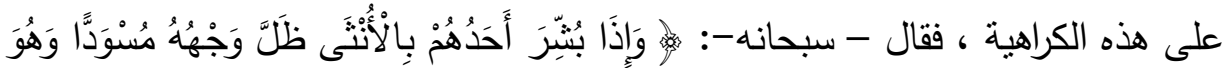

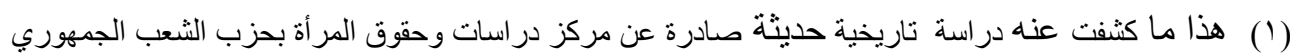

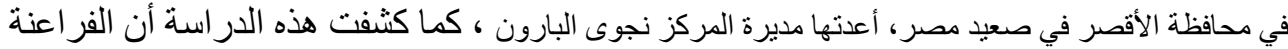

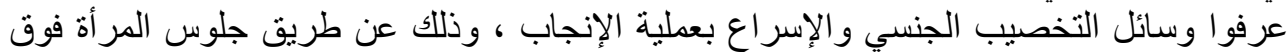

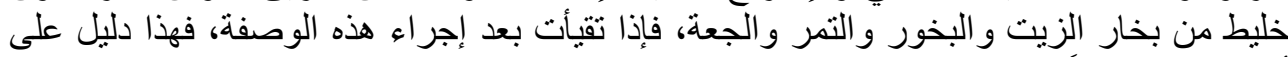

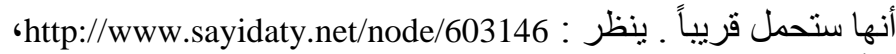

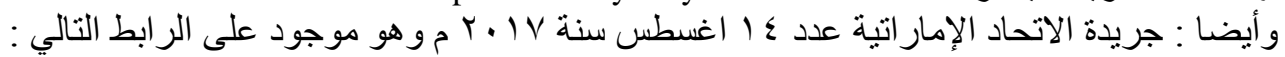
https://www.alittihad.ae/article/47495/2017

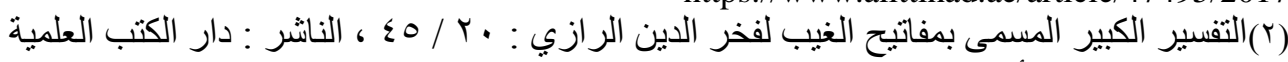

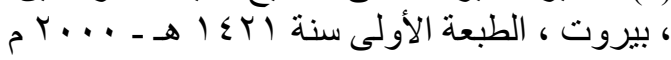

$0 \leqslant$. مجلة بحوث كلية الآداب 


\section{اختيار نوع الجنين ( الاصطفاء الجنسي )}

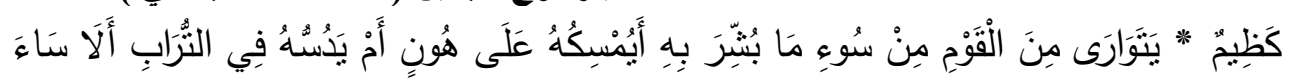

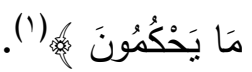
ومما أثر عن حب العرب إنجاب الذكور ، وكراهية إنجاب الإناث ما ورد عن امرأة أعرابية أنها قالت :

وما أبالي أن أكون مُحمِقَة إذا رأيت خصبة معلقة (r)

أي : أنها لا تبالي أن تلد الأولاد الحمقى ، ما دام هذا المولود ذكراً ، وليس أنثى •

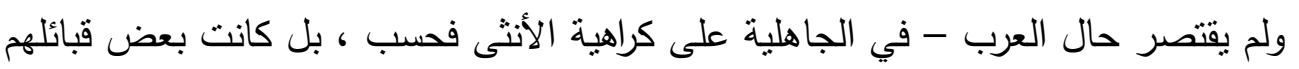

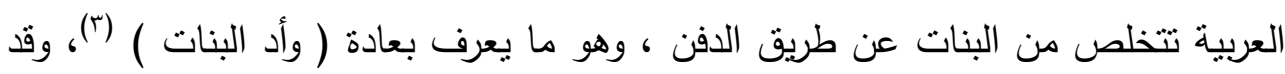

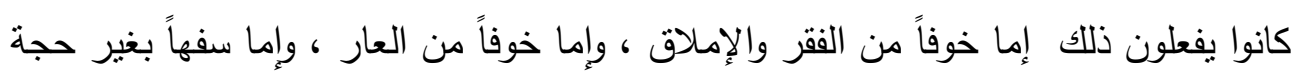

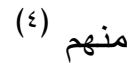
فكان الواحد منهم إذا ولدت له بنت ، وأراد استحياءها ، ألبسها جبة من صوف ، أو شعر

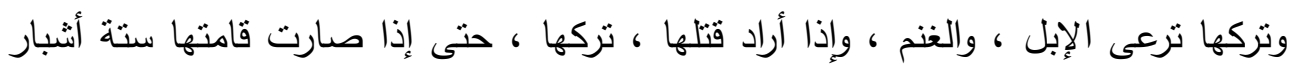

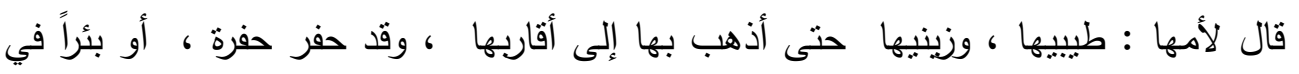

$$
\text { (1) }
$$

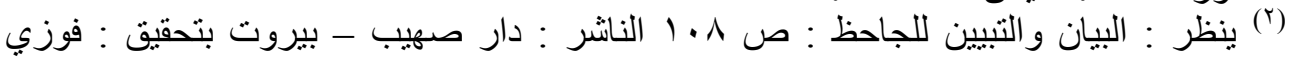

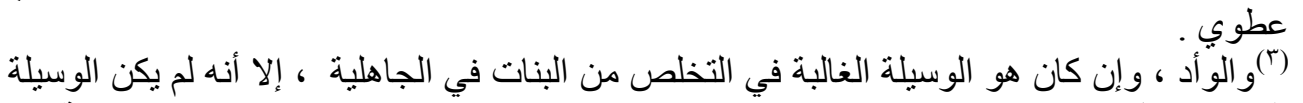

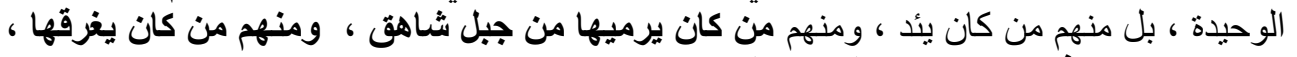

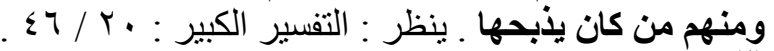

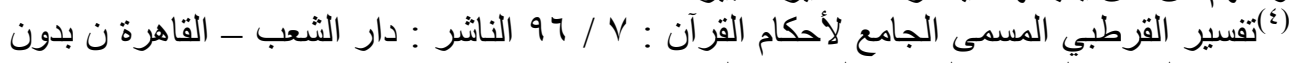

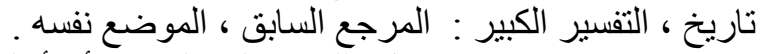

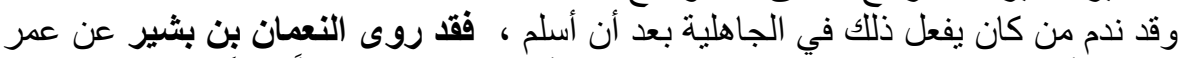

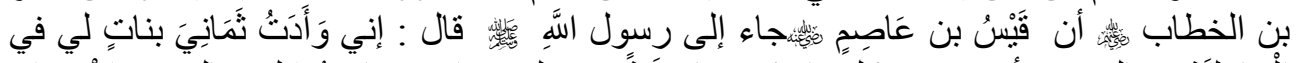

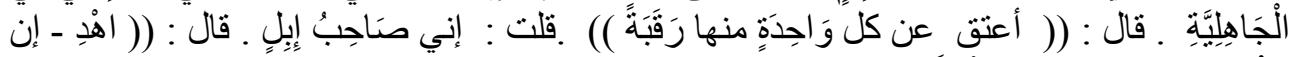

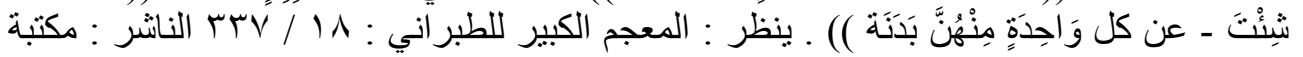

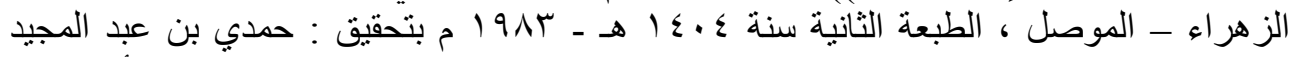

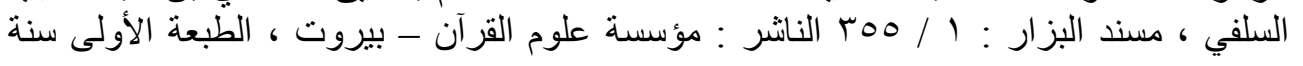

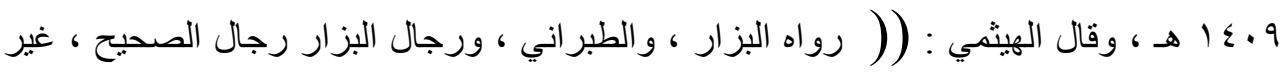

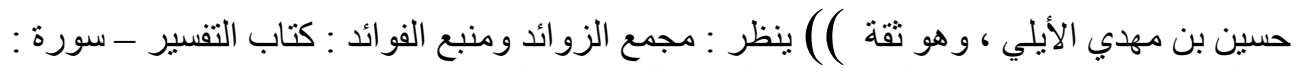

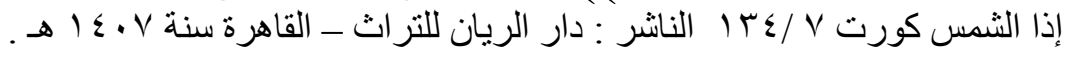




\section{د د الد الد محم حسين إبراهيم}

الصحراء ، فيذهب بها إليها ، ويقول لها : انظري فيها ، ثم بدفعها من خلفها في هذه البئر

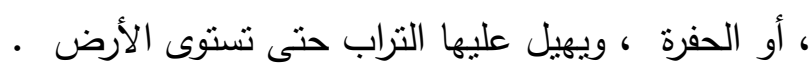
وقيل : كانت الحامل إذا قرب وضعها حفرت حفرة ، فتمخضت على رأسها لأرضا ، فإذا ولدت

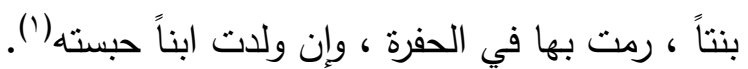
معرفة العرب أن نوع الجنين يرجع إلى الرجل :

وإذا كانت الثعوب القديمة تعتقد أن المرأة هي السبب في تحديد نوبن نوع الجنين ، إلا أن

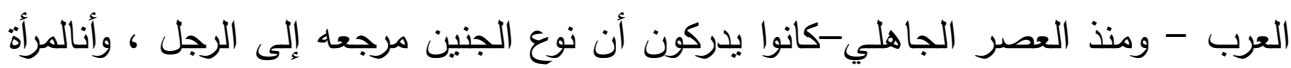

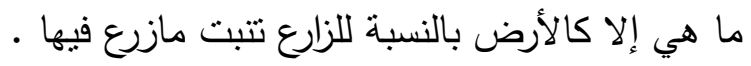

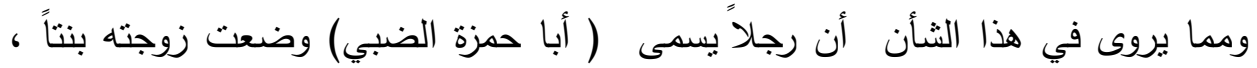

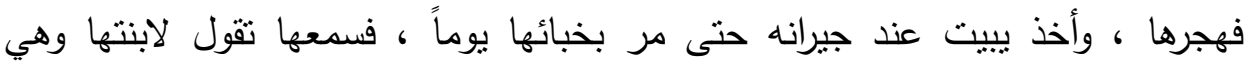
ترقصها :

\section{مـا لأبي حمزة لا بأتينا}

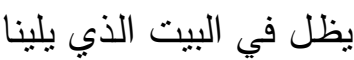

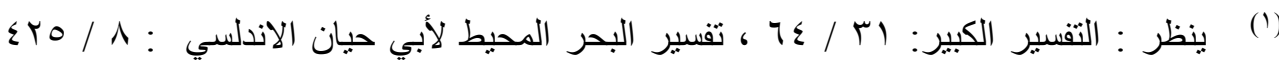

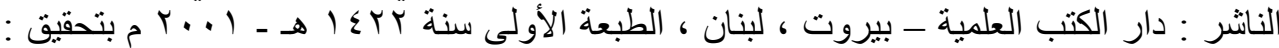

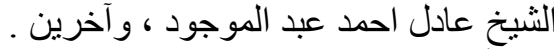
على أن العرب لم يكن جميعهم كذلك ، بل وجل وجد منهم من استقبح هذه العادة الذميمة كالصحابي

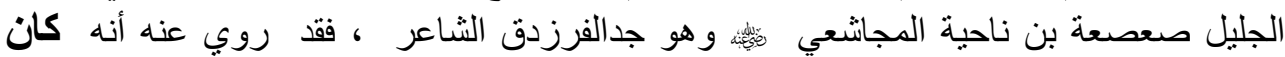

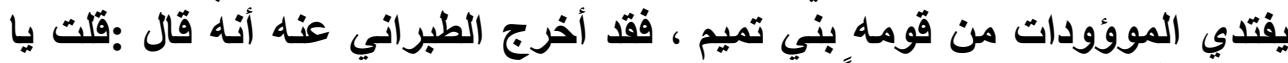

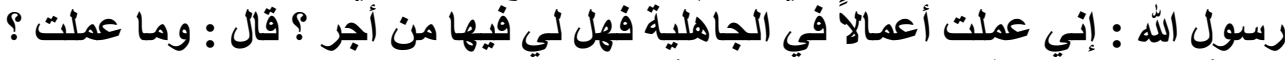

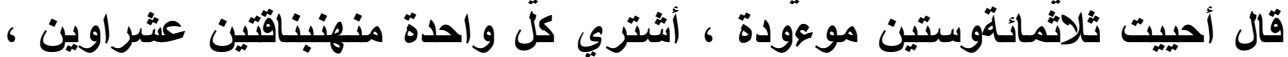

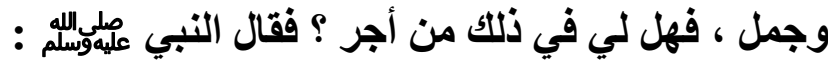

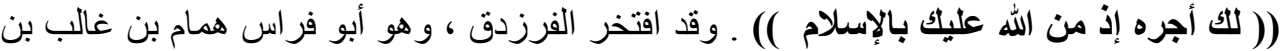

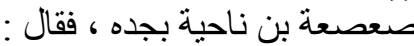

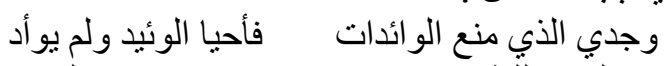

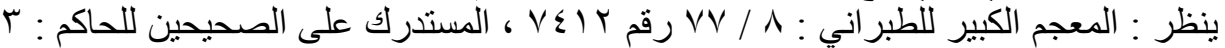

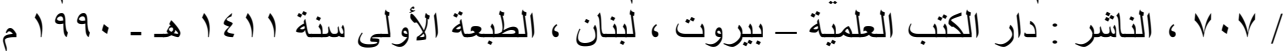

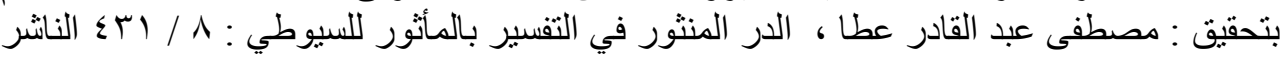

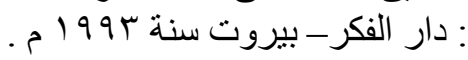

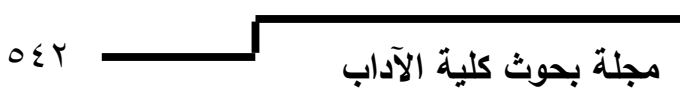


اختيار نوع الجنين ( الاصطفاء الجنسي )

غضبان ألا نلـد البنينا

تالهه ما ذلك في أيدينا

وإنما نأخذ ما أعطينا

ونحن كالأرض لزارعينا

نتبت ما قد زرعوه فينا

فلما سمع أبو حمزة زوجته تقول ذللك أسف على ما فعله أسفاً شديداً ، وأقبل إليها ، وقبل

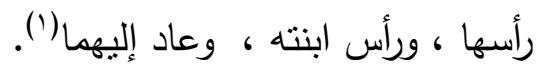

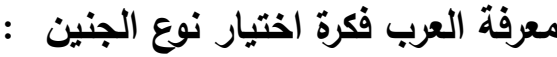

وجدت بعض المحاولات في كتب الطب العربية القديمة يحاولون فيها اختيارنوع الجنين ، وهذه المحاولات عبارة عن ( وصفات طبية ) اعتمدوا فيها على التجربة ، من هذه الوصفات ما يأتي : وهده ا - إن المرأة إذا شربت أنفحة أرنب ذكر بشراب حملت بذكر ، وإن شربت أنفحة أرنب أنثى • حملت بأنثى r - ونقل عنهم أيضاً : أن المرأة إذا شربت مرارة دب أنثى حملت بأنثى وإذا شربت مرارة

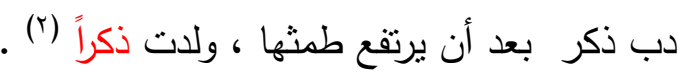
r - وجاء في بعض كتب الطب(r) أن البلد البارد ، والفصل البارد ، والريح الثمالية تعين على إنجاب الذكور ، أما البلد الحار ، والفصل الحار ، وكذا الرياح الحارة فتعين على لئ

$$
\text { إنجاب الإناث }
$$

ويلاحظ أن هذه المحاولات لا تعدوا أن تكون وصفات قد لا يؤيدها الطب الحديث .

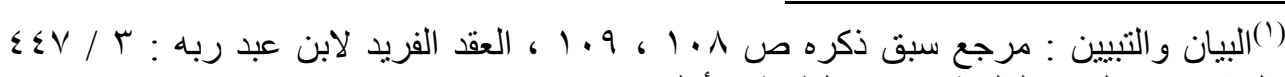

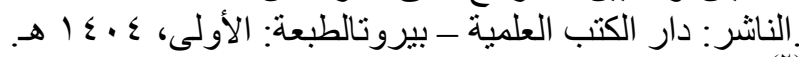

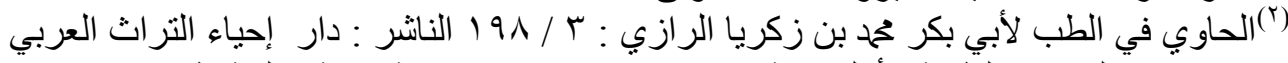

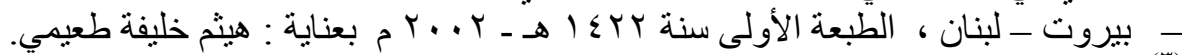

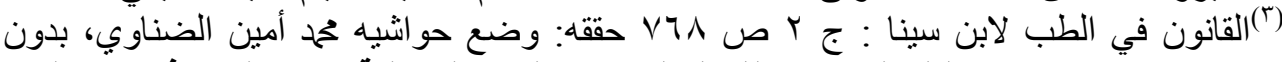
بيانات ، وفيه : (( ....و البلا البارد ، والفصل البارد ، والريح الثمالية تعين على الإذكار ، والضد

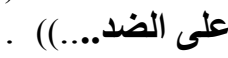




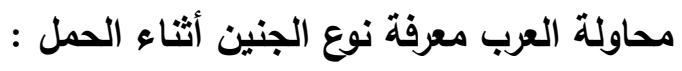

و إذا كان العرب قد حاولوا اختيارنوع الجنين عن طريق بعض الوصفات - على نحو ما

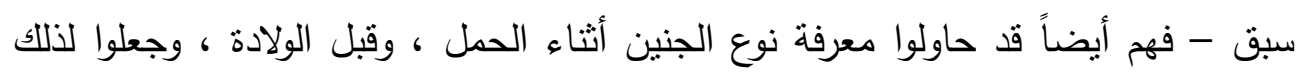

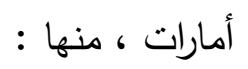

ا- إذا كانت المرأة أثناء حملها حننة اللون ، سمينة الوجه ، قليلة الكلف والنمش ، فأل

فرحة، فهي حامل بذكر ، وإذا كانت عكس ذلك فهي حامل بأنثى .

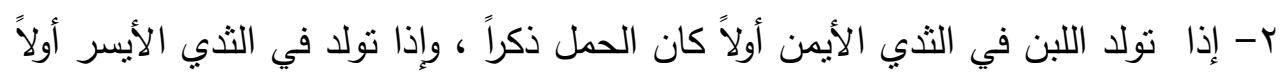

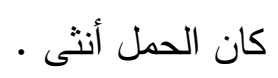
r - إذا كان ثديها الأيمن أكبر من الأيسر فالحمل ذكر ، وإن كان الأيسر أكبر ، فهو أنثى ، وإذا كان الثنيان كبيرين كان الحمل توأماً .

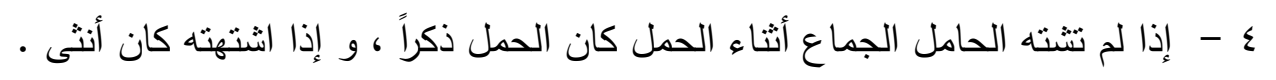

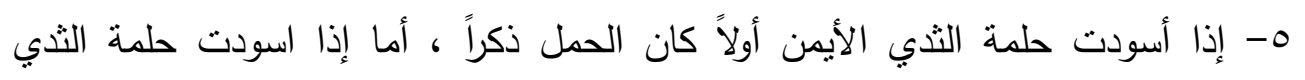

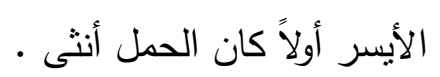
ج- إذا اعتمدت المرأة الحامل على بدها اليمنى عند قيامها ، وقعودها كان حملها ذكراً ، أما

$$
\text { إذا اعتمدت على اليسرى كان الحمل أنثى (') }
$$

والناظر في هذه المحاولات من العرب القدامى لمعرفة نوع الجنين أثثاء الحمل يجدها قد الدي

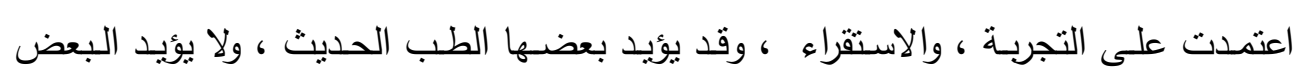
الآخر ، ويكفيهم فضلاً شرف المحاولة .

(') كتاب الحاوي في الطب الرازي : ب / ه ا و وما بعدها . مجلة بحوث كلية الآداب 


\section{اختيار نوع الجنين ( الاصطفاء الجنسي )}

\section{المبحث الثاني \\ الحكم الشرعي للوسائل القديمة لاختيار نوع الجنين}

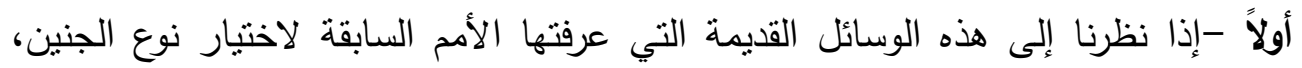

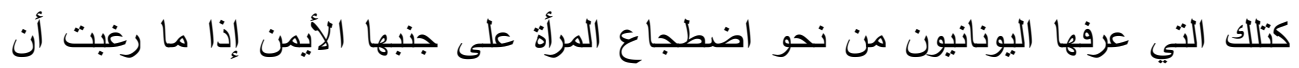

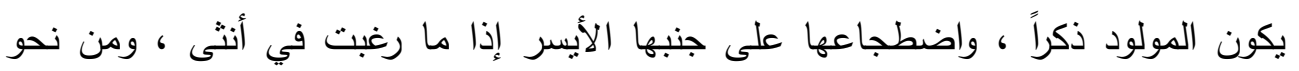

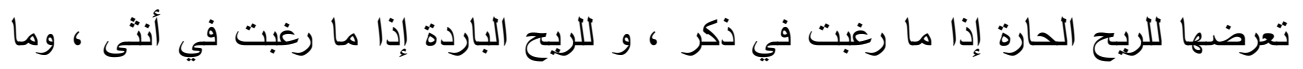

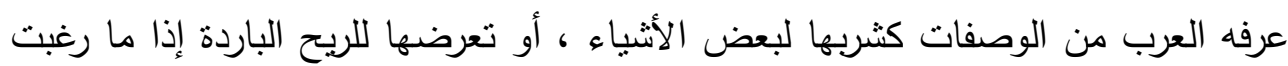

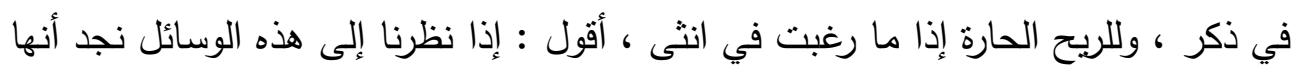

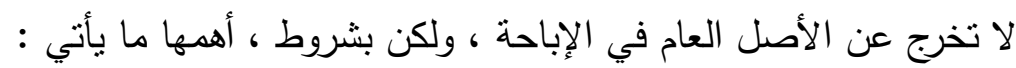

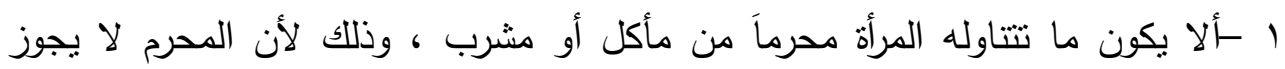
التداوي به ؛ عملاً بما رواه أبو الدرداء - رضي الله عنه - - أن رسول الله صلى الله عليه

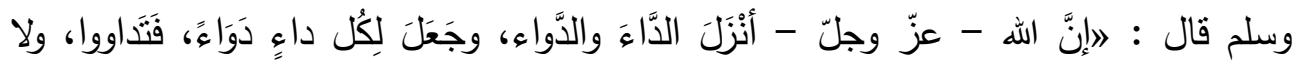
تَََاووا بحرَامه" (') ، وقوله صلى الله عليه وسلم في حديث أم سلمة رضي الله عنها : "إِنَّ اللَّه

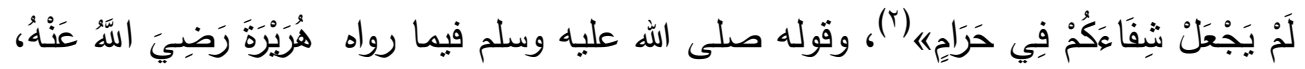

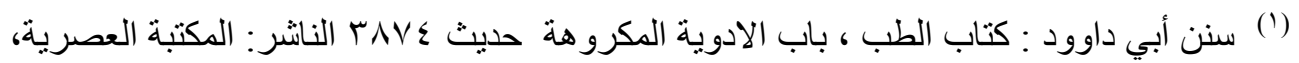

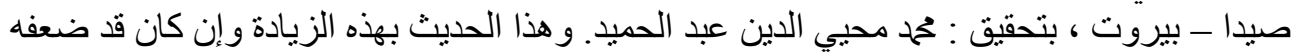

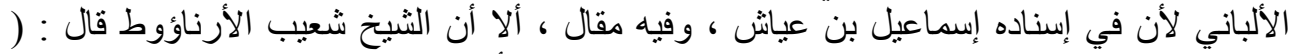

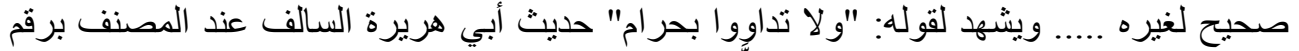

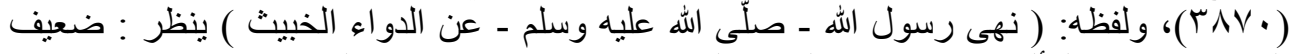

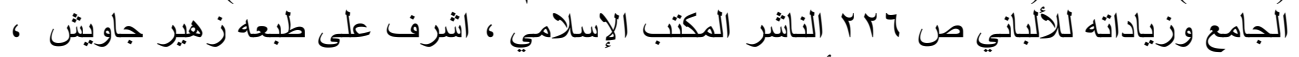

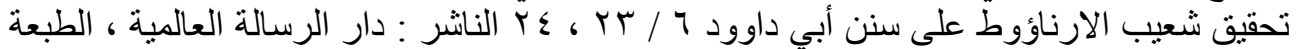

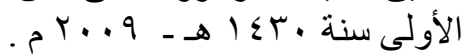

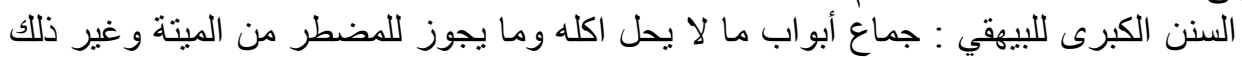

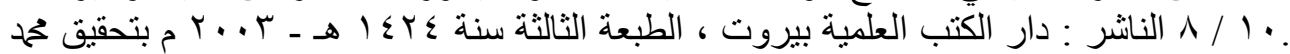

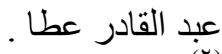

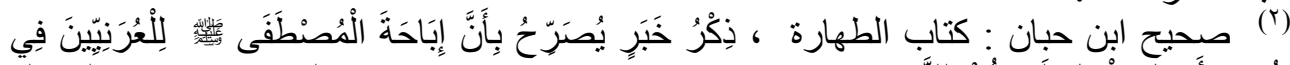

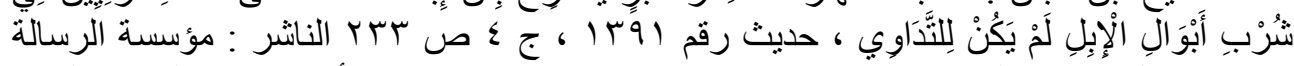

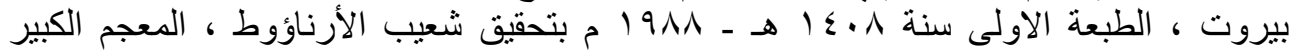

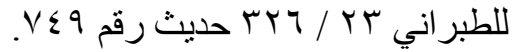




\section{د / خالا محمد حسين إبرا هيم}

قَالَ: انَهَى رَسُولُ السَّهِ

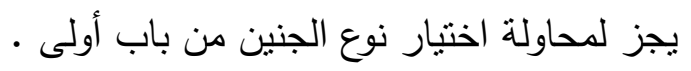
r -ألا يؤدي استخدام تلك الوسائل القديمة إلى الإضرار بمن تتاوله ؛ وذللك لأن تتاول ما فيه إضرار بالثخص ممنوع شرعاً ؛ لقول رسول الله صلى الله عليه وسلم » لا ضرر ولا لالهرديه

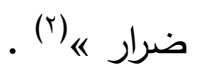

\section{ثانياً - حم الاعتماد على الجدول الصيني في اختيار نوع الجنين :} أما الاعتماد على الجدول الصيني في اختيار نوع الجنين فهو أمر غير جائز ؛ وذلك لأنه يقوم على فرضيات فلكية على أساس وجود علاقة بين عمر المرأة والثهر الذي تم فيه التلقيح ، فكل امرأة في عمر معين ، إذا حدث الحمل في شهر معين جاء الحمل ذكراً ، أو أنتى ، والحقيقة أنه لا علاقة بين عمر المرأة وتاريخ حملها و تحديد نوع الجنين ، بل إن هذاء هين

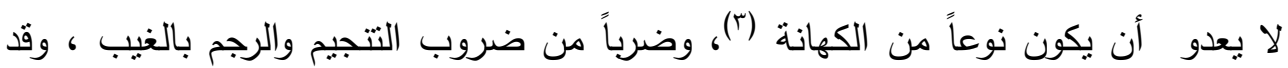

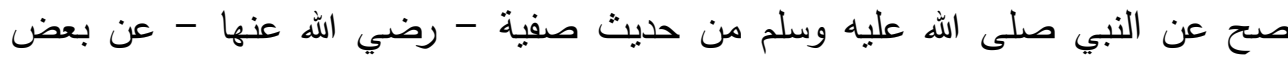

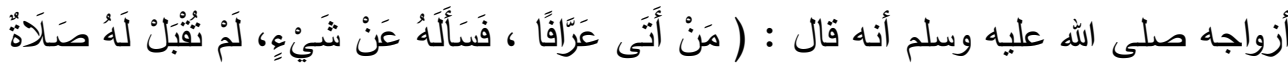

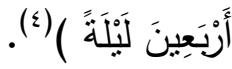

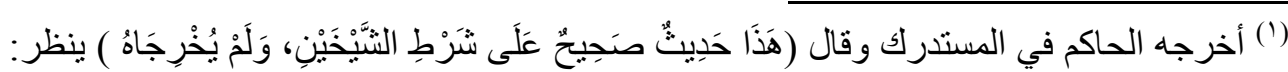

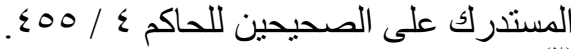

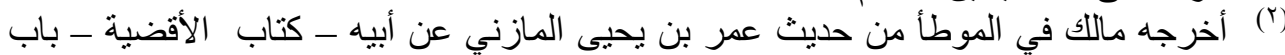

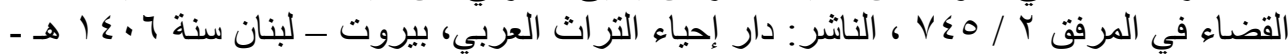

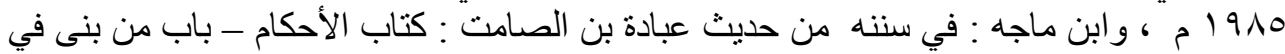

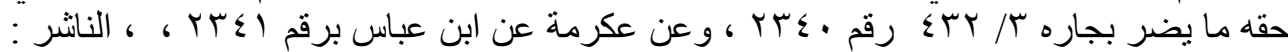

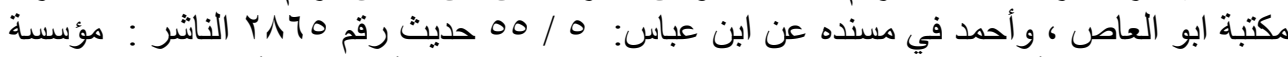

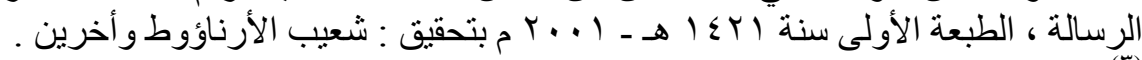

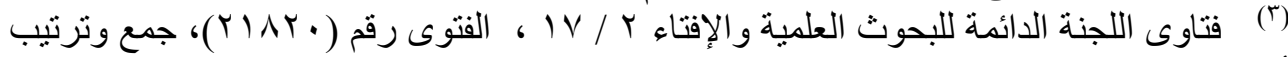

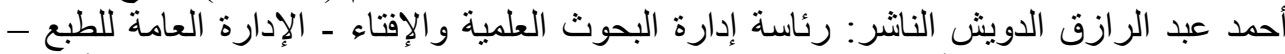

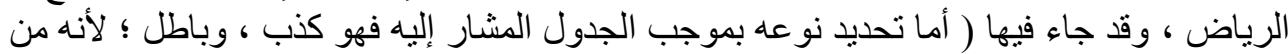

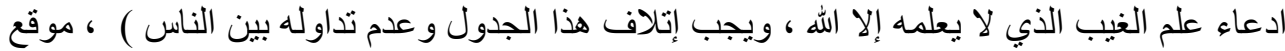

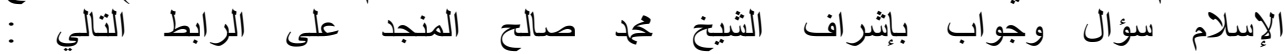
https://islamqa.info/ar/121516

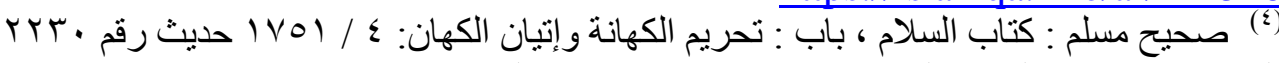
النانر : دار إحياء التراث العربي ، بتحقيق : محمد فؤاد عبد الباقي . 


\section{اختيار نوع الجنين ( الاصطفاء الجنسي )}

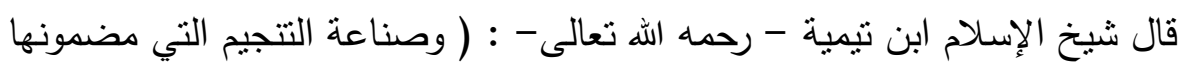
الأحكام والتأثثر ، وهو الاستدلال على الحوادث الأرضية بالأحوال الفلكية ، والتمزيج بين

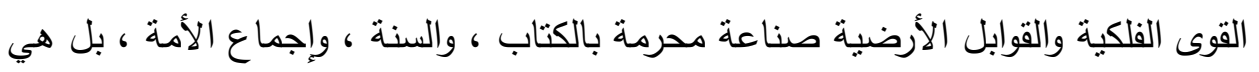
محرمة على لسان جميع المرسلين في جميع الملل)('). علاوة على أنه يؤخذ على الجدول أمور أهمها ما يأني :

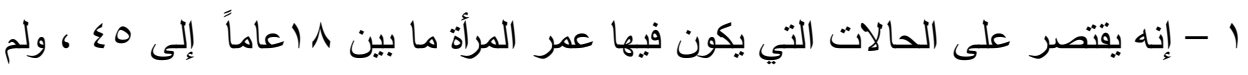
بذكر ما قبل ذلك ، وما بعده . r - إنه لم يذكر الحالات التي يجيء فيها الحمل توائم(r) ، ولم يبين ما إذا كانت التوائم إناثاً ، أم ذكوراً ، أم أن بعضها إناثاُ وبعضها ذكوراً ، على الرغم من نسبة المواليد التوائم

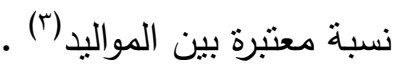

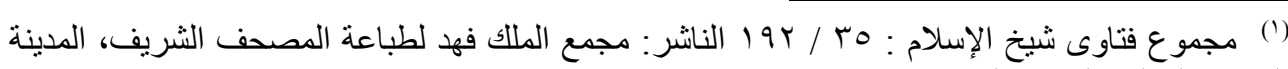

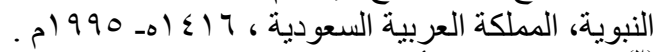

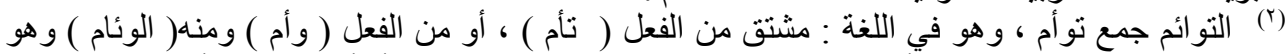

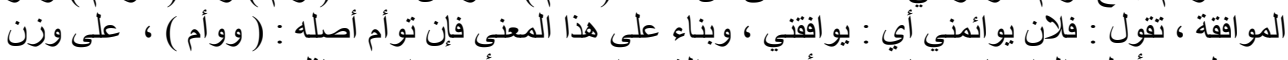

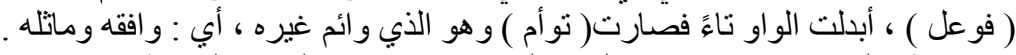

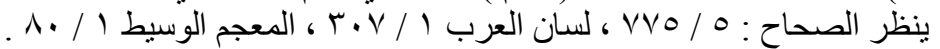

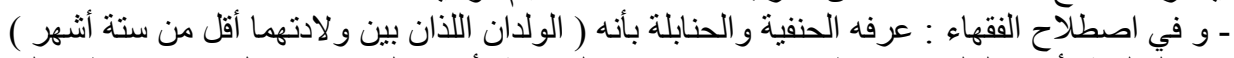

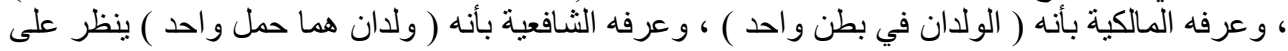

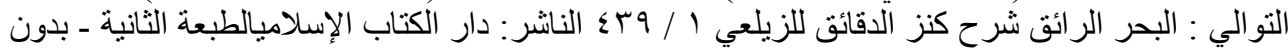

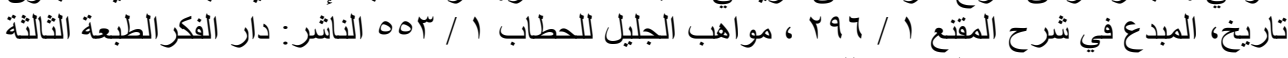

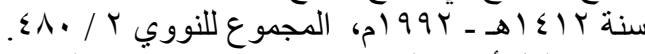

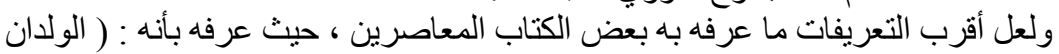

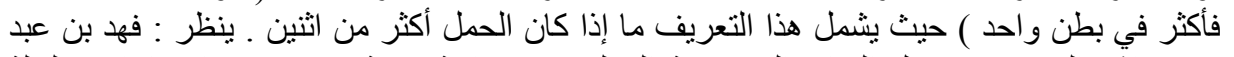

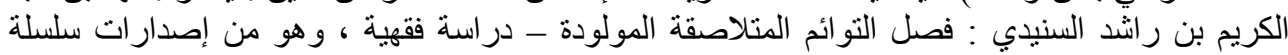

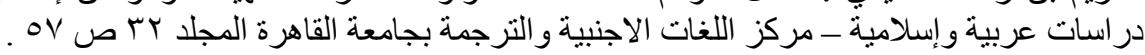

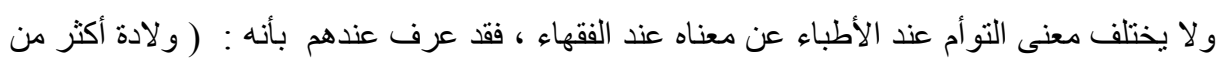

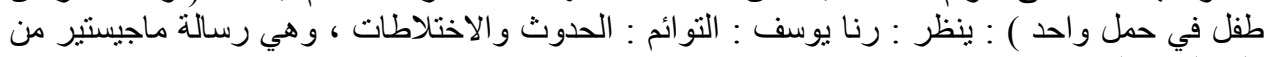

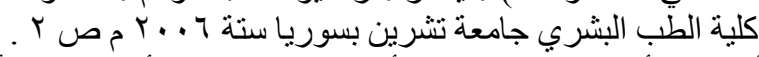

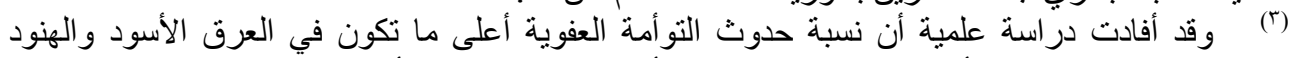

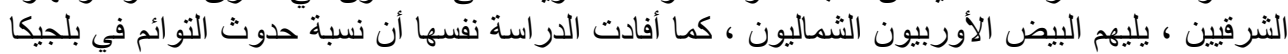

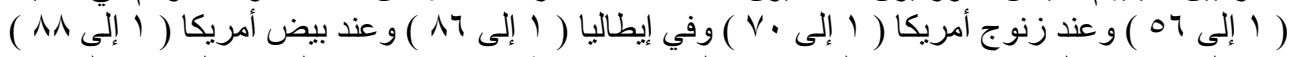

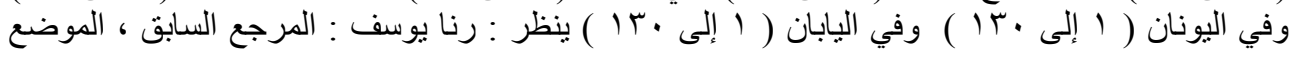




\section{د ا دالد محمد حسين إبرا هيم}

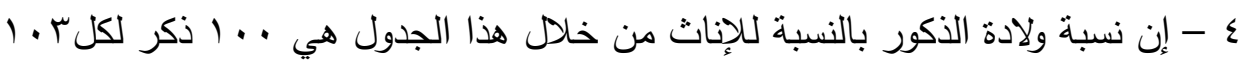

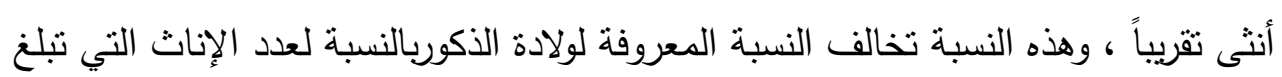

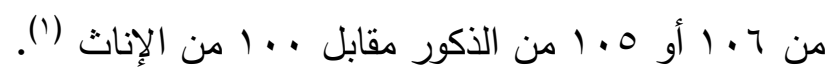

كل ذلك يجعل اللجوء إلى هذا الجدول لاختيار نوع الجنين وسيلة غير مقطوع بها ، علاوة

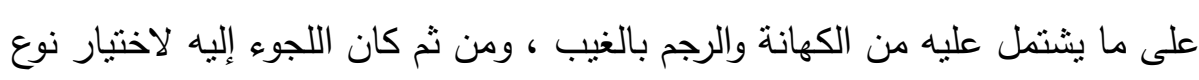
الجنين محرماً . مأ ل

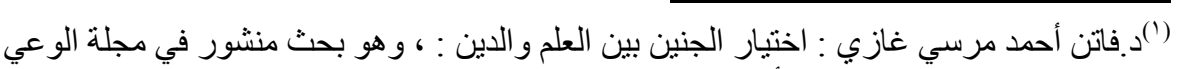

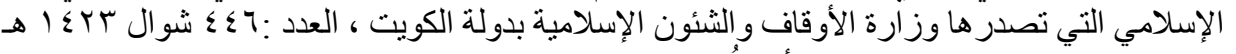

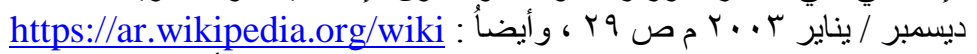

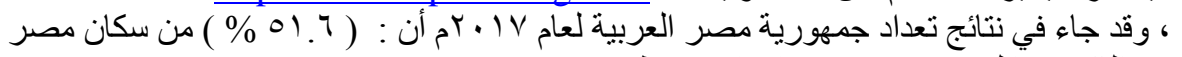

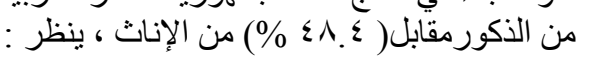
https://www.youm7.com/story/2017/9/302017/3436198

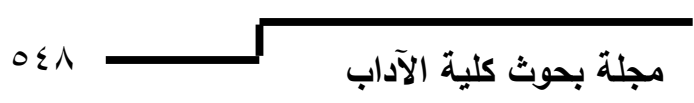


اختيار نوع الجنين ( الاصطفاء الجنسي )

الفصل الثاني

الوبائل الحديثة لاختيار نوع الجنين وحكمها الثرعي

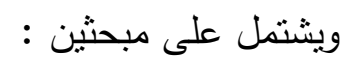

المبحث الأول - الوسائل الطبيعية لاختيار نوع الجنين وحكمها الثرعي لئي

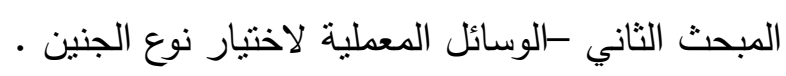

المبحث الأول

الوسائل الطبيعية لاختيار نوع الجنين وحكمهالثرعي الاول

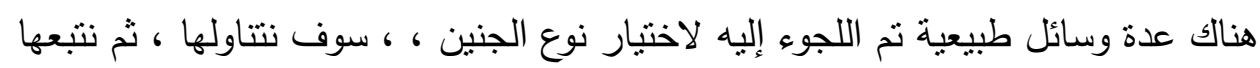
ببان حكمها الشرعي ، وذللك في مطلبين :

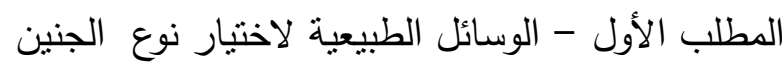

المطلب الثاني - حكم اختيار نوع الجنين بالوسائل الطبيعية . المطلب الأول

الوسائل الطبيعية لاختيار نوع الجنين

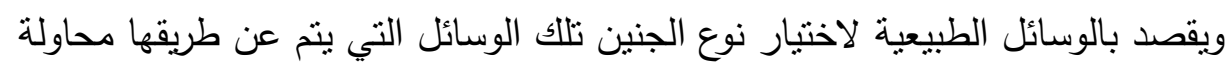

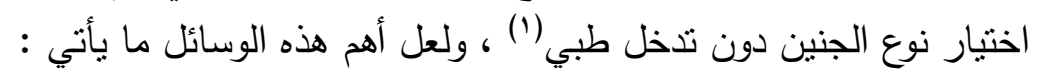
الوسيلة الاولى - النظام الغذائي (r):

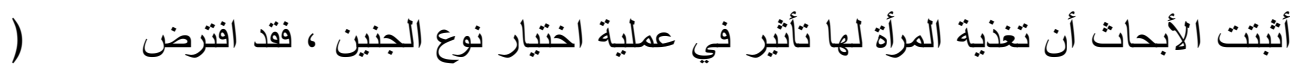
استولوفسكي)أن الايونات الموجودة على سطح البييضة هي التي تتحكم في نوع الحيوان

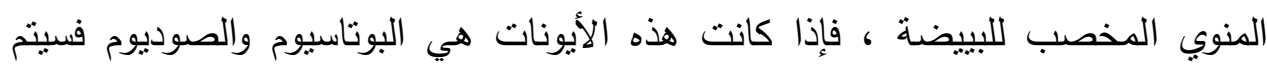

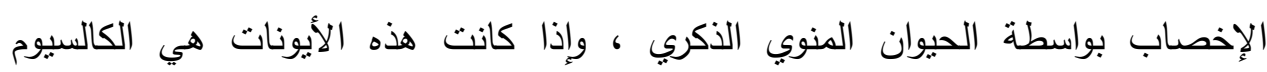

والماغنسيوم فسيتم الإخصاب بواسطة الحيوان المنوي الانثوي (r). وذكر العلماء أنه يمكن التحكم في هذه الايونات بواسطة نظام غذائي ملائم :

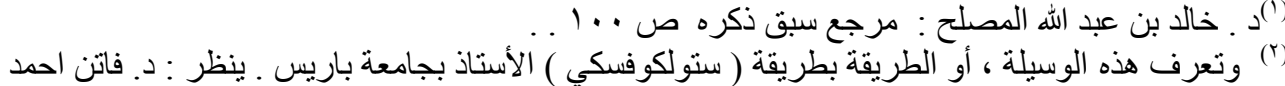

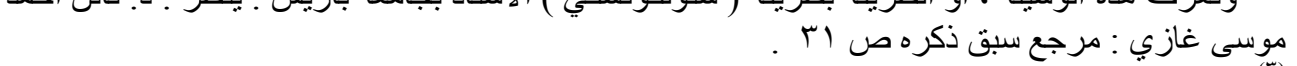

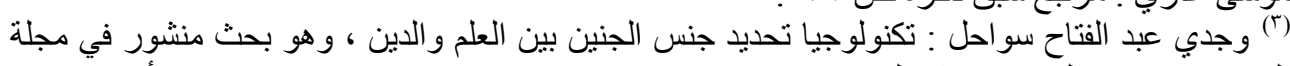

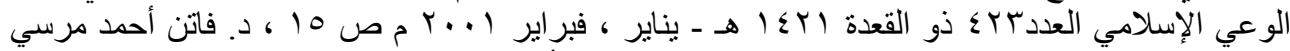

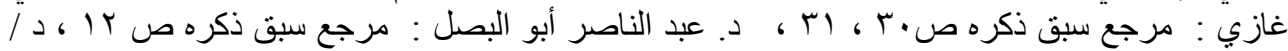

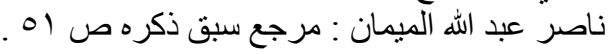

مجلة بحوث كلية الآداب 


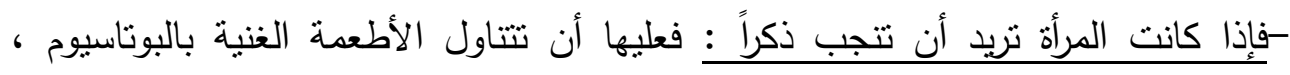

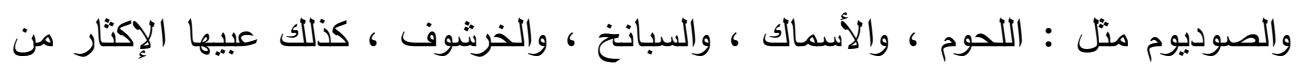

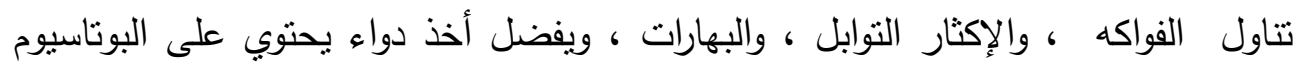

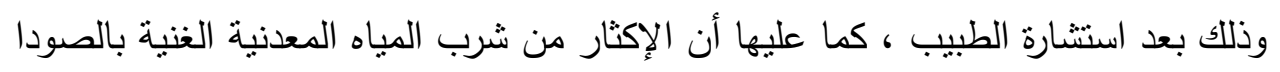
-وإذا كانت تريد أن تتجب أنثى : فعليها أن تتتاول الأطعمة الغنية بالكالسيوم والماغنسيوم

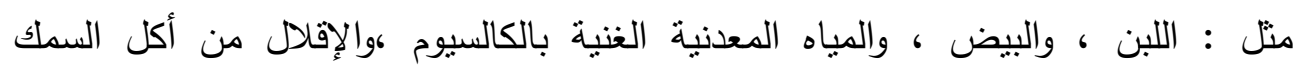
المشوي. و الابتعاد عن أكل اللحوم ، والخضروات والفواكه ، والتوابل ، والبهارات، كما يجب عليه

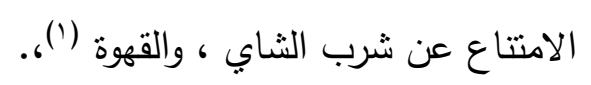

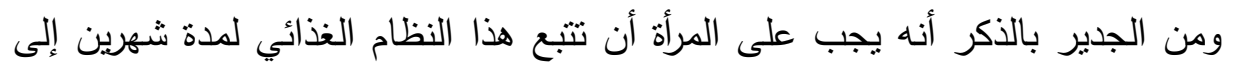

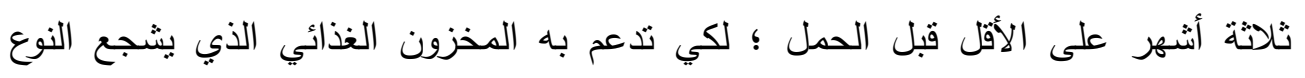
المرغوب فيه، وبيتحسن أن يشارك الزوج زوجنه هذا النظام ؛ لأنه وإن لم يكون هذا الأمر لأله ضرورياً بالنسبة له فعلى الأقل يكون عاملاً مساعداً للزوجة من الناحية النفسية.

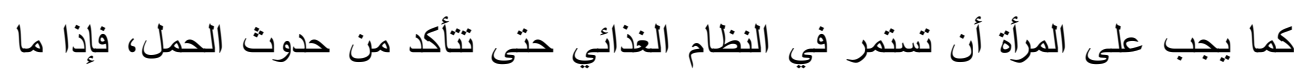
تأكدت من ذلك وجب عليها التخلي عن هذا النظام ، وتتاول جميع المواد الضرورية اللازمة فئي لصحتها ،وصحة جنينها حسبما يقرر الطبيب(r).

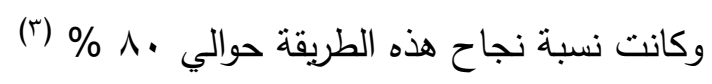

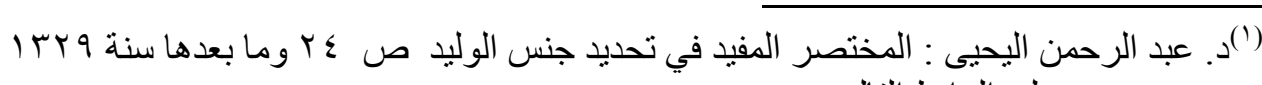
هـ و هو موجود على الرجن اليحئ : النتالي : http://saaid.net/book/open.php?cat=83\&book=4384

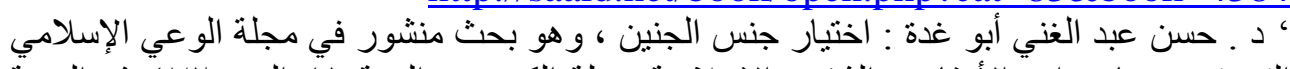

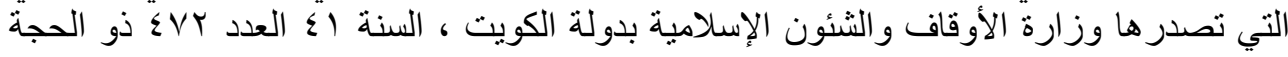

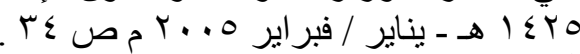

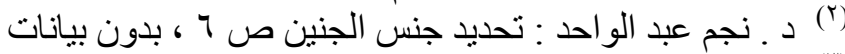

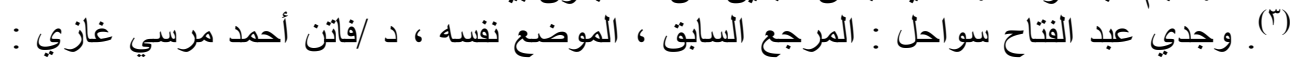
مرجع سبق ذكره ، آس آس 00. مجلة بحوث كلية الآداب 


\section{اختيار نوع الجنين ( الاصطفاء الجنسي ) (1)}

\section{الوسيلة الثانية- توقيت الجماع بين الزوجين حسب وقت التبويض(') :}

بداية يقرر العلماء أن الحيوان المنوي الذكري خفيف الوزن ، سريع الحركة ولكنه يعيش فترة أقصر من تلك الفترة التي يعيشها الحيوان المنوي الانثوي الذي يعيش لفترة أطول لكنه انقل

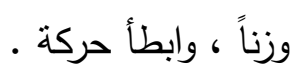

وبناء على ذللك فانه إذا حدث الجماع مباشرة بعد حدوث التبويض فان الكفة ترجح إنجاب الذكور ؛ لأن الحيوان المنوي الذكري لكونه أخف وزنا ، وأسرع حركة سوف يصل أولاً إلى لى إنى البييضة ، فإذا وصل إليها واخترق جدارها كان الحمل ذكراً يإذن الله ، أما إذا حدث الجماع قبل التبويض فإن الكفة ترجح إنجاب الإناث ؛ لأن الحيوان المنوي الذكري سيسرع ويسبق إلى حيث توجد البييضة ، فلا يجدها ، وسرعان ما يموت ، ثم تكون الحيوانات المنوية

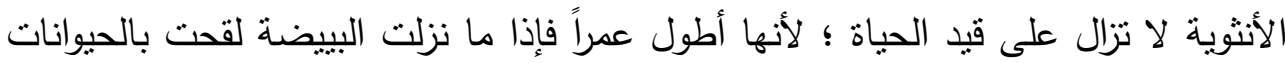

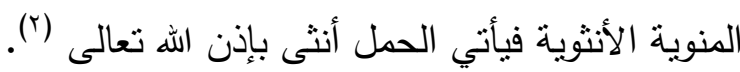
وبناء على ما تقدم إذا رغب الزوجان في أنْ يكون الجنين ذكراً (بإذن الله ) فعليهما اتباع الخطوات التالية :

1 - يفضل الجماع في اليوم الذي ينوقع أنْ تتزل فيه البيضة من المبيض إلى قناة

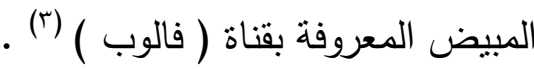

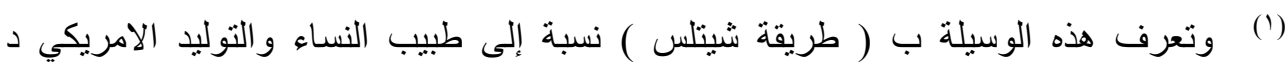

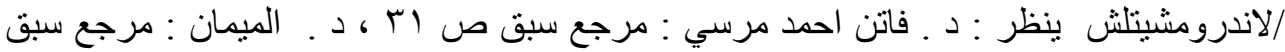

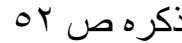

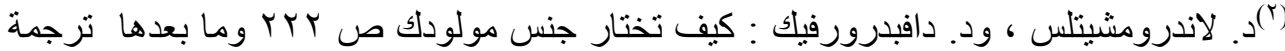

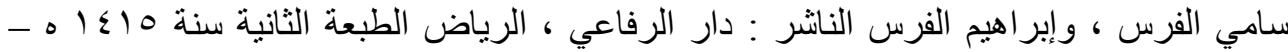

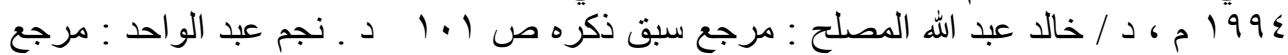

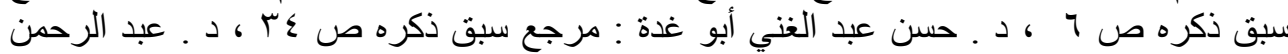

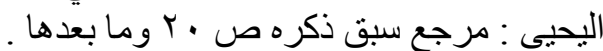

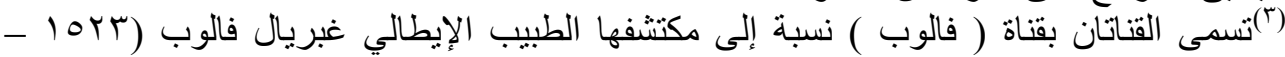

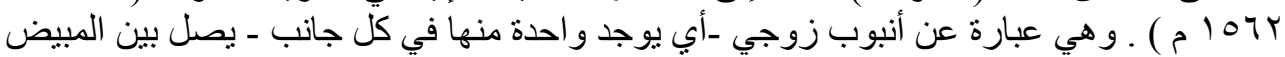

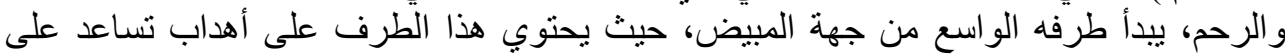

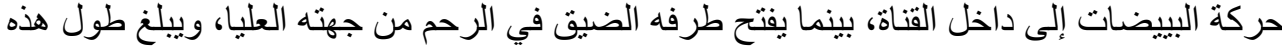

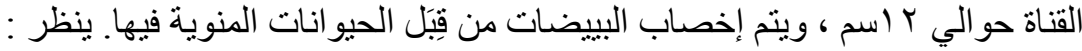
https://ar.wikipedia.org/wiki 


\section{د / خالد محم حسين إبرا هيم}

r - ـ يجب على الزوجين الامتتاع عن الجماع قبل الفترة التي يتوقع أنْ تنزل فيها البييضة (أي يمتتعان عن الجماع بعد اليوم الثالث من توقف الدورة الثهرية إلى اليوم الذي يتوقع أنْ تنزل فيه البييضة).. r - كذلك يجب على الزوجين الامتتاع عن الجماع في بقية أيام الدورة بعد موعد نزول

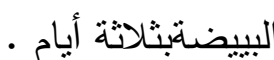

أما إذا رغبا أنْ يكون الجنينأنثى - بإذن الله تعالى - فعليهما اتباع الخطوات التالية : 1

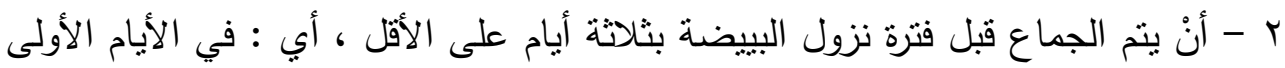
- بعد الطهر r - أنْ يمتتع الزوجان عن الجماع خلال الفترة التي يتوقع فيها أنْ تتزل البييضة - وذلك غالباً من اليوم الخامس إلى اليوم الثاني عشر بعد توقف الدورة الثهرية ، وكذلك خلال الفترة

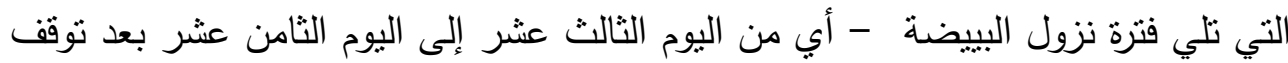

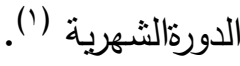
وفي جميع الأحوال لا ينس الزوجان الدعاء بأنْ برزقهما الله الولد الصالح، وأنْ يجنبهما وذريتهما الثيطان ، فكل ذلك بإرادة الله ، ومشيئته(ب) . الوسيلة|الثالثة - تغيير ظروف وحالة القتاة التناسلية عندالمرأةعن طريق (الغسل (المهبلي ): وتهدف هذه الوسيلة إلى تغيير الوسط الكيميائي للمهبل للمساعدة على وصول الحيوان المنوي المطلوب للبيضة(")، فقد ثبت علمياً أن الوسط الحمضي هو أكثر ملائمة للحيوان

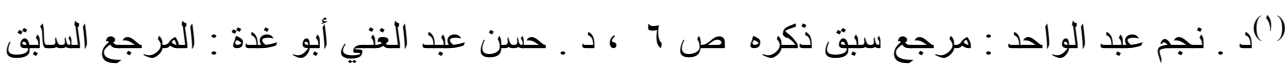

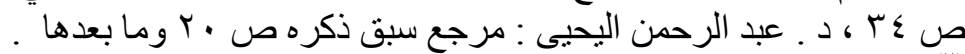

$$
\begin{aligned}
& \text { (T) } \\
& \text { (r) } \\
& \text { مجلة بحوث كلية الآداب }
\end{aligned}
$$




\section{اختيار نوع الجنين ( الاصطفاء الجنسي )}

المنوي الأنثوي ، ، بينما الوسط القلوي ( القاعدي ) هو أكثر ملائمة للحيوان المنوي الإني

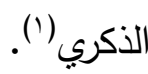

فإذا كانت المرأة راغبة في إنجاب ذكر فعليها القيام بتغيير الوسط الحامضي للمهبل ، وذلك

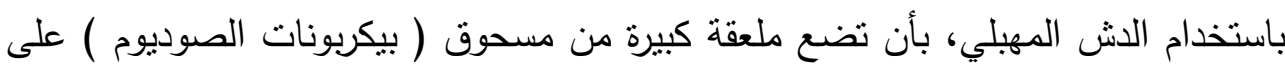
لتز من ماء مغلي ، ومفتر ، ثم إجراء عملية غسل عميقة للمهيل بواسطة هذا المحلول قبل العملية الجنسية. وأما إذا أرادت إنجاب أنثى فعليها استخدام دش مهبلي حامضي ، وذلك تضيف ملعقة كبيرة من ( الخل الأبيض ) إلى لتر من ماء مغلي مفتر ، ثم تقوم بإجراء عملية غسل عميقة

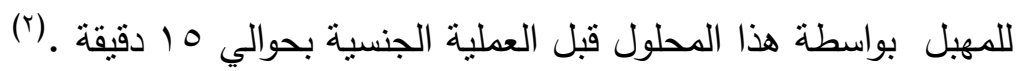
المطلب الثاني

\section{الحكم الشرعي لاختيار نوع الجنين بالوسائل الطبيعية}

أما عن الحكم الثرعي لهذه الوسائل الطبيعية لاختبار نوع الجنين فإن الباحثين المعاصرين

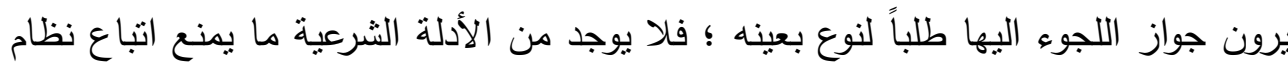

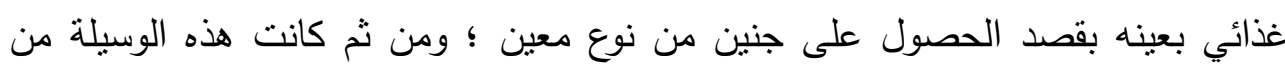

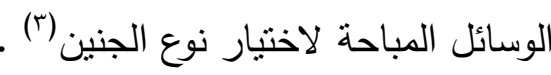

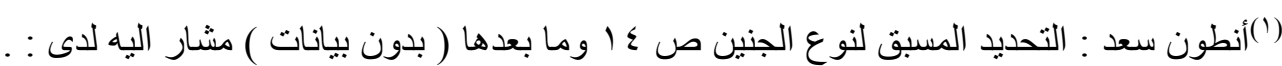

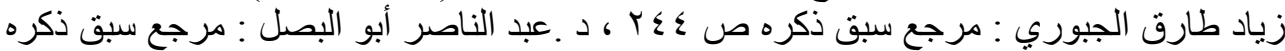

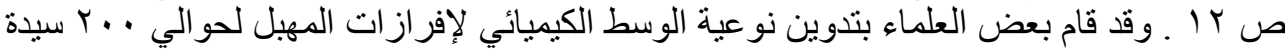

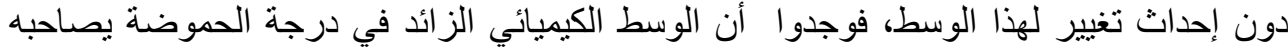

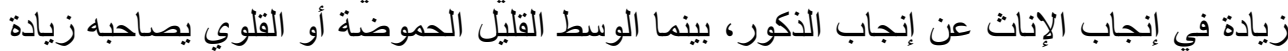

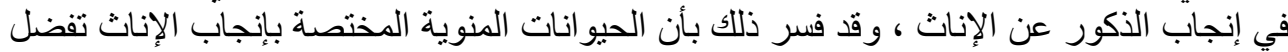

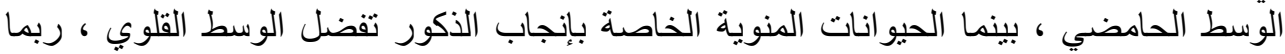

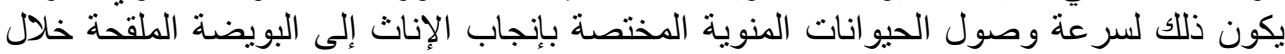

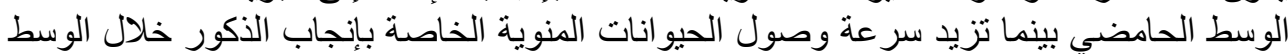

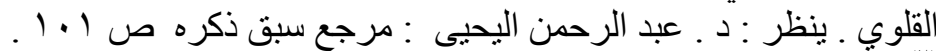

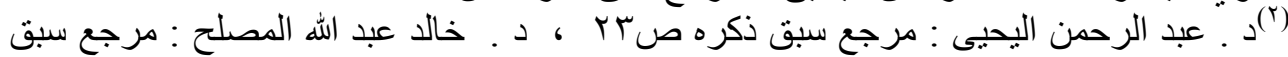

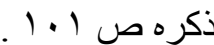
(ז)د. خالد عبد الله المصلح : مرجع سبق ذكره ص . . . . . 


\section{د / خالا محمد حسين إبرا اهيم}

كما أن قيام المرأة بما يسمى ( بالاش الثهين إئلي ) تهيئة للرحم لاستقبال نوع معين من الأجنة

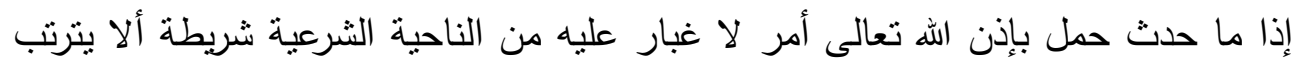

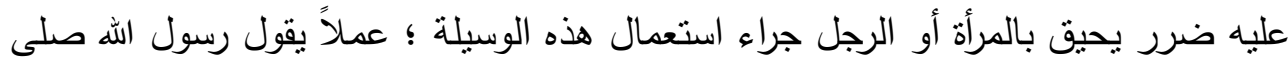

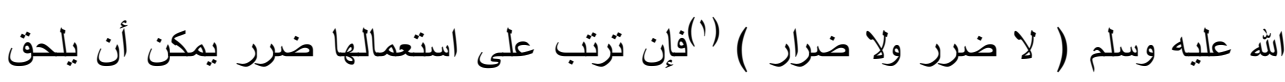
الزوجة أو الزوج كان استعمالها غير جائز ، والقول بما إذا كان بترتب على استعمالها ضرر

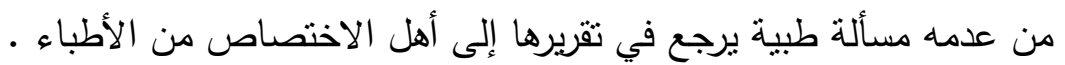

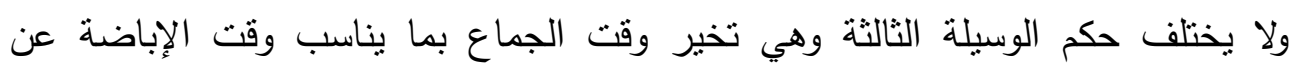

$$
\text { سابقتيها من حيث الجواز الثرعي . }
$$

ويتضح مما تقدم أن الوسائل الطبيعية لاختيار نوع الجنين هي وسائل جائزة عند الفقهاء المعاصرين (r) (باصن وهذا القول بالجواز هو ما قرره المجمع الفقه الإسلامي التابع لرابطة العالم الإسلامي في دورة مؤتمره التاسعة عشر المنعقدة بمكة المكرمة في الفترة من ب - Y ش شوال سنة

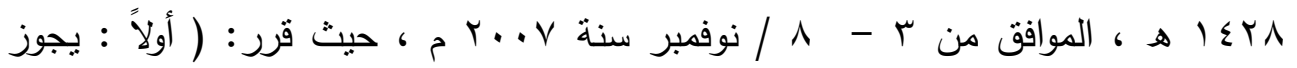
اختيار نوع الجنين بالطرق الطبيعية ، كالنظام الغذائي ، والغسول الكيميائي ، وتوقيت

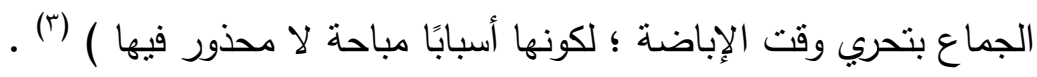
أدلة جواز اختيار نوع الجنين بالوسائل الطبيعية : ومما يدل على جواز اتباع هذه الوسائل في اختيار نوع الجنين ما يأتي :

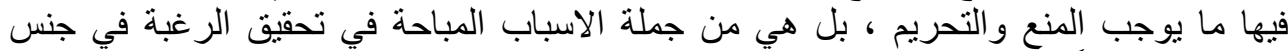

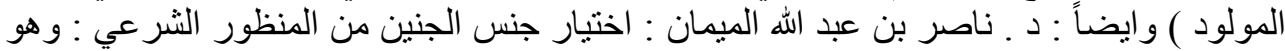

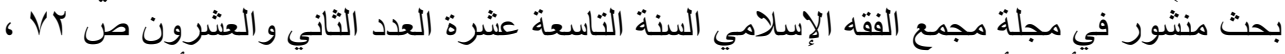

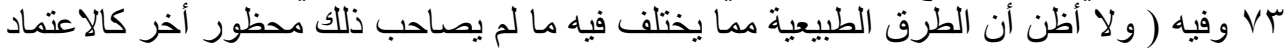

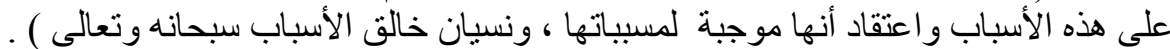

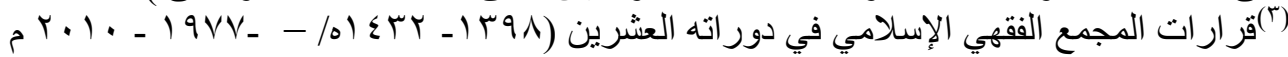

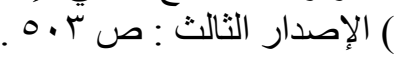




\section{اختيار نوع الجنين ( الاصطفاء الجنسي )}

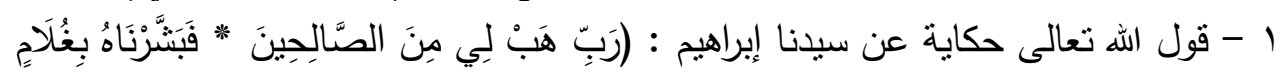

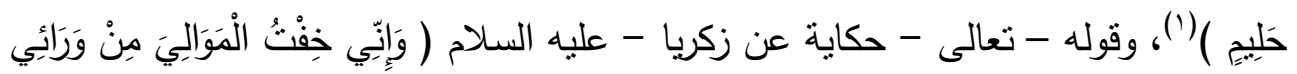

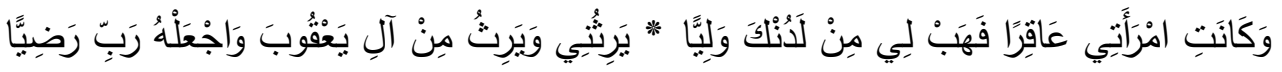

\section{وجه الاستدلال من هذه الآيات :}

إن كلأ من نبي الله إبراهيم ، و نبي الله زكريا - عليهما السلام - سأل الله - تعالى - أن الن النال يرزقه ولداً ذكراً فأجاب الله دعاءهما ، فدل ذلك على أنى أن الدعاء بنوع معين جائز شرعاً ،ودعاء الله سبب من أسباب تحصيل الولد(")، فتقاس عليه سائر الطرق والوسائل الطبيعية

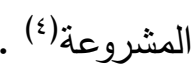

r - ما ورد في الصحيحين (0)من مشروعية العزل عن الزوجة ، وهو تعدد قذف السائل المنوي أثناء الجماع خارج الرحم ؛ لضبط ميعاد الإنجاب ، فيقاس على ذلك محاولة ضبط

نوع الجنين بالوسائل الطبيعية(؟). r - إن هذه الوسائل الطبيعية المستخدمة في اختيار نوع الجنين إنما هي أسباب مباحة في باني نفسها، إذ لا يوجد ما يمنع من نوقيت الجماع وضبطه حسب وقت نزول البييضة ، كما لو يوجد مانع شرعي من اتباع برنامج غذائي معين حتى ولو كان الغرض من ذلك انتقاء نوع

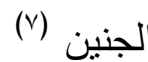

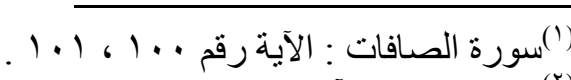

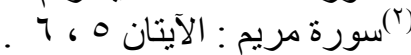

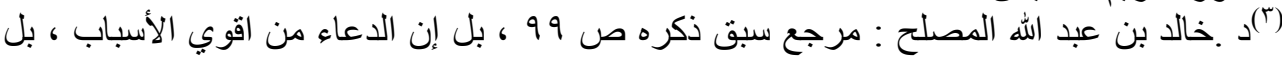

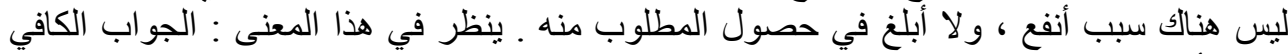

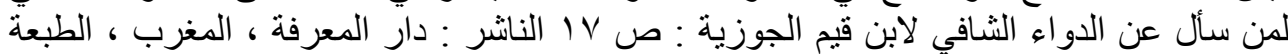

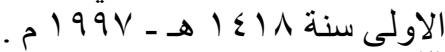

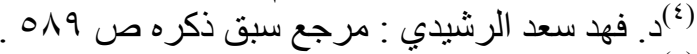

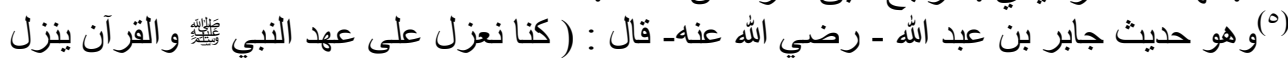

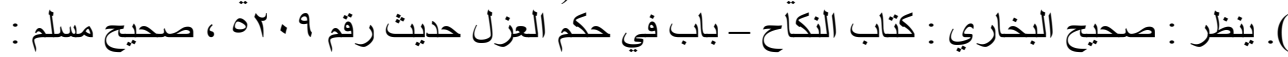

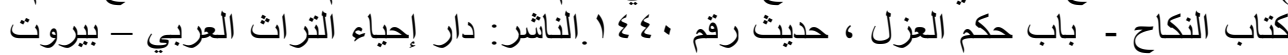

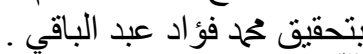

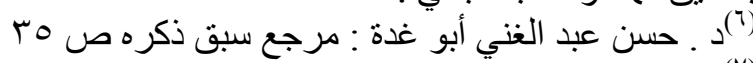

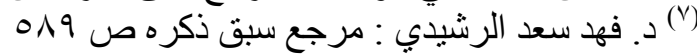




\section{د / خالا محمد حسين إبراهيم}

\section{شروط جواز اختيار نوع الجنين بالوسائل الطبيعية :}

وإذا كان الفقهاء المعاصرون قد قرروا جواز اختيار نوع الحنين بهذه الوسائل ، إلا أنهم بإن اشترطوا لذلك شروطاً أهمها ما يأتي : 1 - ألا يؤدي استخدام هذه الوسائل إلى الاعتماد على هذه الأسباب، واعتقاد أنها موجبة

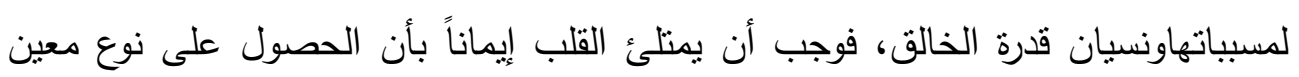
إنما هو بقدرة الله جل وعلا وتدبيره('). r - ألا يتزتب علي استعمال هذه الوسائل ضرر يحيق بالمرأة أو الرجل ، فإن ترتب على وعلى

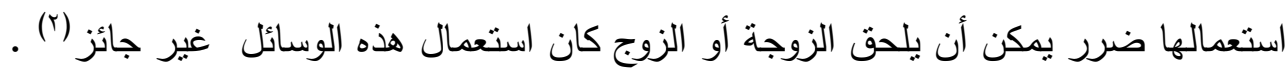
r - ألا يكون ذلك سياسة عامة على مستوى الأمة ، أو الثعوب ؛ خشية الإخلال بالتوازن

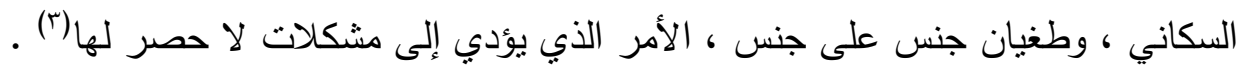

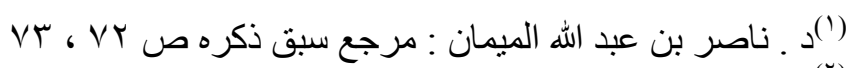

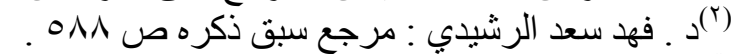
(r)

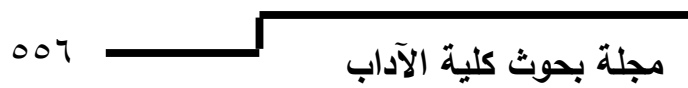


اختيار نوع الجنين ( الاصطفاء الجنسي )

المبحث الثاني

الوسائل المعملية لاختيار نوع الجنين وحكمها الشرعي

ويشتمل على مطلبين :

المطلب الأول - الوسائل المعملية لاختيار نوع الجنين .

المطلب الثاني - الحكم الثرعيلاختيار نوع الجنين بالوسائل المعملية ـ لوسية لاعنيل

المطلب الأول

الوسائل المعملية لاختيار نوع الجنين

علاوة على ما سبق ذكره من الوسائل الطبيعيةلاختيار نوع الجنين ، فإن هناك وسائل معملية ، أو مختبرية يمكن عن طريقها تحقيق هذالهدف قبل الحمل ، ولعل أهم هذه

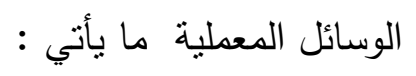

الطريقة الأولى : التلقيح الاصطناعي الداخلي : لاتئي

وذللك بفصل الحيوانات المنوية الذكرية الحاملة للكروموزوم ( y ) عن الحيوانات الحئ المنوية الذكرية الحاملة للكروموزوم ( x ) ثم تلقيح البييضة بالنوع المرغوب فيه د داخلياً حال انطلاقها من المبيض إلى الرحم ، فإذا كان النوع المرغوب فيه ذكراً لقحت البييضة بالحيوان

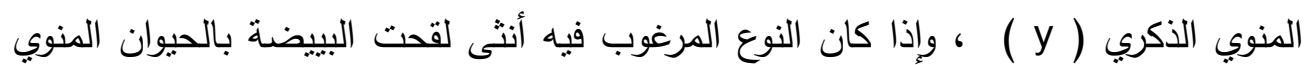

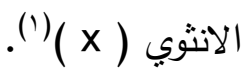

ذلك أن العلماء في الآونة الاخيرة تمكنوا من معرفة خصائص كل من الحيوانات المنوية

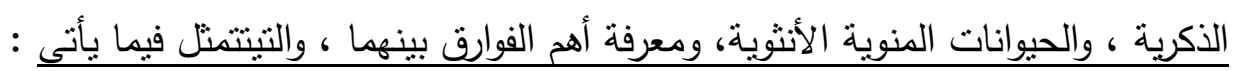
( أ ) - إنّ الحيوان المنوي الذكري أصغر حجماً ، وأخف وزنًا من الحيوان الأنثوي. ( ب ) - الحيوان المنوي الذكري أكثر سرعة ، وحيوية من الحيوان الأنثوي ،إذ يسنطيع

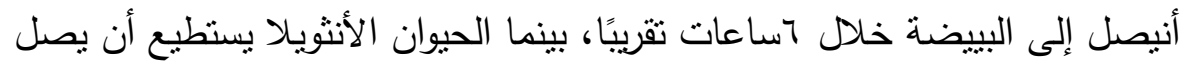
إلى البييضة إلا بعد r اساعة أو أكثر ل

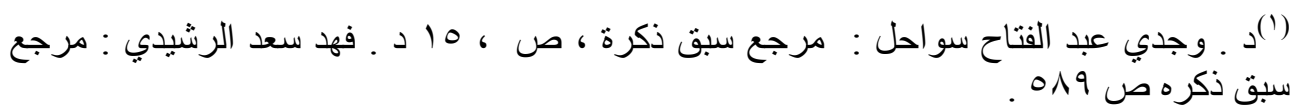
مجلة بحوث كلية الآداب OOV 
د / خالا محمه حسين إبراهيم

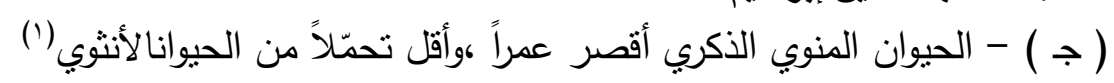
( د ) - الحيوان المنوي الذكري يميل إلى الوسط القاعدي، بينما يميل الأنثوي إلى (الوسط - الحامضي ) ( و ) - الحيوان المنوي الذكري يحمل شحنة موجبة، بينما الحيوان المنوي الأنثوي يحمل(

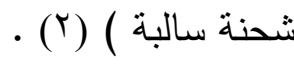
طرق فصل الحيوانات المنوية الأكرية عن الحيوانات المنوية الأنثوية : ويتم فصل الحيوانات المنوية الذكرية عن الحيوانات المنوية الأنثوية بعدة طرق ، أهمها ما يأتي : ( أ ) - استخدام محاليل حمضية ، أو قلوية :

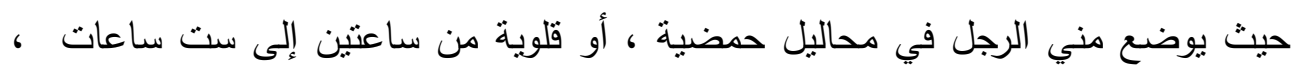

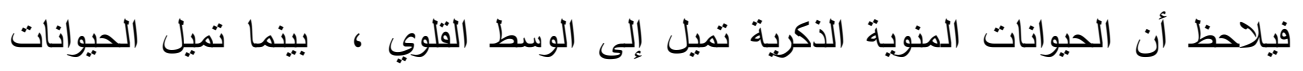
المنوية الأنثوية إلى الوسط الحمضي ، وبذلك يمكن فصل الحيوانات المنوية الذكرية عن

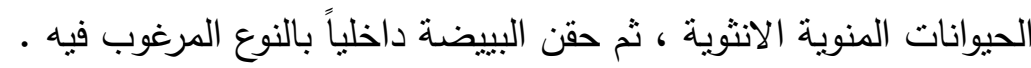
كذلك - أيضاً - إذاأضيف هرمون ( الإستراديول) إلى المني فإن ذلك يعمل على زيادة حركة الحيوانات المنوية الذكرية زيادة كبيرة بالمقارنة بحركة الحيوانات المنوية الانثوية(r). ( ب ) -طريقة الترتيب والفصل من المركز : توجد أسالب كثثرة للفصل في هذه الحالة كوضع محلول زلالي يجعل حركة الحيوانات المنوية

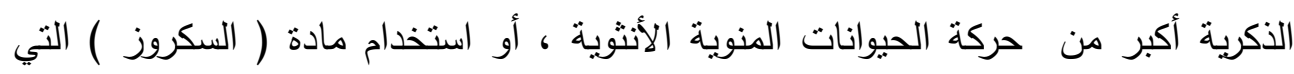

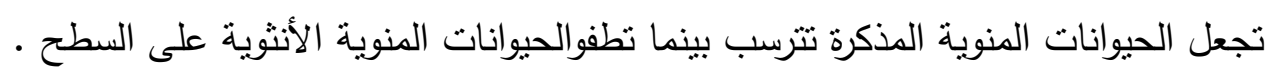

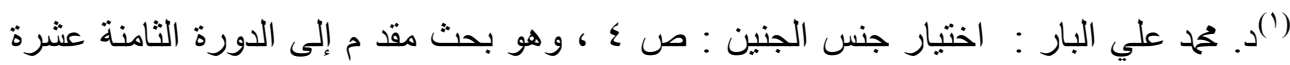

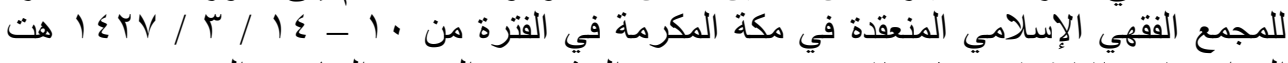

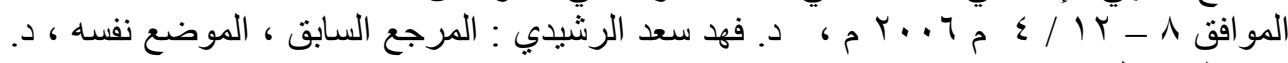

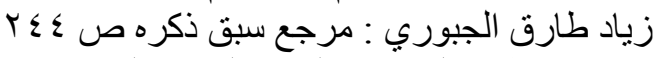

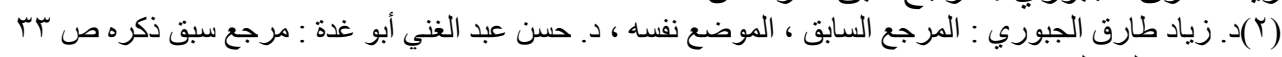

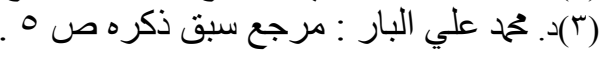

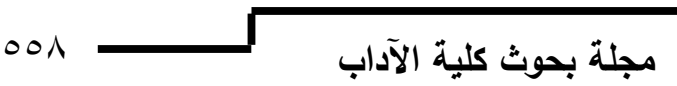




\section{اختيار نوع الجنين ( الاصطفاء الجنسي )}

9. وبواسطةالطرق سالفة الذكر استطاع الباحثون أن يحصلوا على سائل منوي يحتوي علي الأني

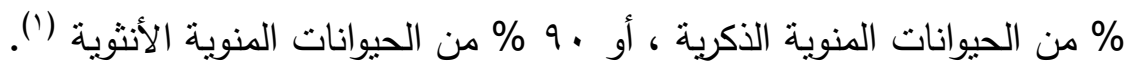
الطريقة الثانية : التلقيح الاصطناعي الخارجي : وهو عبارة عن عدة عمليات طبية مختلفة يتم بموجبها أخذ بييضات من مبيض المرأة ،وتلقيحها بمني الرجل في وعاء خارج الجسم ، وبعد التأكد من تمام عملية الإخصاب ينقل عدد من هذه البييضات المخصبة ( اللقائح ) إلى رحم المرأة ، حيث نترك لينمو الجنين نمواً

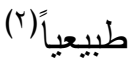
ويتم التلقيح الاصطناعي الخارجي بإحدى وسيلتين : إحداهما : أطفال الانابيب ( IVF ) : وفي هذه الحالة يتم تتشيط المبيضين لاى المرأة ، ومتابعة نشاط البييضات ، ثميقوم الطبيب بالتقاط عدد من هذه البييضات ، ووضعها في سائل داخل أطباق بلاستيكية معقمة ذات

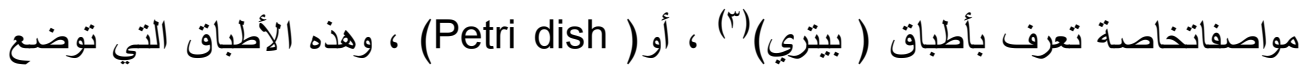

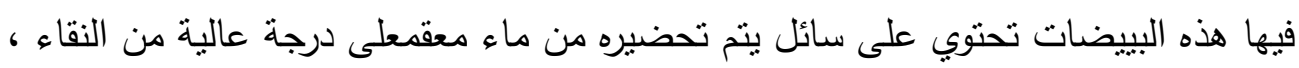

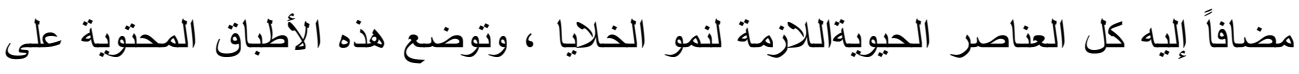
البييضات فيحضانة خاصة ذات درجة حرارة مماثلة لحرارة جسم الإنسان ، وفى هذه الأثتاءتحضر عينة من السائل المنوي للزوج ، وتوضع كل بيضة في طبق ، ويوضع حولها عدد من الحيوانات المنوية ، لتوفير الظروف الملائمة ، والسماح لأحد هذه الحيوانات المنوية لهنية

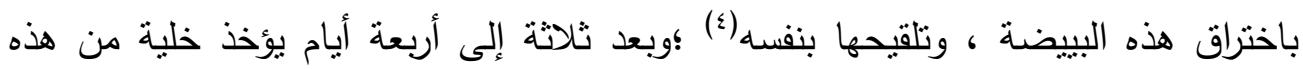

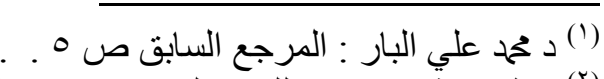

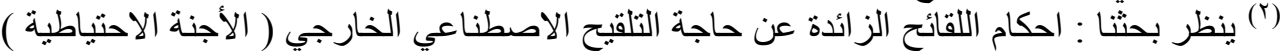

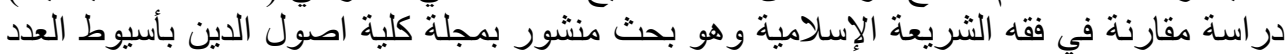

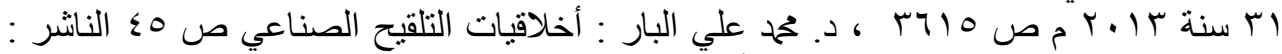

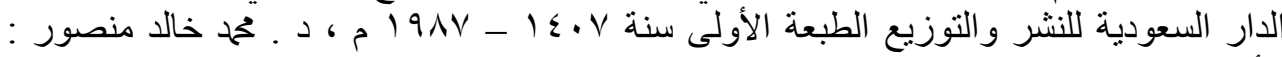

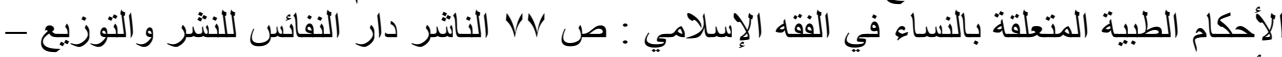

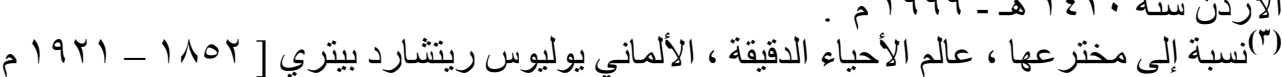

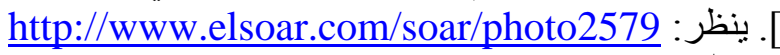

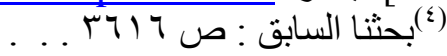




\section{د ا دالد محمد حسين إبرا هيم}

اللقيحة، ويتم فحصها للتعرف على ما إذا كنت ذكراً ، أم انثى ، فإذا وجد الطبيب النوع المرغوب فيه أعاد زرعهذه البييضة الملقحة في جدار الرحم بعد خمسة أيام - في الغالب لينمو الحمل بشكل طبيعي (') . ثانيتهما : الحقن المجهري السيتويلازمى (ICSI): وهي عملية أطفال الأنابيب نفسها، إلا أنهبدلاً من وضع الحيوانات المنوية مع البييضة في اليضي طبق ليلقحها الحيوان المنوية بنفسه - كما هو الحالفي عملية أطفال الأنابيب- فإنه يتم حقن كل بييضة بحيوان منوي واحد تحت الميكروسكوب المجهري ، ثم بعد عملية التلقيح يتم فحص البييضة الملقحة، للتعرف على نوع الجنين القادم عن طريق مادة بروتين النواة (؟)، تم بعد ذلك يعاد زرع النوع المرغوب في جدار الرحم لينمو نمواً طبيعياً. المطلب الثاني

\section{الحكم الشرعي لاختيار نوع الجنين بالوسائل المعملية}

اختلف الفقهاء المعاصرون في حكم اختيار نوع الجنين بالوسائل المعملية على رأيين : الرأي الأول :

ويرى أصحابه أن اختيار نوع الجنين بالوسائل المعملية جائز شرعاً ، وممن قال بهذا الرأي :د ـ نصر فريد واصل ، والثيخ وهبـة الزحيلي ، ود . بدر المتولي عبد الباسط ، والثيخ

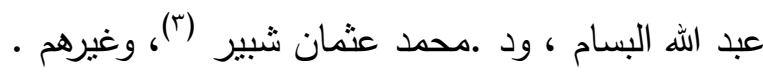

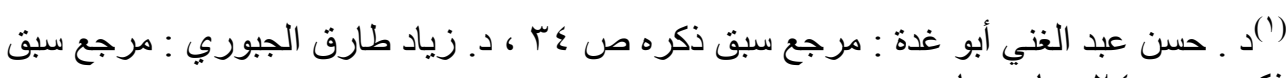
ذكره ص آد (T)

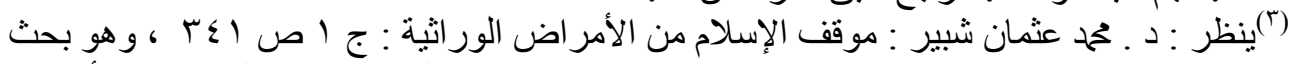

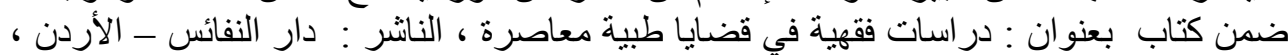

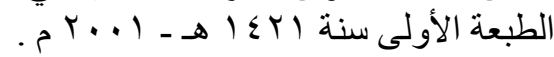

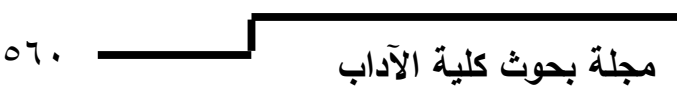


اختيار نوع الجنين ( الاصطفاء الجنسي )

الرأي الثاني :

و يرى أصحابه عدم جواز اختيار نوع الجنين مطلقاً ، وممن قال بهذا الرأي : الثيخ عبد

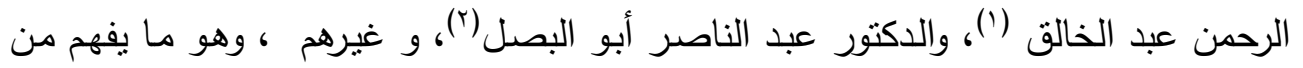

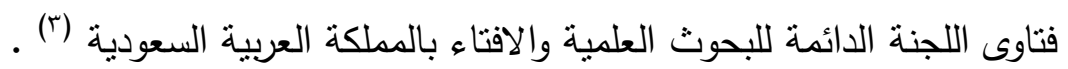
الرأي الثالث :

ويرى أصحابه جواز اختبار نوع الجنين إذا كان للضرورة العلاجية كالأمراض الوراثية ، وعدم جوازها في غير ذلك ، وقد قال بهذا الرأي وهو قول جمهور الباحثين المعاصرين (؛)،

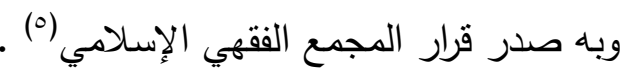

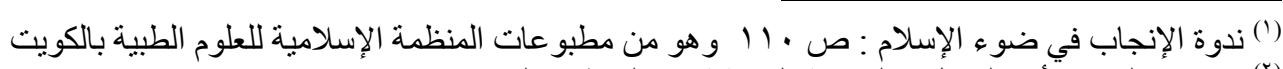

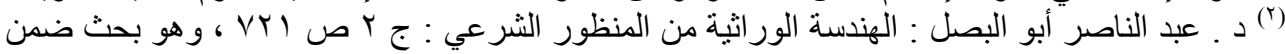

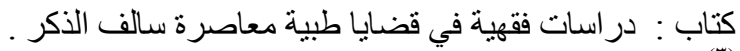

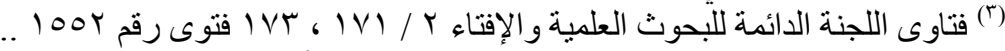

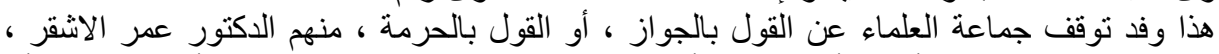

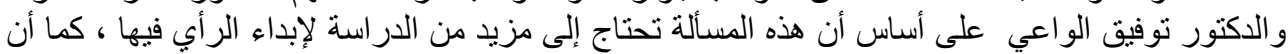

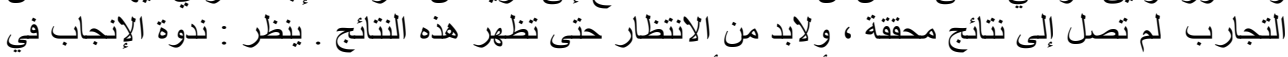

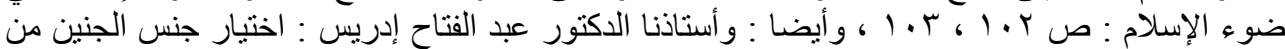

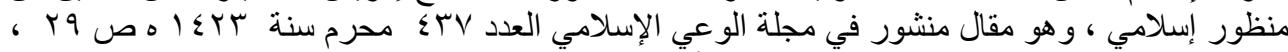

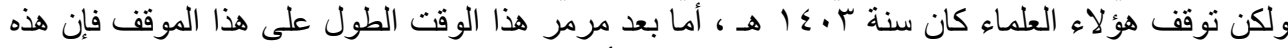

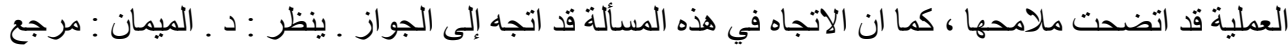

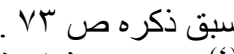

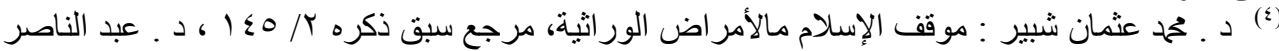

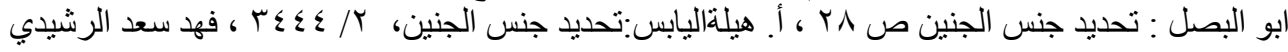

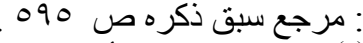

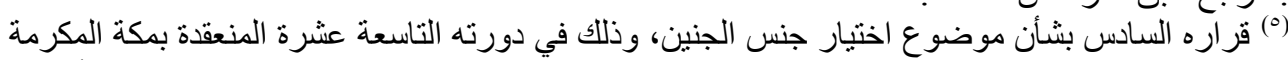

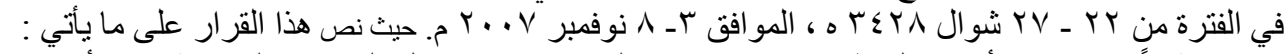

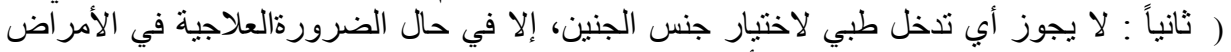

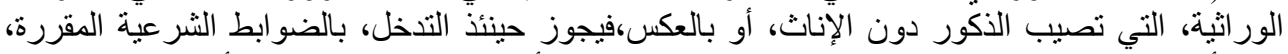

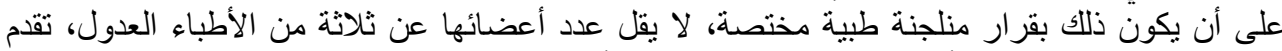

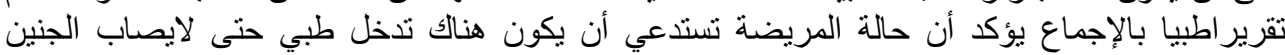

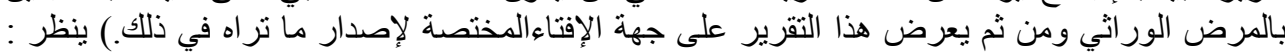

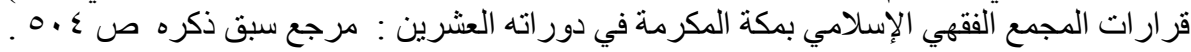




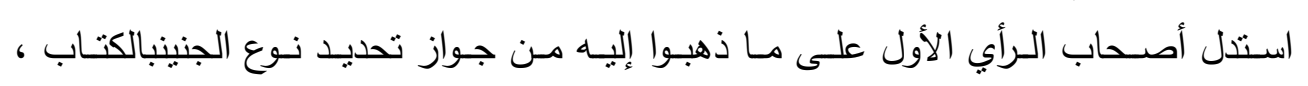

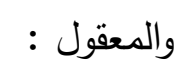

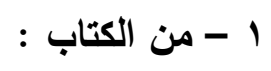

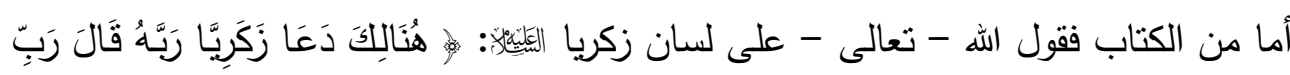

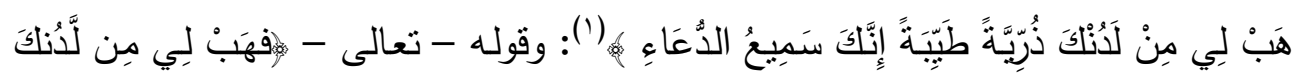

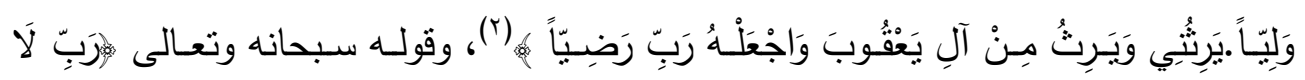

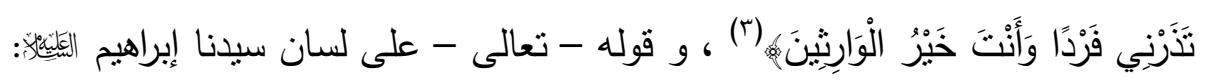

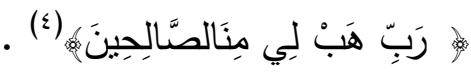

$$
\begin{aligned}
& \text { وجه الاستدلال من هذه الآيات : }
\end{aligned}
$$

إن هذه الآيات الكريمات ناطقة بأن سيدنا زكريا - عليه السلام - ، قد دَعَا الله سبحانه

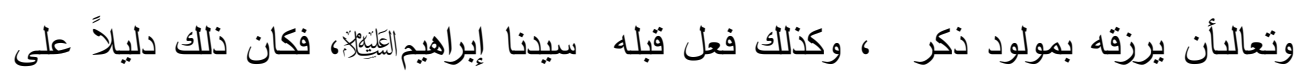

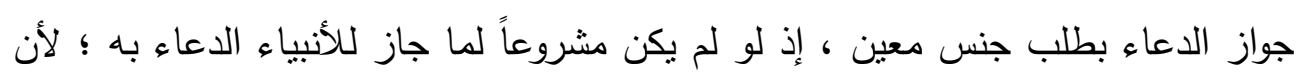

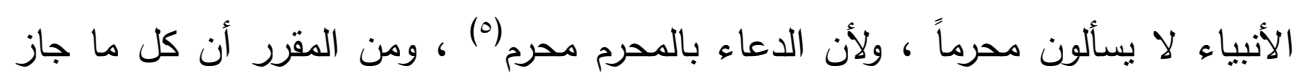

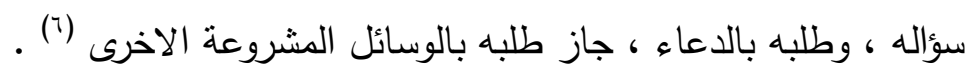

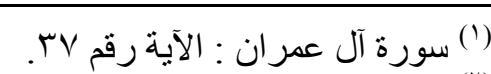

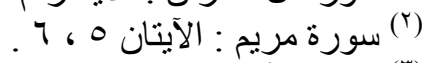

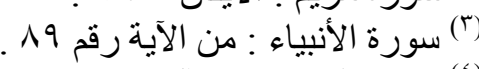

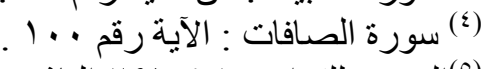

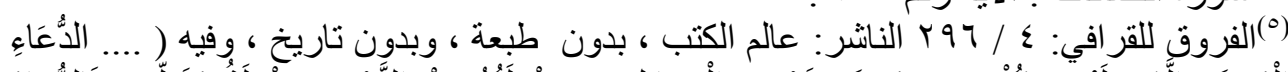

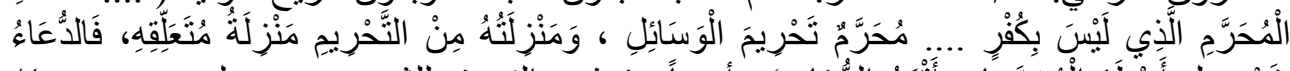

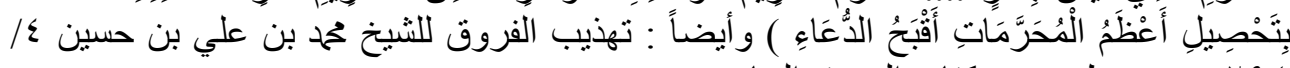

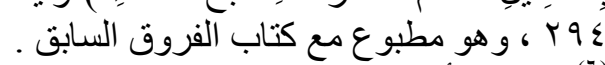

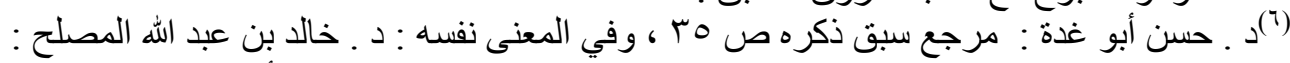

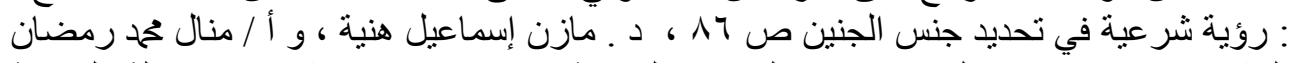

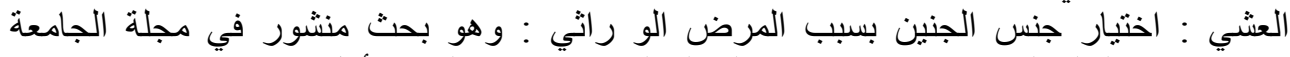

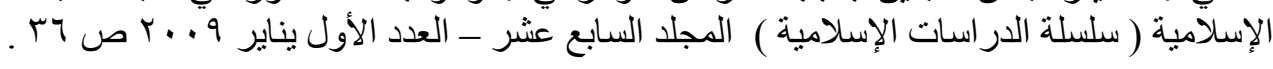

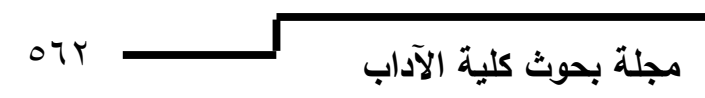




\section{اختيار نوع الجنين ( الاصطفاء الجنسي )}

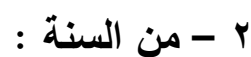

وأما من السنة فما روي عن جابر بن عبد الله رضي الله عنه قال : ( كنا نعزل على عهد النبي صلى الله عليه وسلم والقرآن ينزل ) (') وفي رواية : ( فبلغ ذلك النبي صلى الله عليه

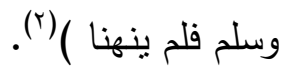

\section{وجه الاستدلال من الحديث :}

أن العزل سبب بسلكه الإنسان لمنع الحمل ، أو ضبطميعاد حصوله والحديث نص في جوازه

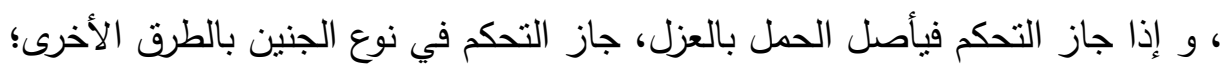
قياساً على العزل (r). مناقشة هذا الاستدلال :

ويناقش هذا الاستدلال بأن المقيس عليه الذي هو العزل قد اختلف فيه أهل العلم بين مانع، ومبيح (ء) ومن ثم يكون هذا القياس قياساً على مختلف فيه فلا يكون صحيحاً؛

$$
\begin{aligned}
& \text { (1) }
\end{aligned}
$$

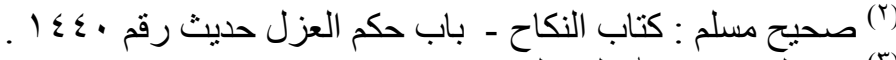

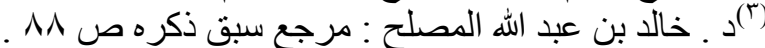

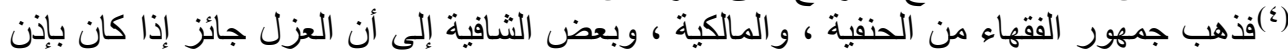

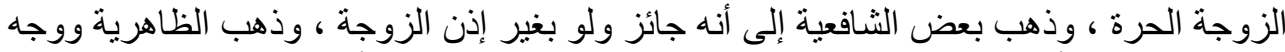

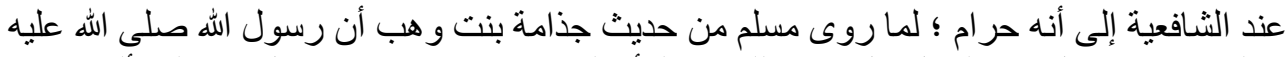

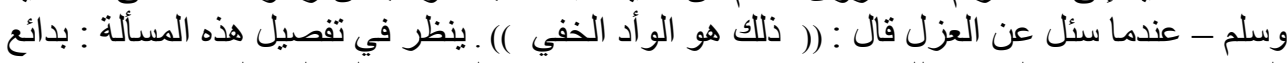

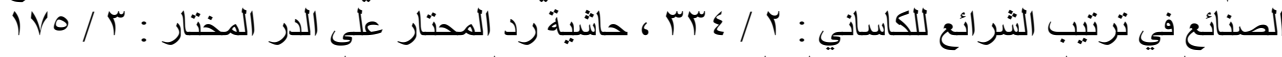

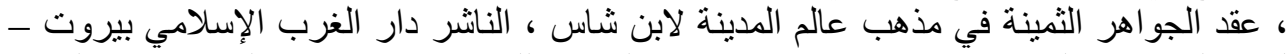

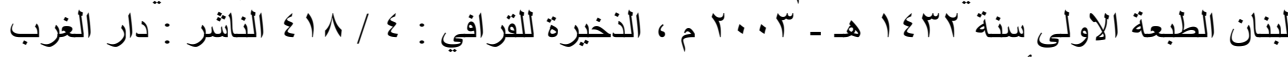

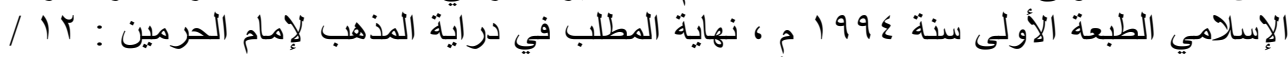

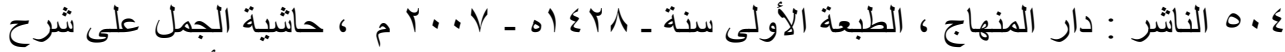

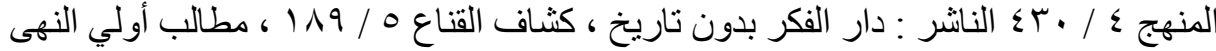


د / خالا تحمل حسين إبراهيم

لأنمن شروط صحة القياس الاتفاق على حكم الاصل حلى (').

دفع هذه المناقشة :

ويمكن دفع هذه المناقتنة بأن مجرد الاختلاف في حكم الأصل لا يمنع صحة القياس مطلقاً ،لأنه كما سبق الذكر يكفي - على الراجح - أن يكون حكم الاصل متفقاً عليه بين

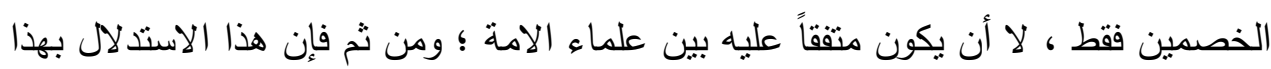
الحديث يكون ملزماً لكل من يقول بمشروعية العزل ، وتكون هذه المناقثة الواردة على هذا

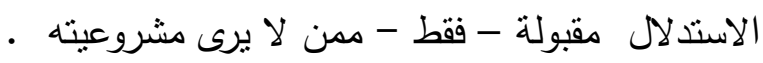

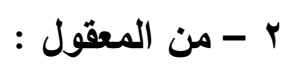

$$
\begin{aligned}
& \text { وأما من المعقول فما ما يأتي : }
\end{aligned}
$$

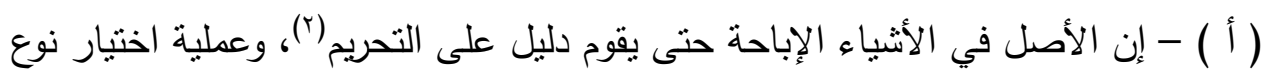

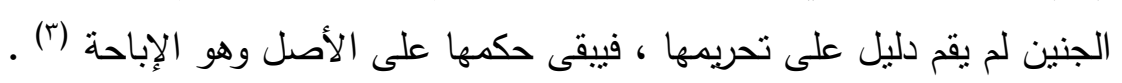

(1)

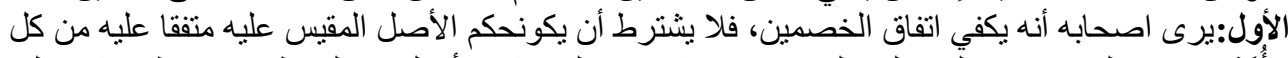

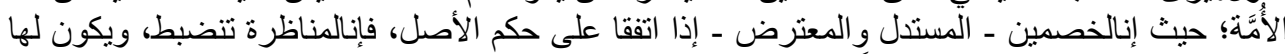

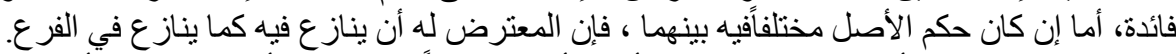

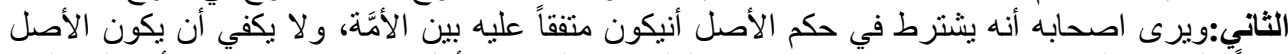

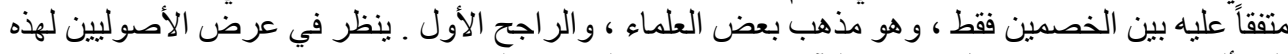

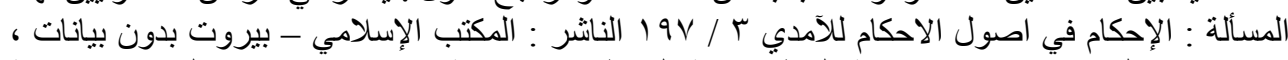

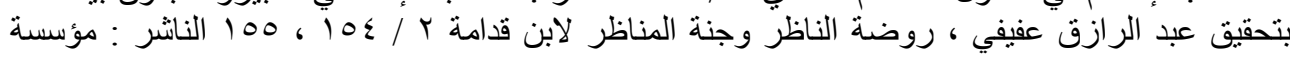

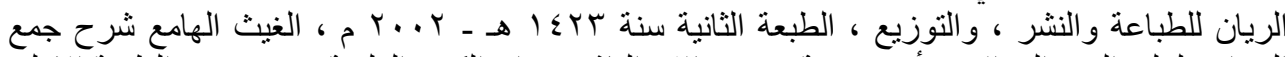

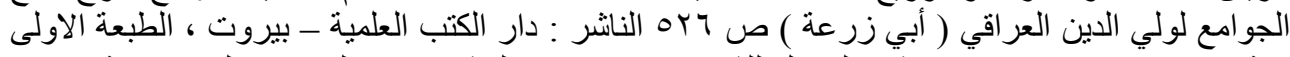

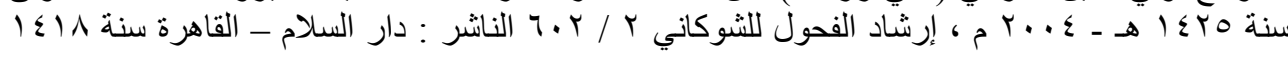

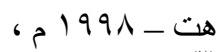

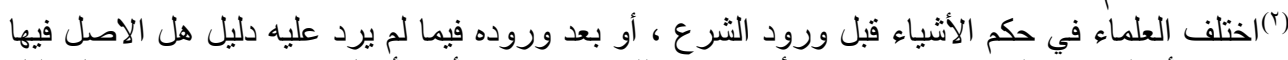

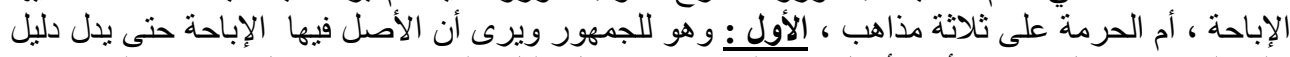

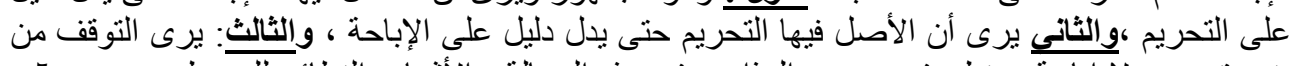

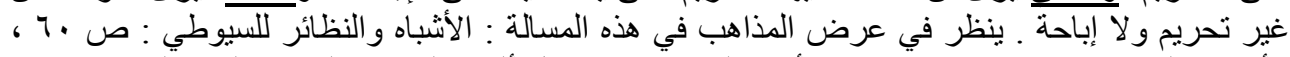

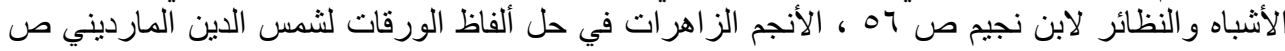

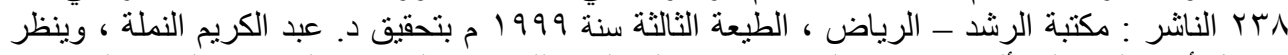

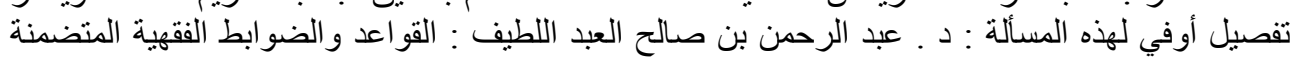

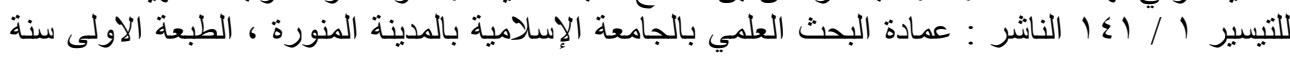
.

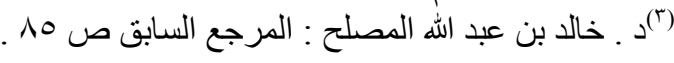




\section{اختيار نوع الجنين ( الاصطفاء الجنسي )}

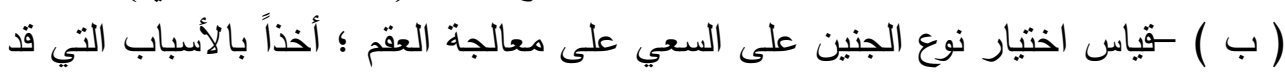

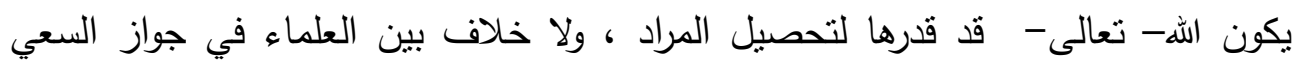

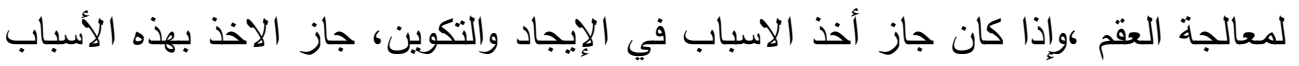

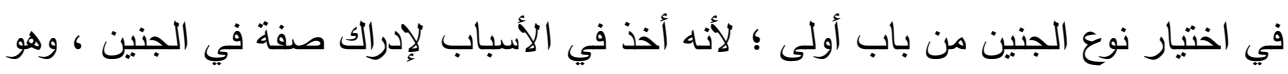

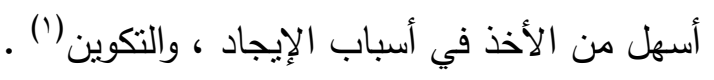

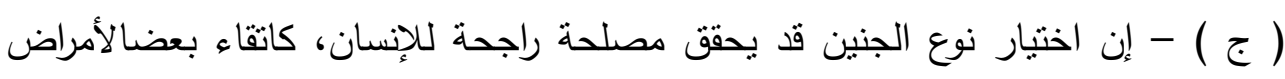

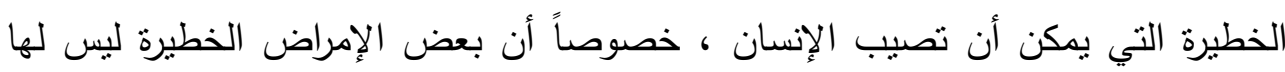

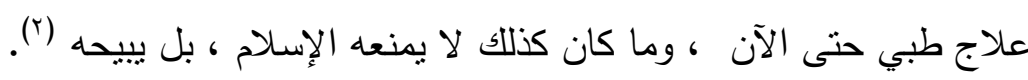

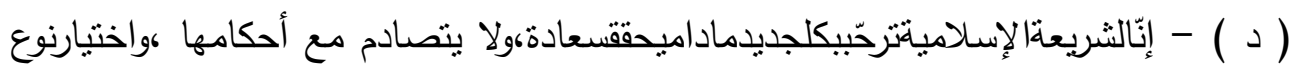

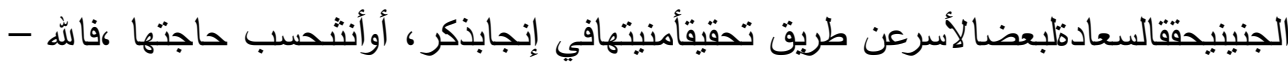

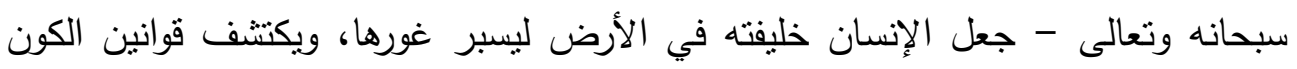

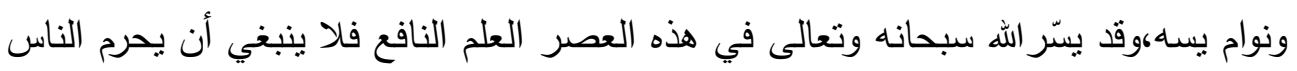

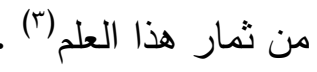

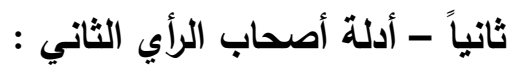

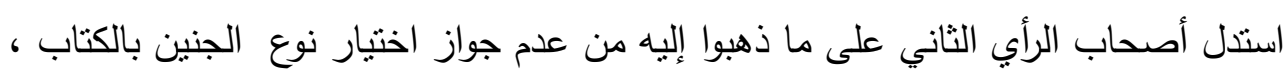
والمعقول :

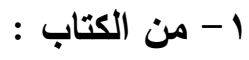

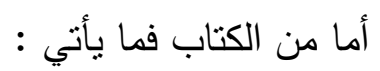

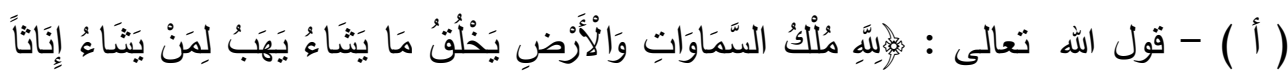

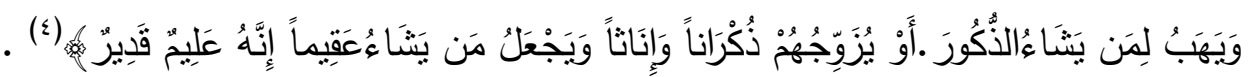

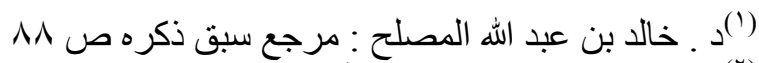

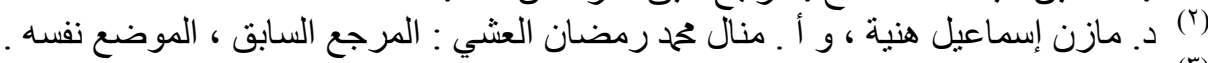

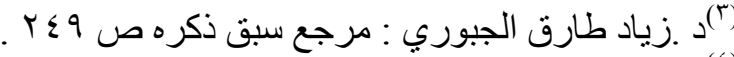

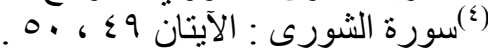




\section{د د الدالد محم حسين إبراهيم

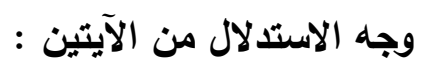

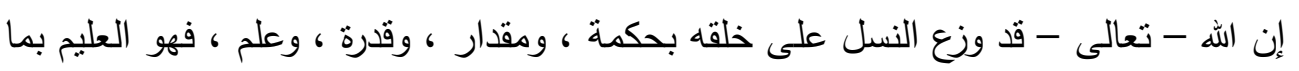

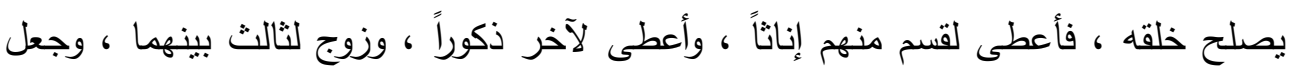

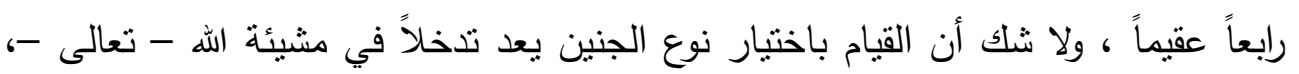

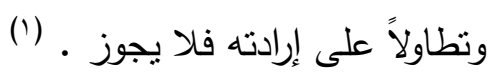

مناقثة هذا الاليل :

ويناقش هذا الدليل بأن القول بأن اختيار نوع الجنين من شانه أن يعد تدخلاً في مشيئة الله -

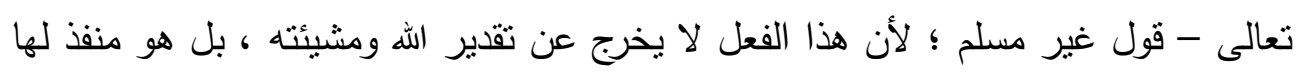

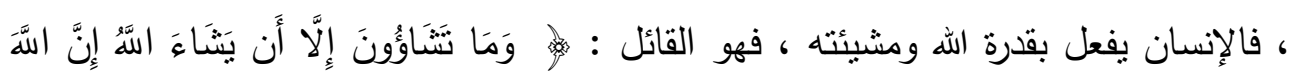

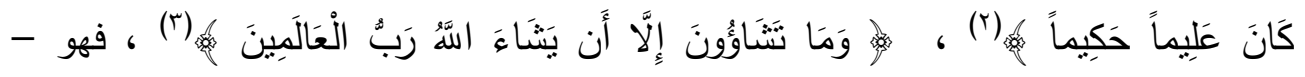

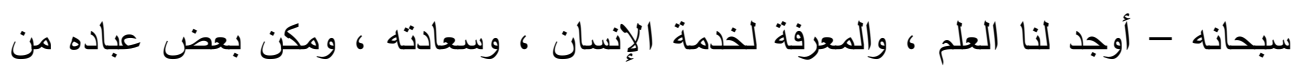

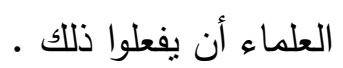

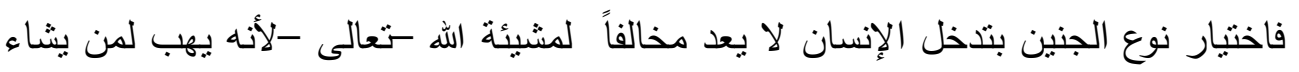
إناثاً بواسطة كذا ، ويهب لمن بشاء الذكور بواسطة كذا ، أو يزوجهم ذكراناً وإناثاً بواسطة لإنهاء

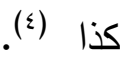

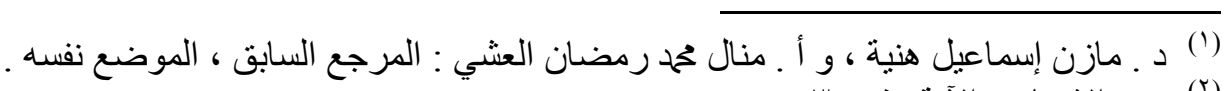

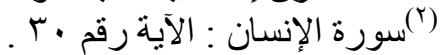

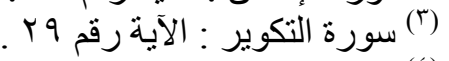

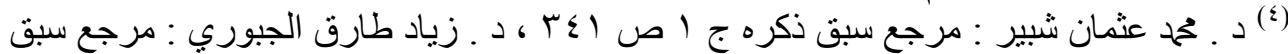

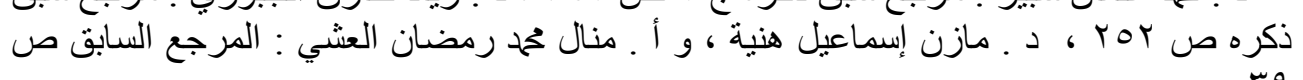




\section{اختيار نوع الجنين ( الاصطفاء الجنسي )}

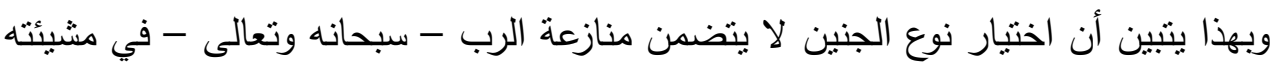

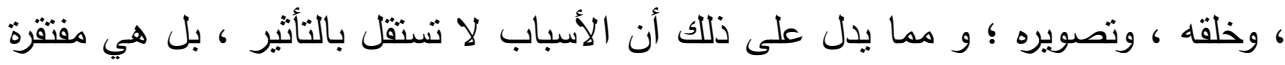

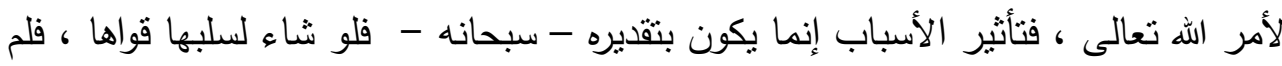

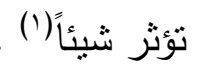

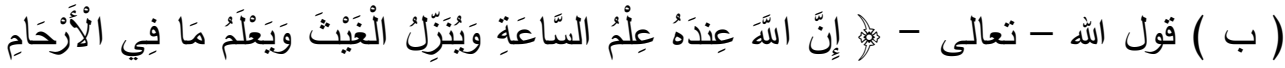

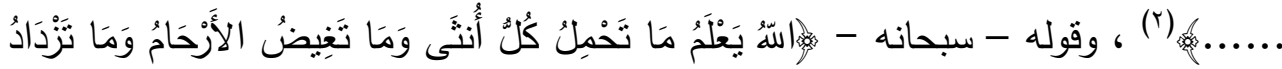

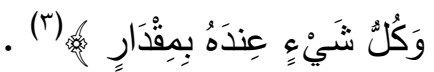

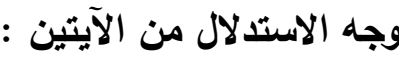

فقد بينت هاتان الآيتان الكريمتان أن علم ما في الأرحام بعد من الغيب الذي لا يعلمه إلا الله - تعالى - وادعاء البشر معرفة ذللك مخالف لما جاء في الآيتين ، ويدخل في ذلك الكان اختيار

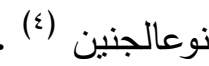

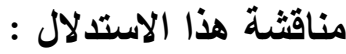

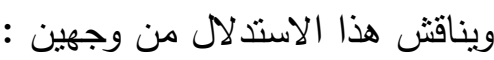

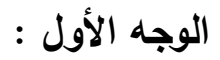
بأن المراد بعلم ما في الأرحام في الآيات الكريمات ، هو العلم التفصيلي بكل ما يتعلق بها

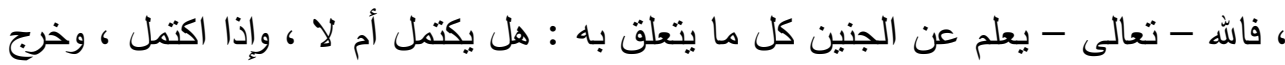

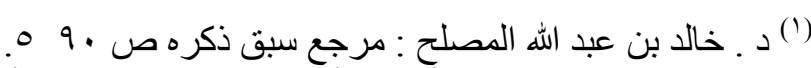

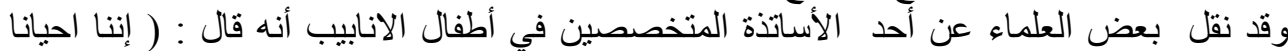

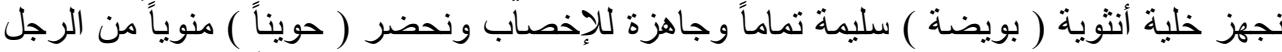

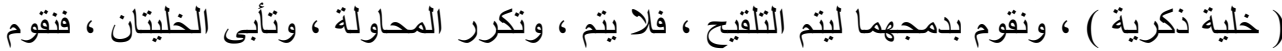

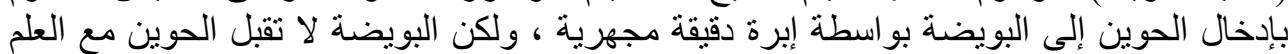

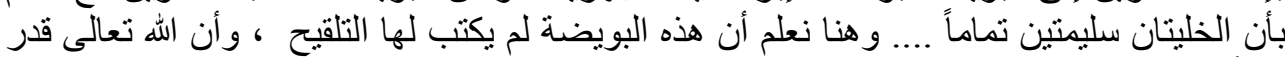

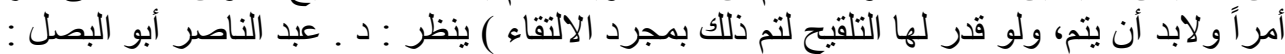

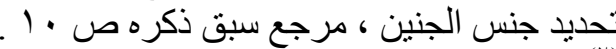

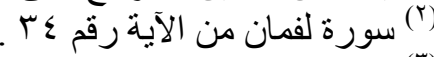

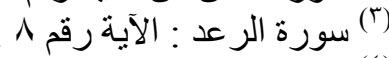

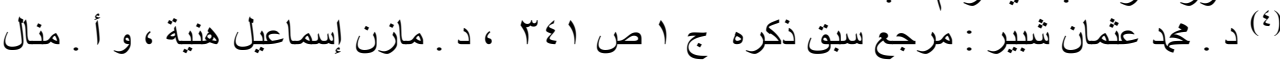

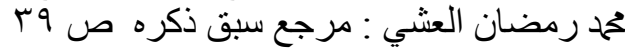




\section{د / خالا محمد حسين إبراهيم}

من بطن أمه حياً ، هل يكون صحيحاً ، أم سقيماً ، غنياً أم فقيراً ، شقياً أم سعيداً ؟ إلى إيم

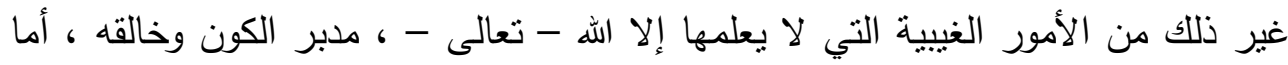

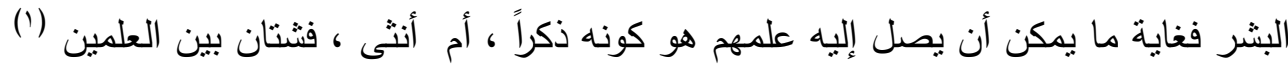

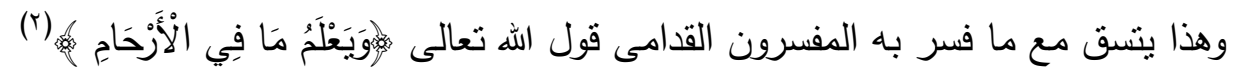

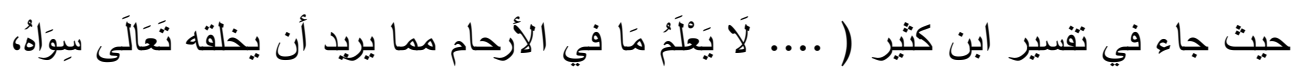

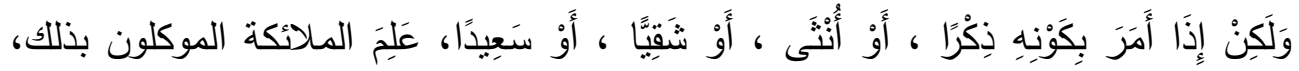

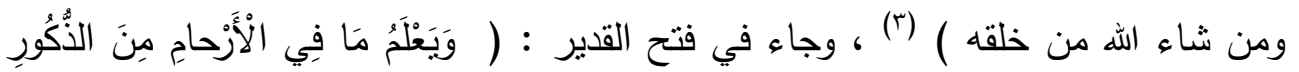

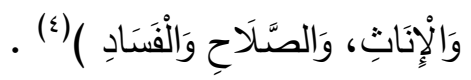
الوجه الثاني :

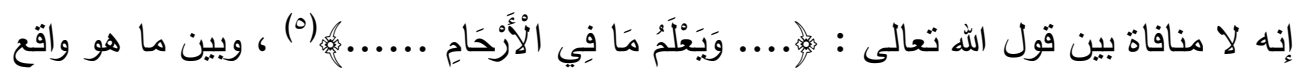

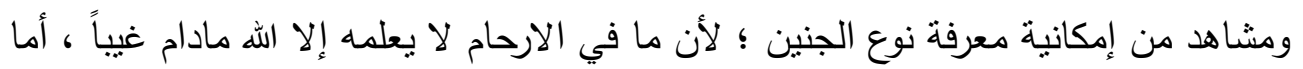

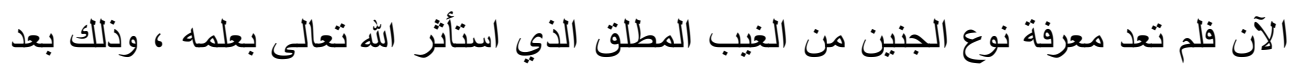
أن فتح الله تعالى على البشر أبواب العلم والمعرفة ، وأحاطهم ببعض من علمه ، وأمكنهم من معرفة نوع الجنين إما برؤيته في الرحم مباشرة ، أو عن طريق روئية اماراته وقرائنه

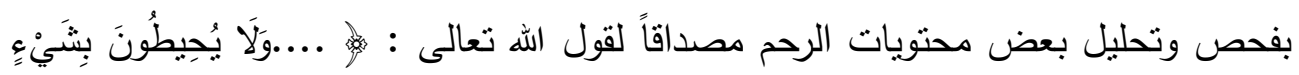

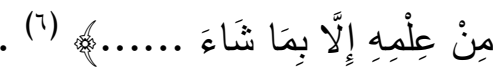

فمعرفة نوع الجنين من علم الغيب النسبي، أبي الذي لا يعلمه إلا الله تعالى قبل الفحص ،

أم عند الفحص فلا يعد من الغيب ، بل من المشاهد المعلوم بالنسبة لمن يطلع عليه (V) . ل

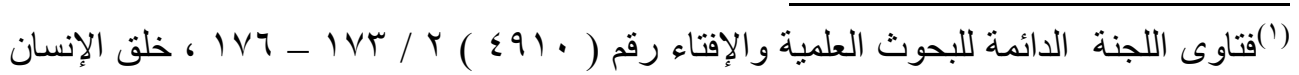

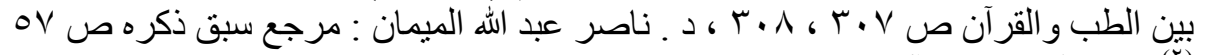
(r)

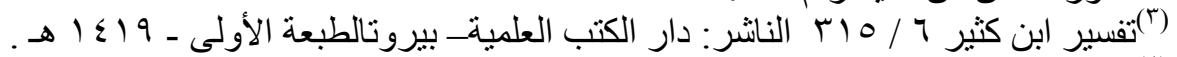

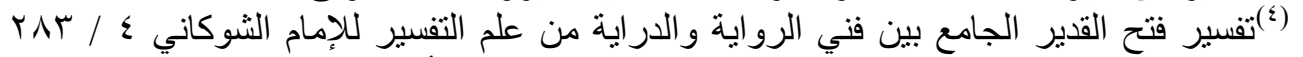

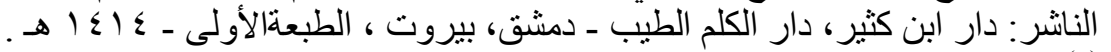

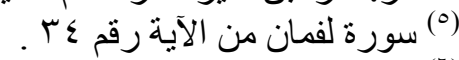

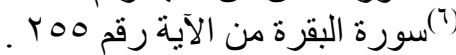

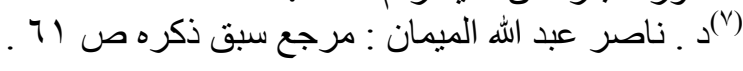

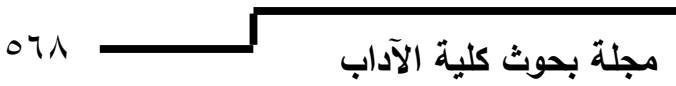




\section{اختيار نوع الجنين ( الاصطفاء الجنسي )}

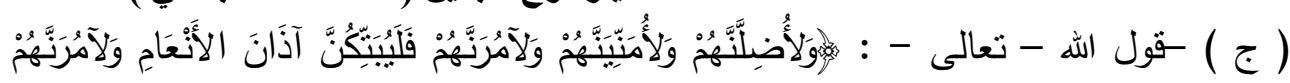

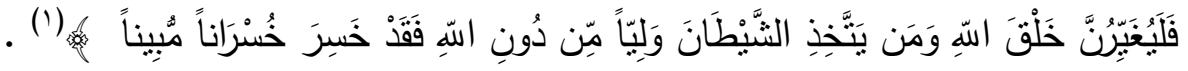

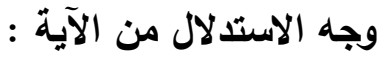

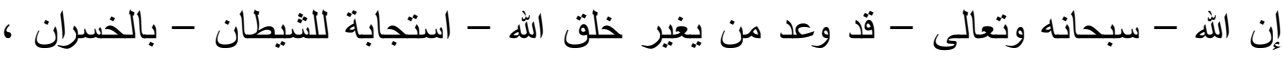

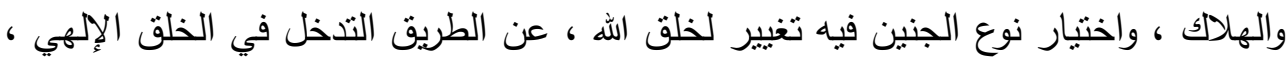

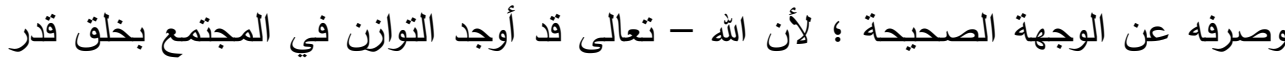

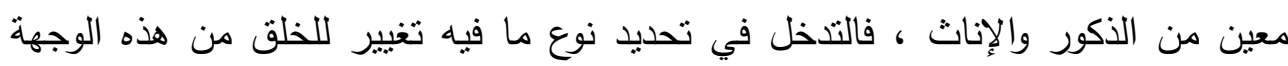
فيدخل في هذا الوعيد (؟). مناقثة هذا الاليل :

ويناقش هذا الدليل بان القول : إن اختيار نوع الجنين فيه تغيير لخلق الله إنما هو قول غير

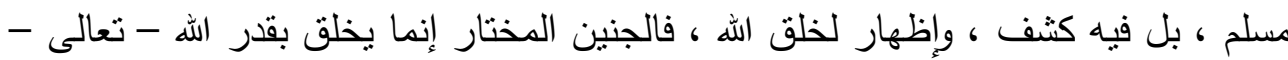
وعلمه ، فلو لم يقدر الله - تعالى - له أن يخلق على النحو الذي تمت عليه عملية الاختيار

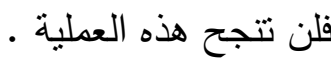

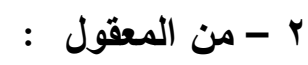

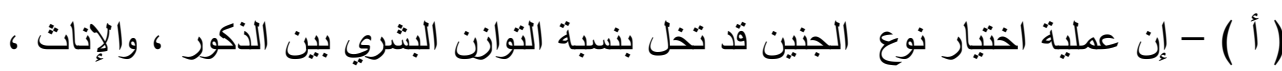

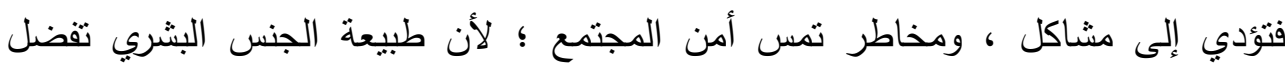

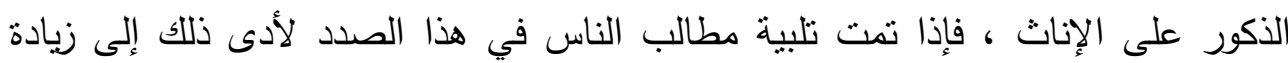

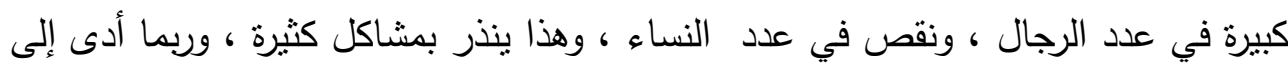

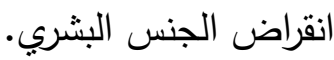

مناقشة هذا الاليل :

ويناقش هذا الدليل بأن اختيار نوع الجنين يجري في نطاق فردي ، وفي حدود ضيقة ، فلا

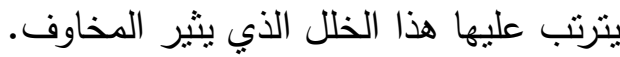
(1) (1) سورة النساء : الآية رقم 119

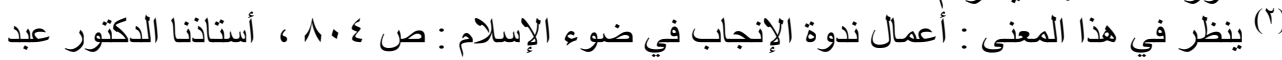

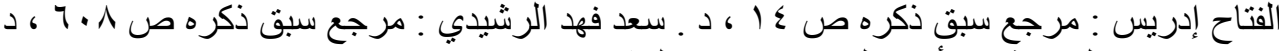

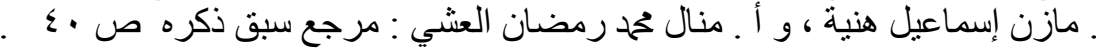


د / خالا محمد حسين إبراهيم

( ب ) - أن استخدام تلك الوسائل المخبرية سيكون وسيلة من وسائل الثرك بالربوبية، ذلك أن العامة فيحال نجاح العملية - وهي لن تخرج مطلقاً عن إرادة الله - سيتعلقون بهذا ونات الطبيب، ويعتقدون قدرته على اختيار نوع الجنين، وسد ذرائع الثرك ما زال مطلباً عريضاً للمطماء) (') مناقشة هذا الاليل : أن هذا لا يكون إلا عند من التبس عليه الفرق بين الأسباب المسببات والنتائجهوهذا لا أثز

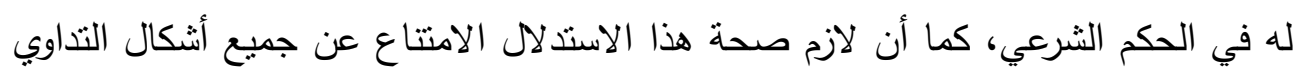
عند الأطباءلإمكان تحقق الثرك باله جل وعلا، وهذا باطل لم يقل به أحد(؟)

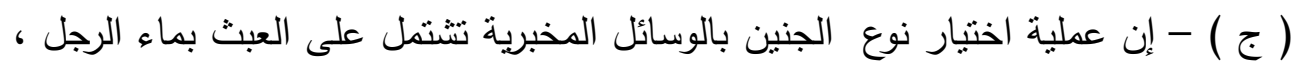

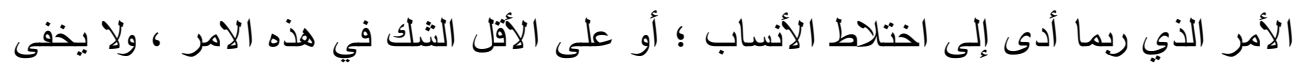

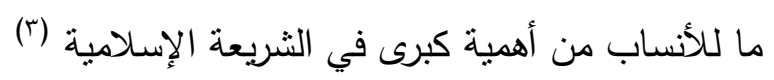
مناقشة هذا الاليل : ويناقش هذا الدليل بأن المجيزين يقيدون الجواز بشرط أن يؤمن اختلاط الأنساب ، وذلك باتخاذ كافة التدابير اللازمة ، بل والصارمة لعدم الوقوع في هذا المحذور (؛)، كما أن التقنية

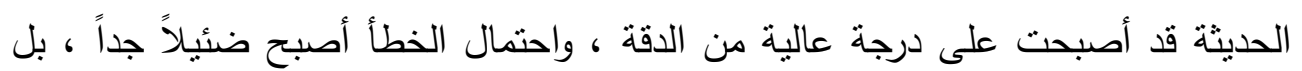

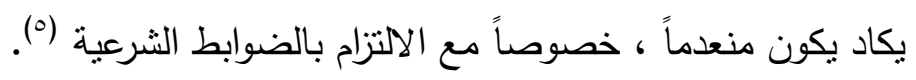
( د ) - إن القول بإباحة عملية اختيار نوع الجنين من شأنه أن يفتح باب جاهلية معاصرة تعدد إلى قتل الأنثى قبل ولادتها ؛ تخلصاً من تبعاتها ، وتربيتها ، والقيام على أمرها ، كمثل ما كان يحدث في عصر الجاهلية الأولى عندما كانوا يئدون البنات ، وقد ذمهم الله - تعالى الى الهي

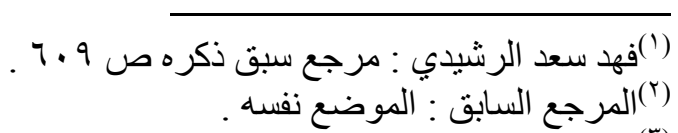

ا(ז) المن كلام الثيخ عبد الرحمن عبد الخالق ، ينظر : ابحاث ندوة الإنجاب في ضوء الإسلام ص

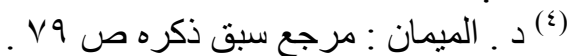

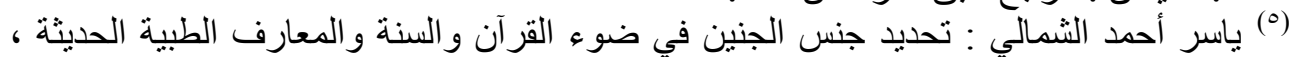

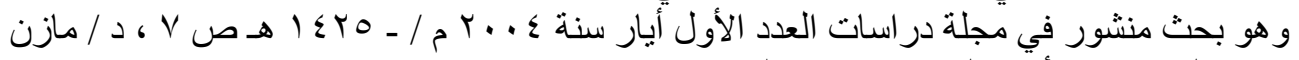

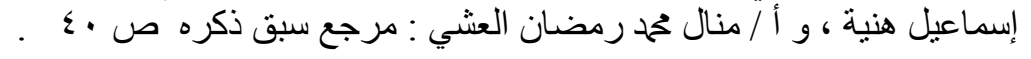




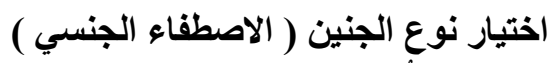

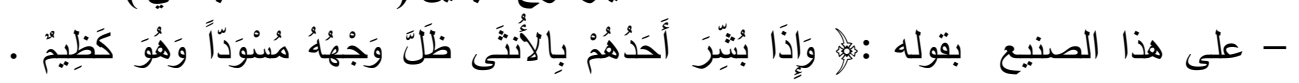

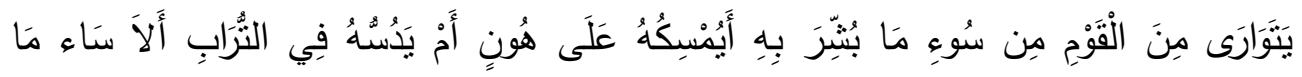

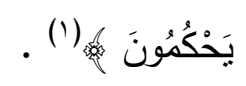
مناقشة هذا الاليل : ويناقش هذا الدليل بان قياس اختيار نوع الجنين على ما كان يقوم به أهل الجاهلية من وأد بناتهم أحياء ، إنما هو قياس مع الفارق ، ووجه الفرق :أن أهل الجاهلية كانوا يئدون بناتهم

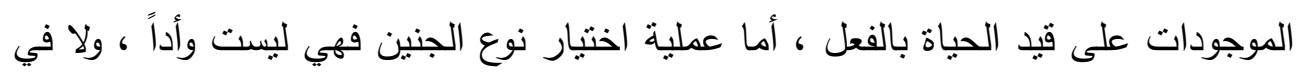

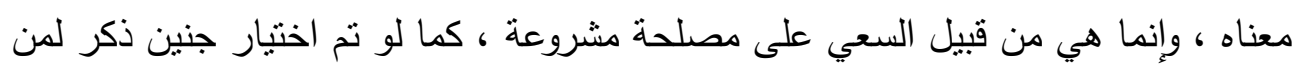

لم ينجب إلا البنات ، فإن ذلك جائز ؛ لأنه يكون عوناً لوالده ، أو والدته ، أو أخواته (؟). ( هـ ) - إن اختيار نوع الجنين بالطرق المخبرية يستلزم كثف المرأة عورتها المغلظة أمام

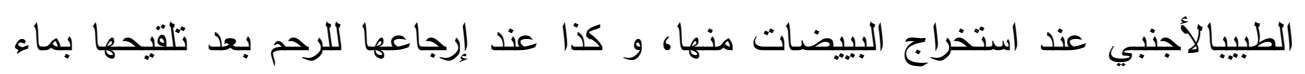
الزوج، وكثف العورة المغلظة لا يباح لمجرد رغبة الزوجين في إنجاب نوع معين (ّ). مناقشة هذا الاليل :

ويناقش هذا الدليل بأن كثف العورات في هذه الحالة إنما كان لا لمجرد رغبة الزوجين في

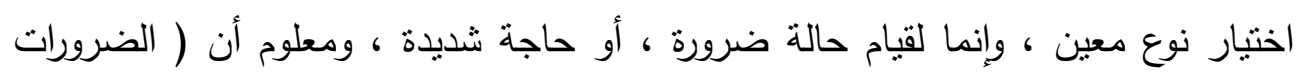

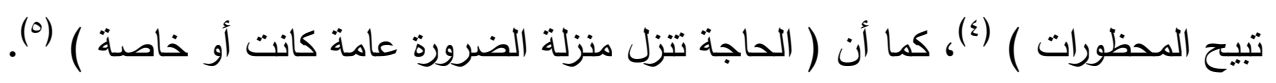

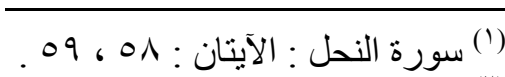

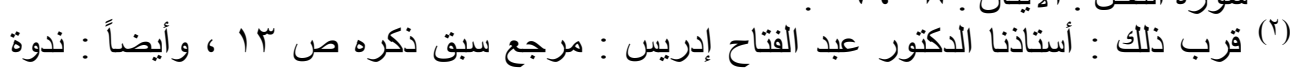

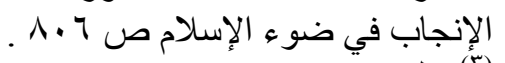

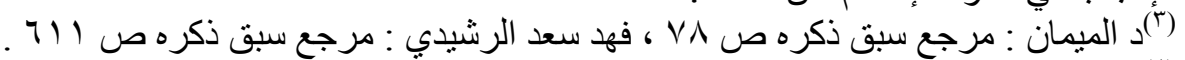

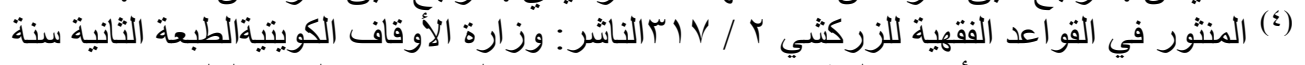

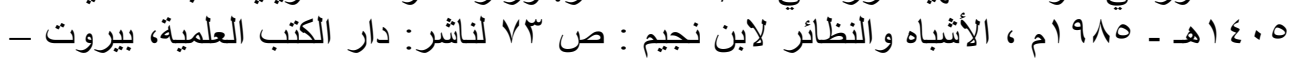

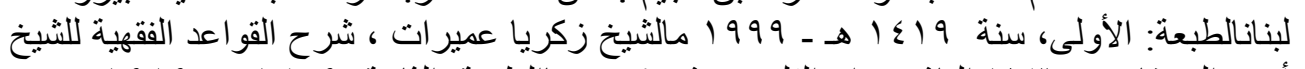

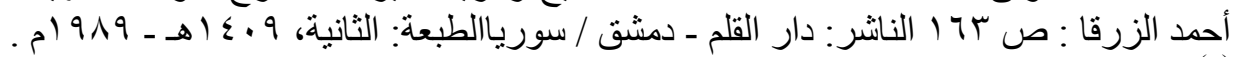

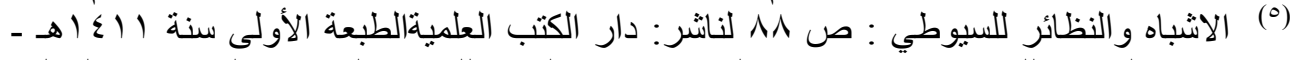

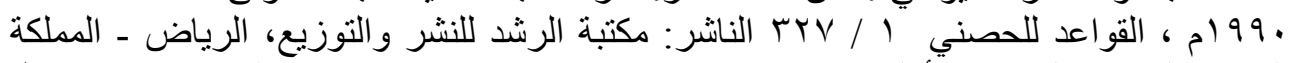

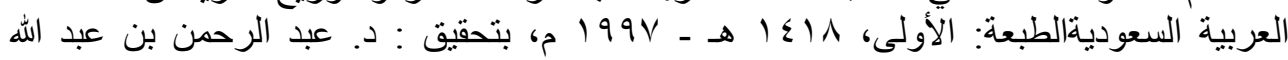

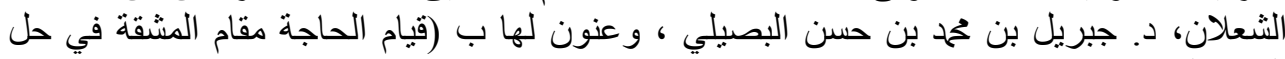

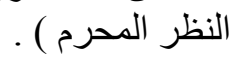


دالد / خالد محم حسين إبراهيم ثالثأ - أدلة أصحاب الرأي الثالث : الثين

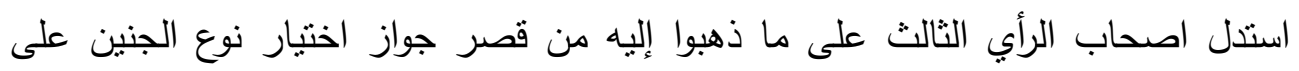

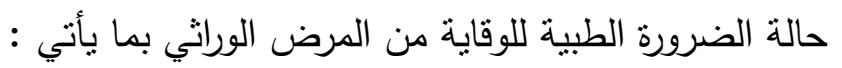

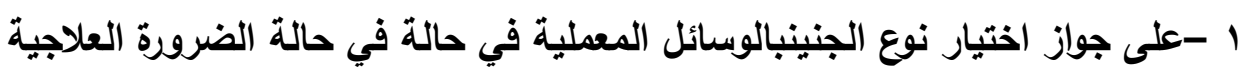

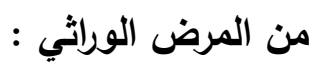

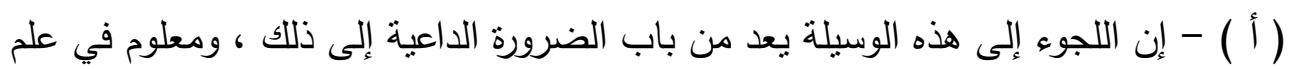

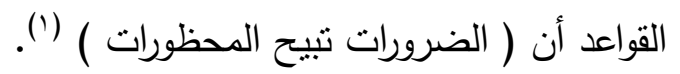

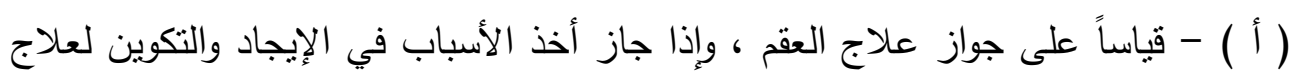

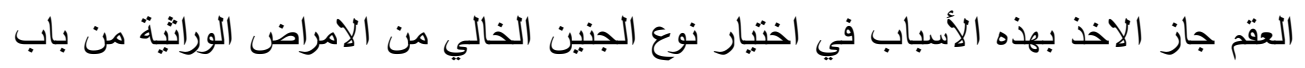

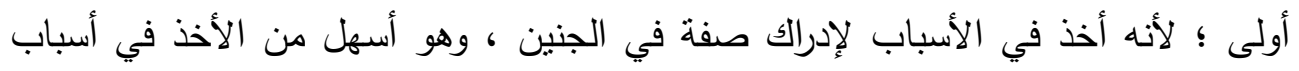
الإيجاد ، والتكوين • الأه الخد

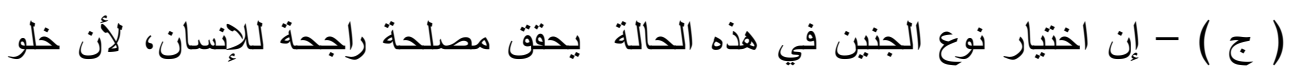

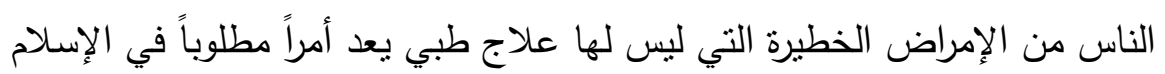

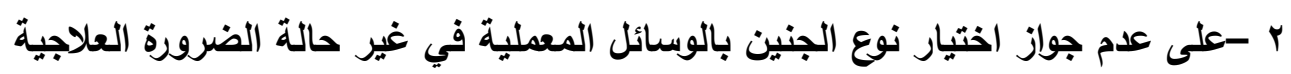

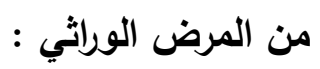

( أ ) - إن اختيار نوع الجنين بالطرق المخبرية بيتلزم كثف المرأة عورتها المغلظة أمام

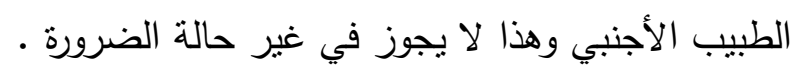
مناقثة هذا الاليل : ويناقش هذا الدليل بأن قصر إباحة كثف العورات على حالة الضرورة العلاجية - وصولاً

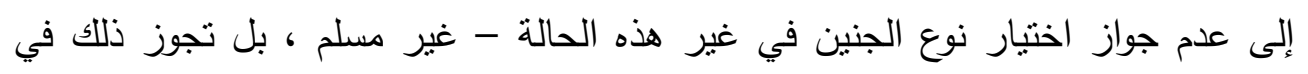

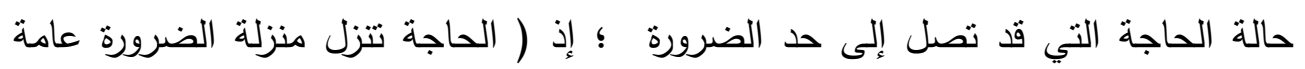

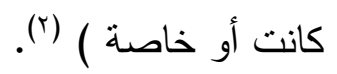

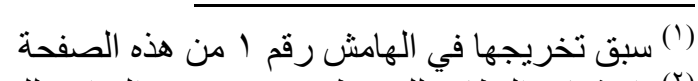

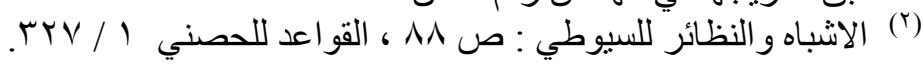

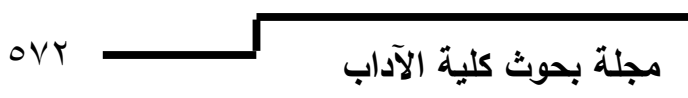


اختيار نوع الجنين ( الاصطفاء الجنسي )

$$
\text { سبب الخلاف في المسألة : }
$$

والناظر إلى خلاف العلماء في هذه المسألة يمكن أن يرجعه إلى أسباب،أهمها ما يأتي :

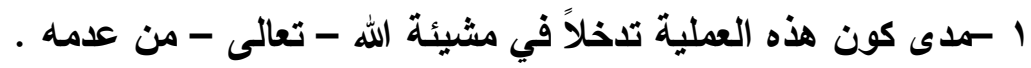

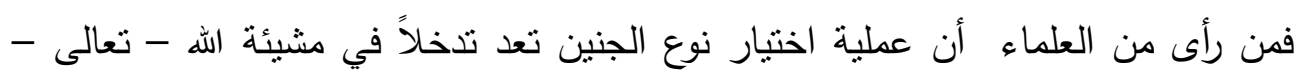

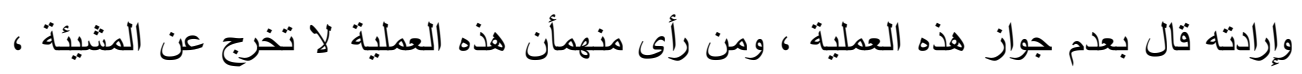

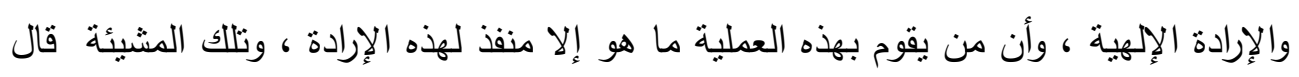

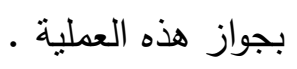
r - ممدي إخلال عملية اختيار نوع الجنين بالتوازن البشري من عدمه :

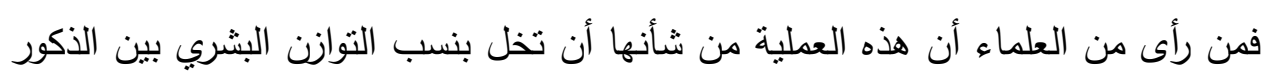

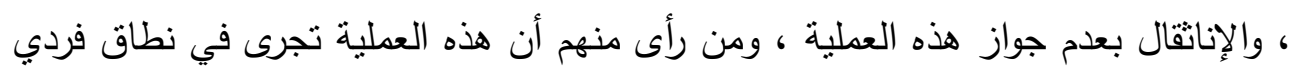

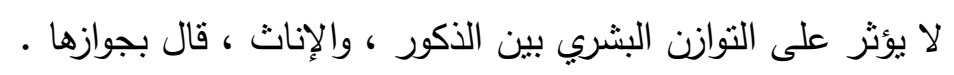

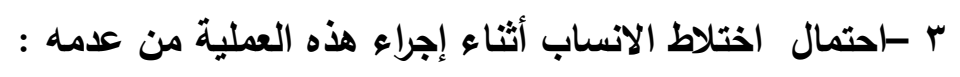

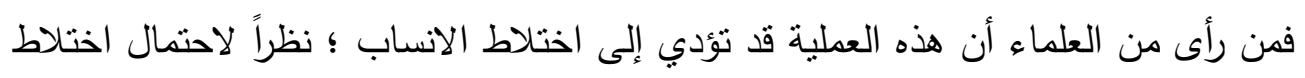

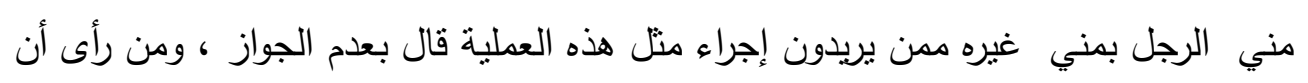

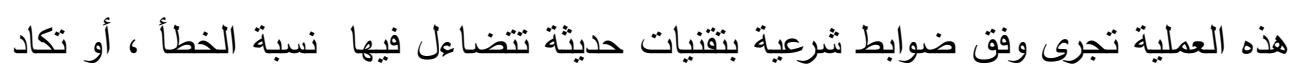

تتعدم ، قال بالجواز ('). الترجيح وضوابطه : بعد عرض آراء الفقهاء في هذه المسالة ، وأدلتهم ، ومناقتنة ما أمكن مناقشته منها بتضح - أبته

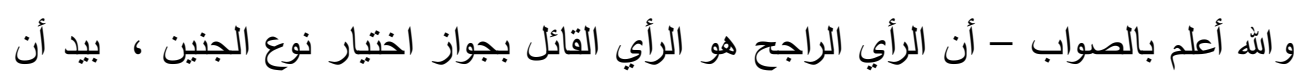

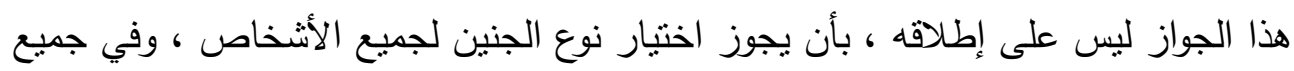

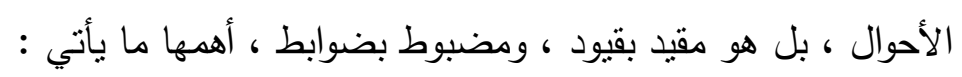

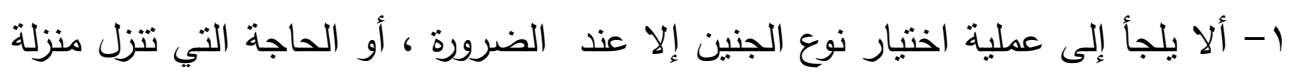

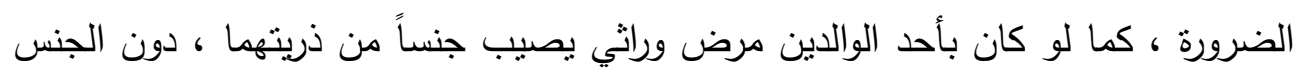
(') قرب ذلك : د ـ مازن إسماعيل هنية ، و أ ـ منال ححم رمضان العثي : مرجع سبق ذكره ص اء؟ 


\section{د خالا محمد حسين إبراهيم}

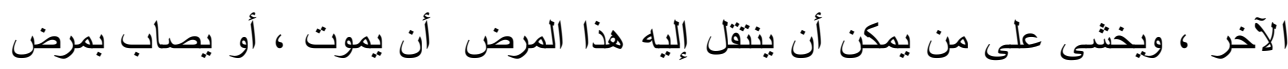

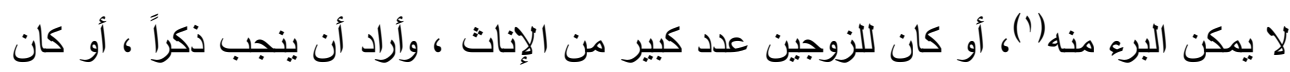

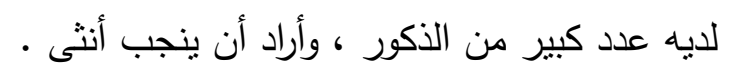

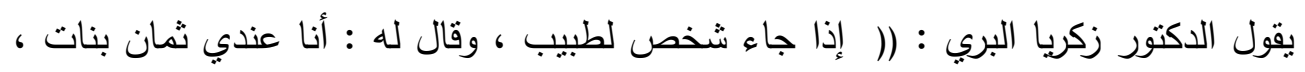

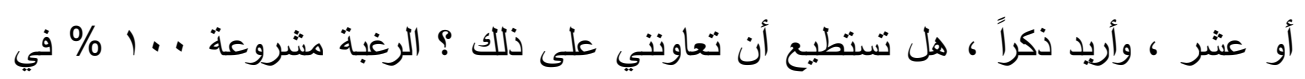

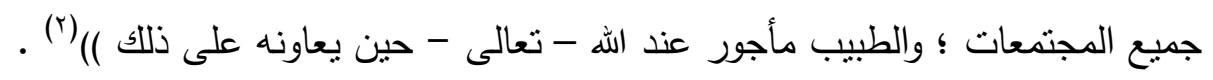
r - أن يكون اختيارنوع الجنين ، والتحكم فيه على مستوى فردي ، بأن يقوم به شخص البه ، أو أو

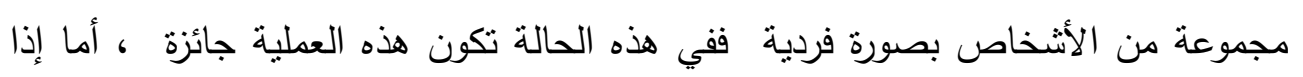

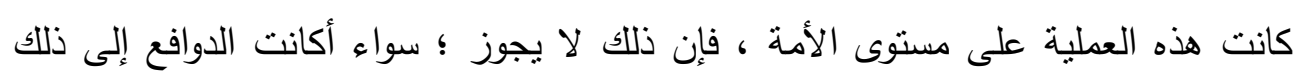

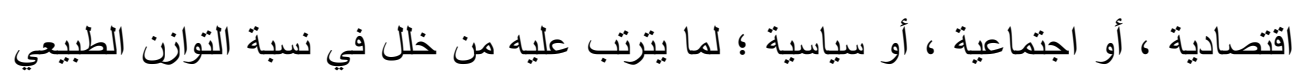
بين الذكور والإناث في المجتمع ().

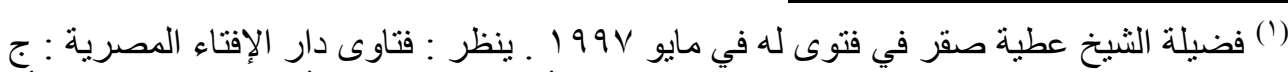

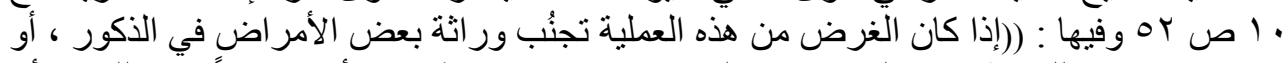

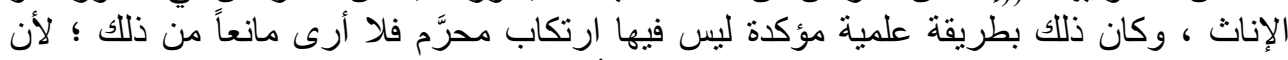

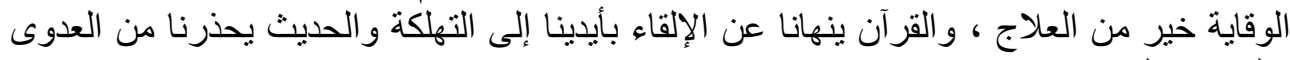

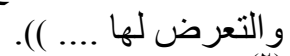

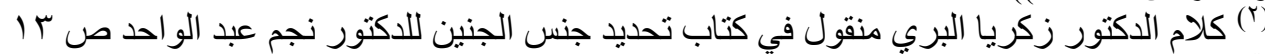

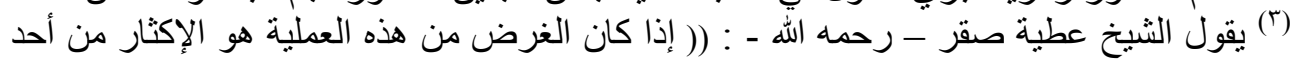

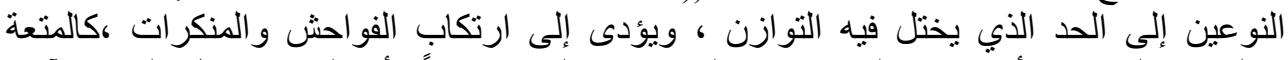

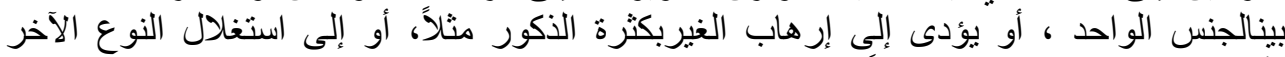

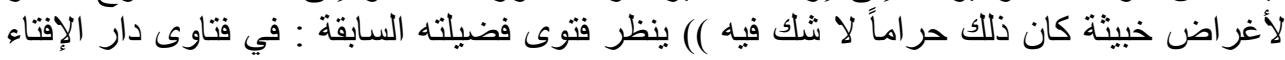

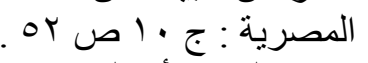

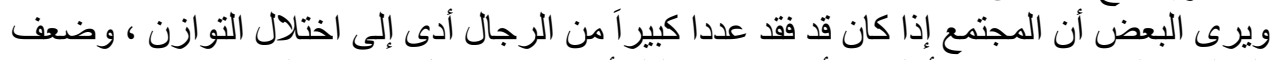

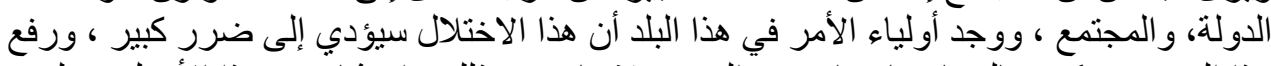

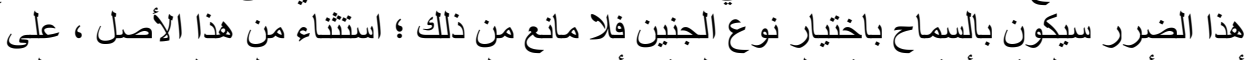

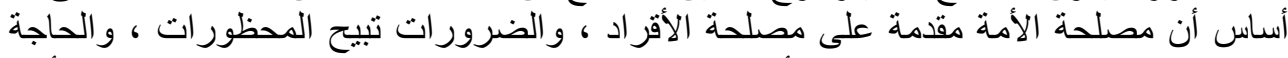

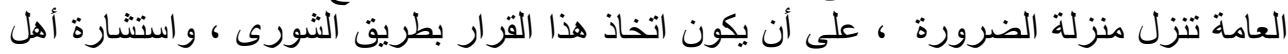

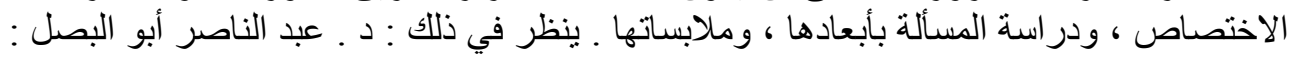

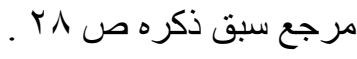




\section{اختيار نوع الجنين ( الاصطفاء الجنسي )}

ب - ألا تتم عملية اختيارنوع الجنين عن طريق الإجهاض بعد الحمل ، فإذا تمت على هذاء الألى

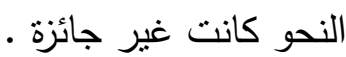

ع - يجب أن براعى في هذه العملية الضوابط الثرعية ذاتها التي يجب مراعاتها في عملية

$$
\text { التلقيح الاصطناعي من ضرورة أن: }
$$

- يكون الإخصاب لخلايا زوجين بينهما علاقة زوجية صحيحة ، وقائمة .

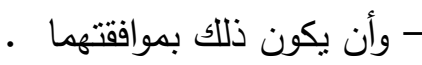

- وأن تتم كل مراحل التلقيح حال حياة الزوجين ، من أخذ خلايا الزوج ، وتلقيح البييضة -

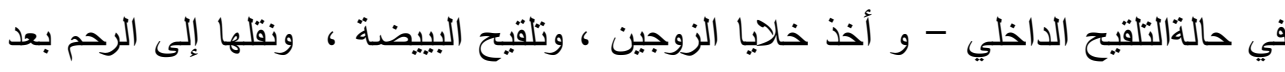
تلقيحها - في حالة التلقيحالخارجي .

- وأن يحتاط أثند احتياط عند إجراء هذه العملية بحيث لا تختلط خلايا الزوجين بخلايا غيرهما

- أن يقتصر كثف العورة أثناء العملية على القدر اللازم لذلك('). ه - أن يكون تحديد نوع الجنين بتراضي الزوجين ؛ لأن لكل واحد منهما حقًا في الولد فإن

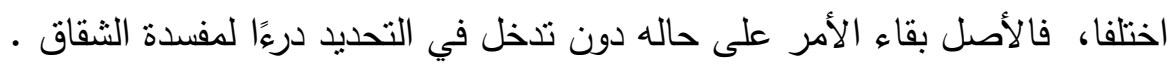

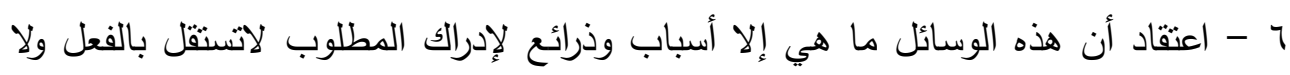

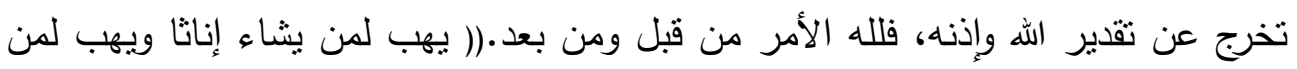

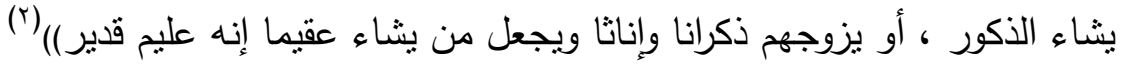

$$
\begin{aligned}
& \text { (') أستاذنا الدكتور عبد الفتاح إدريس : مرجع سبق ذكره ص ، ، د د ـ حسن عبد الغني أبو غدة : مرجع }
\end{aligned}
$$

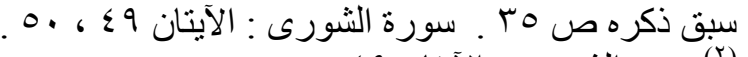

$$
\begin{aligned}
& \text { (ז)سورة الثورى : الآيتان 9 ؟ ، .0. }
\end{aligned}
$$




\section{الخاتمة}

وتتضمن أهم النتائج التي انتهى إليها البحث ، والتوصيات التي يوصي بها .

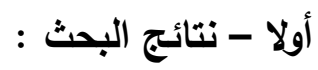

1 - اختيار نوع الجنين هو ( ما يقوم به الزوجان من أعمال طبيعية بنفسيهما ، أو طبية من خلال مختص ؛ بهدف تحديد ذكورة الجنين ، أو أنوثته ) .

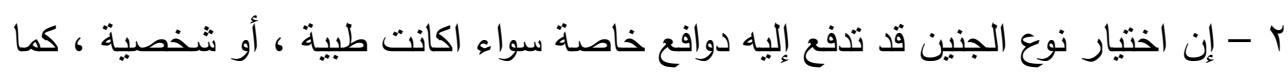
قد تدفع إليه دوافع عامة سواء كانت اقتصادية ، و اجتماعية ، أو عسكرية .

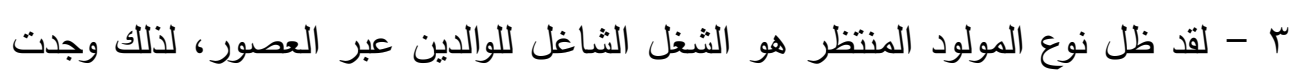
محاولات قديمة لاختيار نوع الجنين عند كثثر من الأمم ، كاليونانيين ، والصينيين ، والفراعنة ، والعرب . ماته

ـ - إن الوسائل القديمة التي عرفتها الأمم السابقة لاختيار نوع الجنين ، كتلك التي عرفها

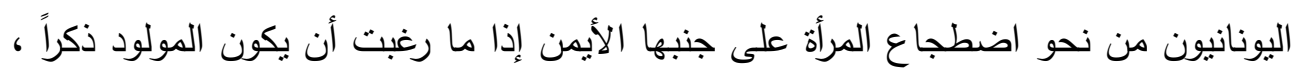
واضطجاعها على جنبها الأيسر إذا ما رغبت في أنثى ، ومن نحو تعرضها للريح الحارة إذا لها

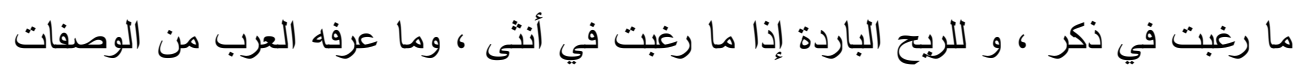

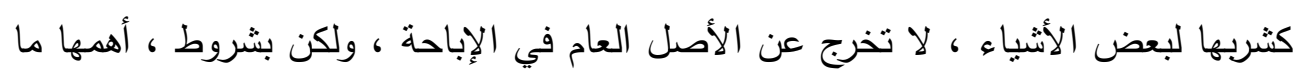
:أني :

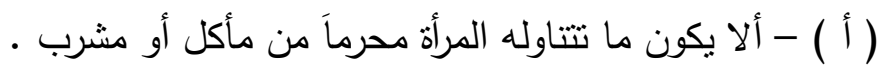

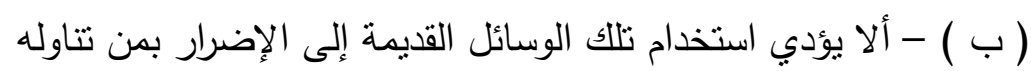

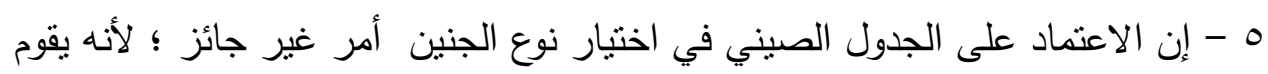

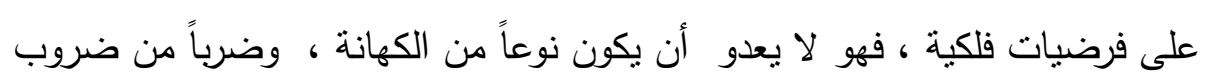
التجيم ، والرجم بالغيب . التئ.

7 - إن الوسائل الحديثة لاختيار نوع الجنين تتقسم إلى وسائل طبيعية ، ووسائل معملية .

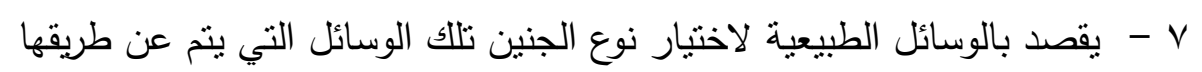

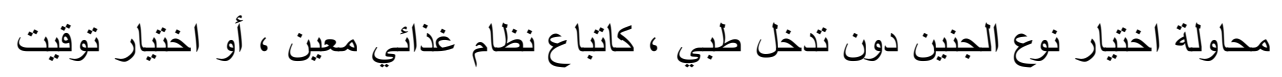




\section{اختيار نوع الجنين ( الاصطفاء الجنسي )}

للجماع يتتاسب مع وقت التبويض ، أو تهيئة ظروف وحالة القناة التتاسلية عند المرأة لكي الاصني

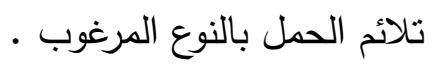

9 - إن اختيار نوع الجنين بالوسائل الطبيعية السابقة يعد من الأمور الجائزة شرعاً ؛ إذ لا لإن

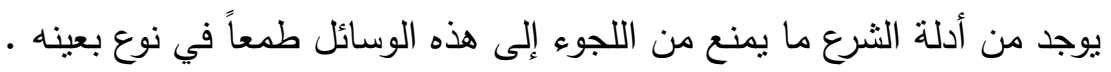

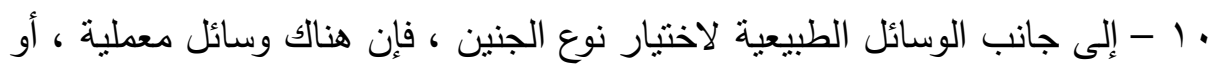
مختبرية يمكن عن طريقها تحقيق هذا الهدف كالتلقيح الاصطناعي الداخلي ، أو التلقيح الاصطناعي الخارجي ، سواء أكان ذلك بوسيلة أطفال الانابيب ، أو الحقن المجهري

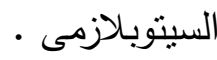

11 - إن الفقهاء المعاصرين قد اختقوا في اختيار نوع الجنين بالوسائل المعملية ، أو المخبرية بين مؤيد ، ومعرض ، وقد ترجح لدينا الجواز ، ولكن بالضوابط الآتية :

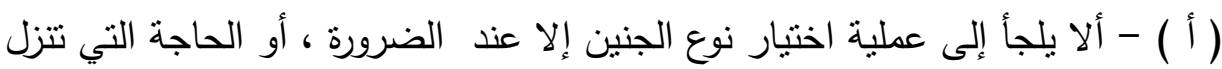
منزلة الضرورة م

( ب ) - أن يكون اختيار نوع الجنين ، والتحكم فيه على مستوى فردي ، بأن يقوم به

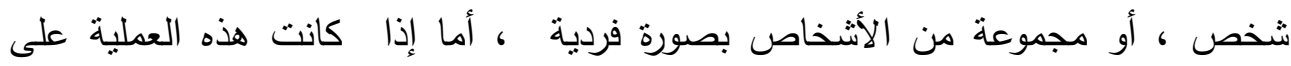
مستوى الأمة ، فإن ذلك لا يجوز ؛ للا يترتب عليه من خلل في نسبة التوازن الطبيعي بين

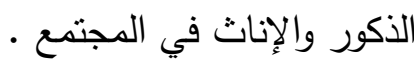
( ) ) ألا تتم عملية اختيار نوع الجنين عن طريق الإجهاض بعد الحمل ( ) ) - أن يراعى في هذه العملية الضوابط الثرعية ذاتها التي يجب مراعاتها في عملية التلقيح الاصطناعي من ضرورة أن: يكون الإخصاب لخلايا زوجين بينهما علاقة زوجية صحيحة ، وقائمة ، وأن يتم هذا الامر بموافقتهما ، وأن تتم كل مراحل التلقيح حال حياة الزوجين ، وأن يحتاط أثند احتياط عند إجراء هذه العملية بحيث لا تختلط خلايا الزوجين

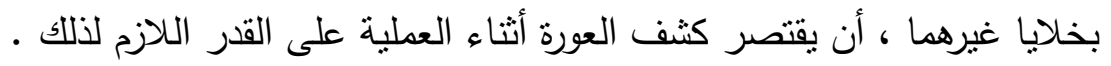
( هـ ) - أن يكون اختيار نوع الجنين بتراضي الزوجين ؛ لأن لكل واحد منهما حقًا في

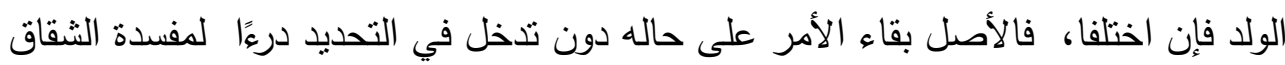


د / خالا محمد حسين إبرا هيم

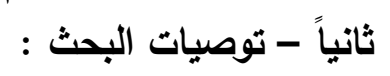

وأهم التوصيات التي يوصي بها الباحث ما يأتي : توصيات

1- يوصي الباحث الفقهاء المعاصرين بأن بتصدوا للنوازل الفقهية بصفة عامة ، والطبية

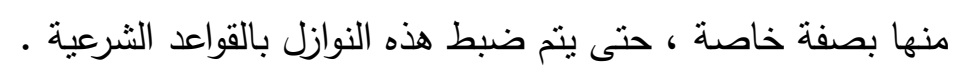

r - و يوصي الأطباء في العالم الإسلامي بأن برجعوا إلى الفقهاء لسؤالهم عن الحكم

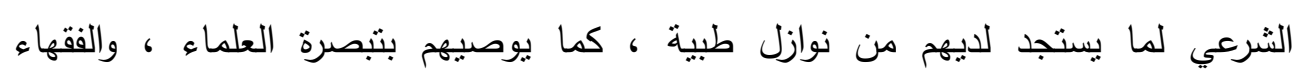

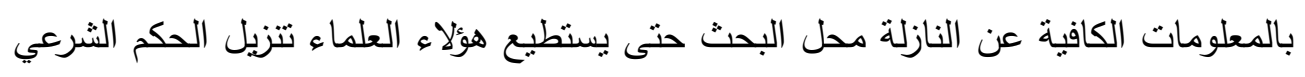
- الصحيح عليها

r- كما يوصي - أيضاً - بعقد مؤتمرات مشتركة بين الأطباء ، والفقهاء بصفة دورية ؛ لكناقتنة المستجدات على الساحة الطبية . ع - كوبخصوص قضية اختيار نوع الجنين ضرورة وجود جهات للرقابة المباشرة والدقيقة على المستتفيات ، والمراكزالطبية؛ التي تمارس مثل هذه العمليات في الدول الإسلامية، لتمنع أية

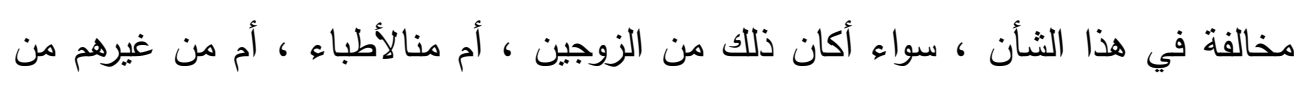

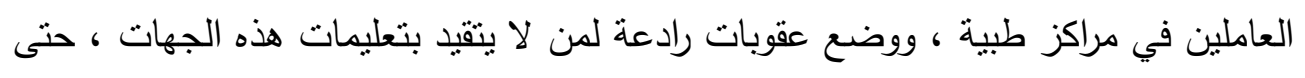

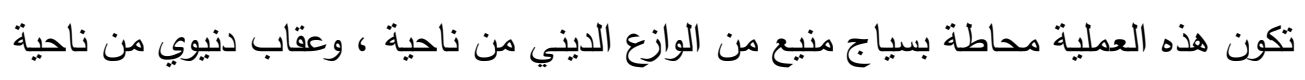

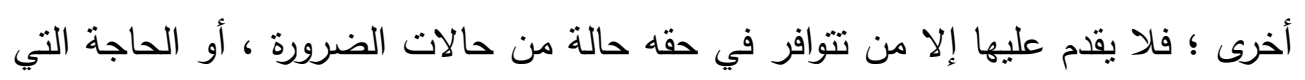

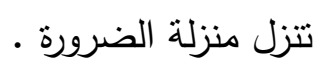




\section{اختيار نوع الجنين ( الاصطفاء الجنسي )}

\section{قائمة بأهم مراجع البحث}

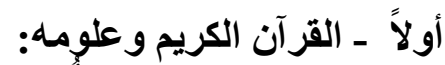

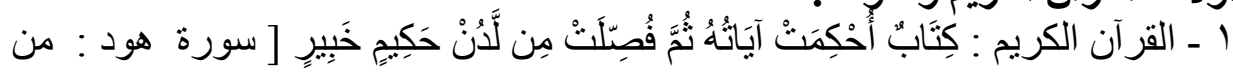

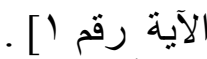

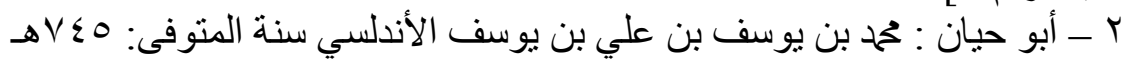

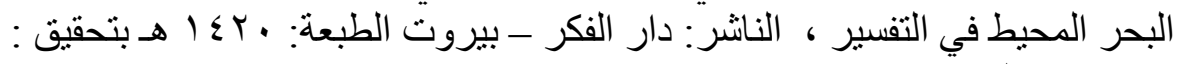

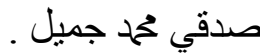

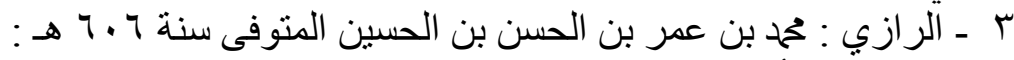
التفسير الكبير ، أو مفاتيح الغيب ، الناشر : د دار الكتب العلمية ـ بيروت الطبن الطبعة الأولى سنة

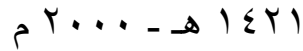

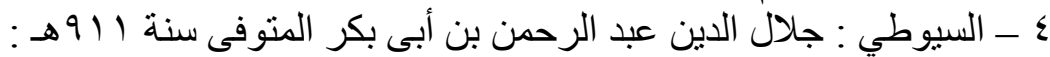

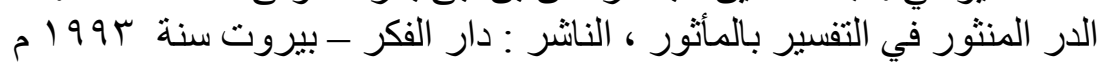

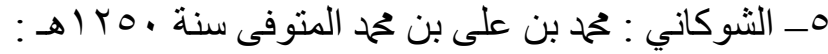

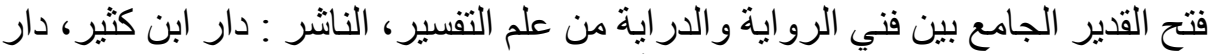

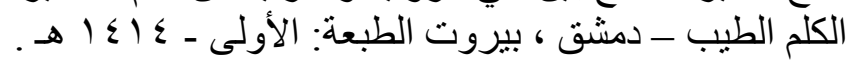

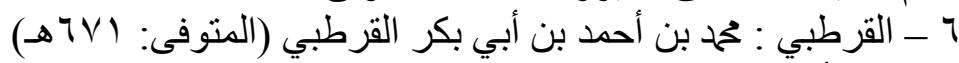

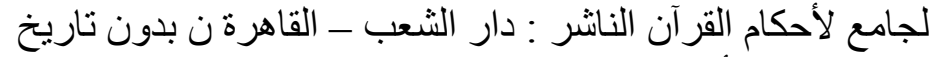

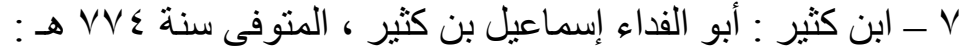

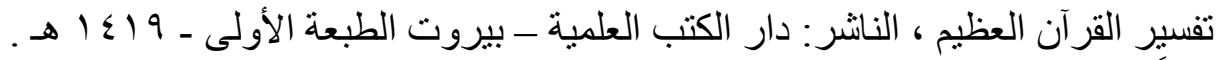

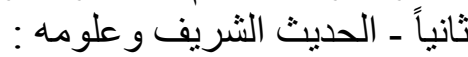

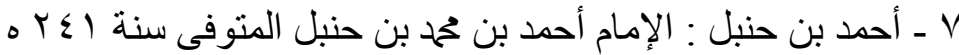

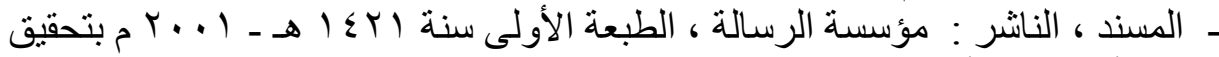
: معيب الأرناؤوط و أخرين.

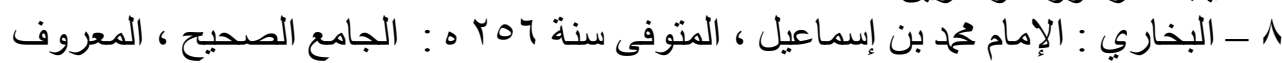

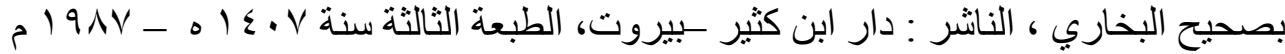

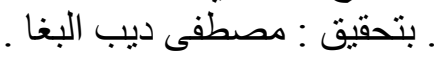

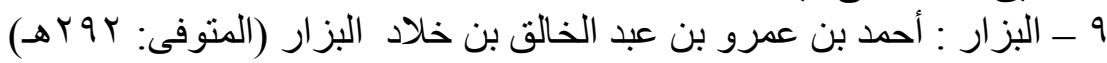

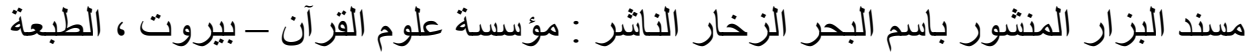

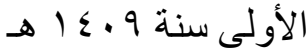

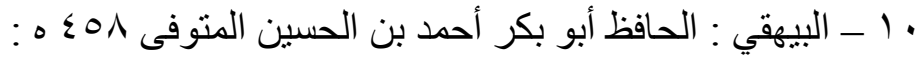

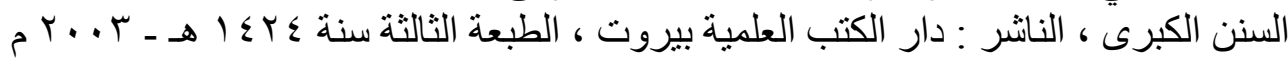

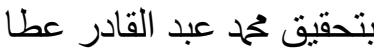

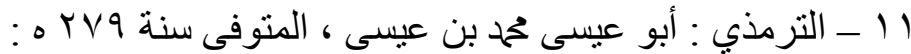

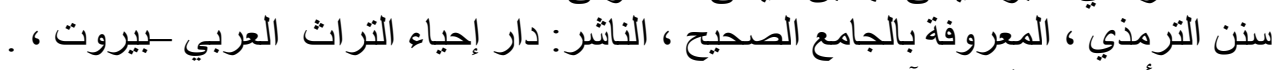
بتحقيق : أحمد محمد شاكر وآخرين . 
د / خالد محمد حسين إبراهيم

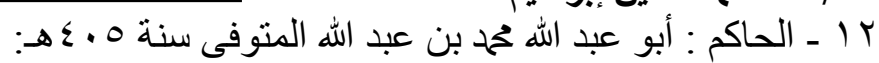

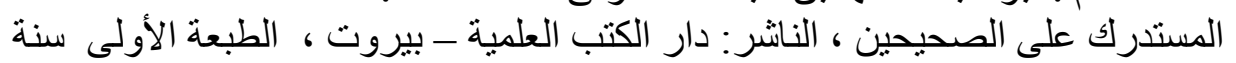

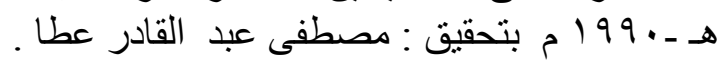

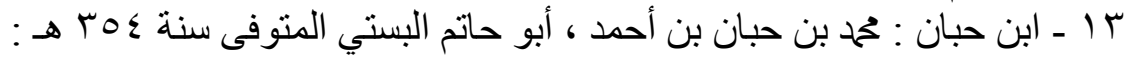

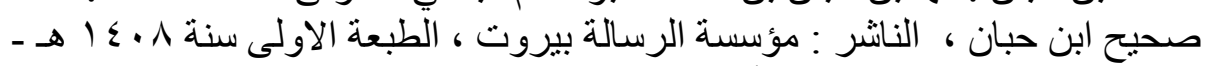

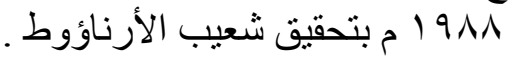

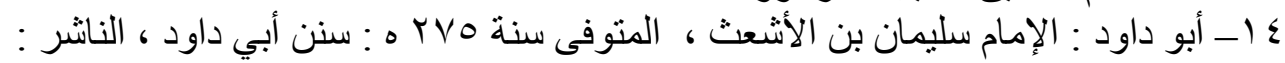

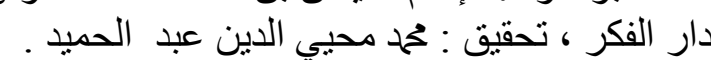

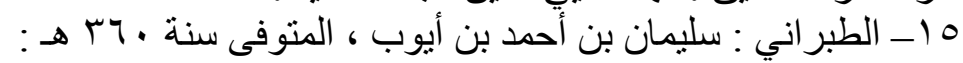

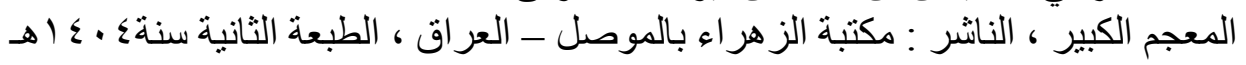

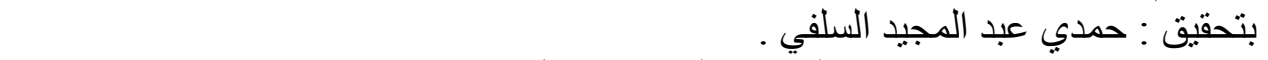

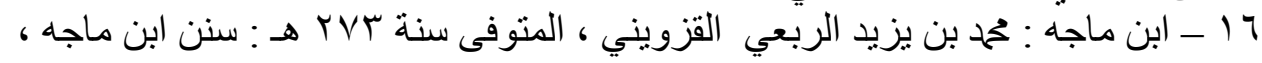

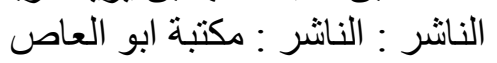

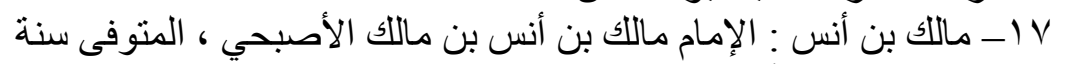

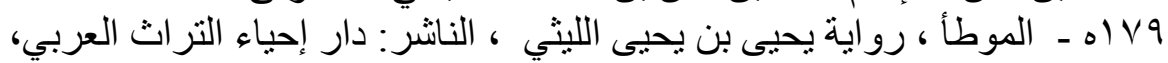

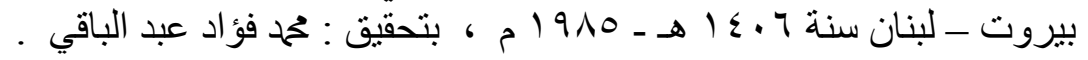

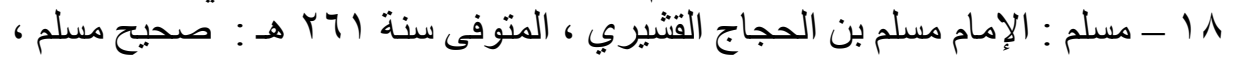

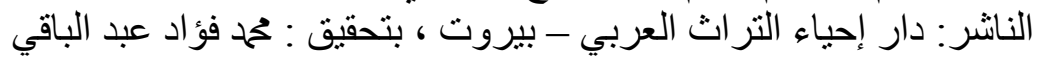

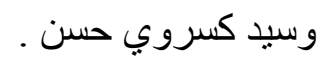

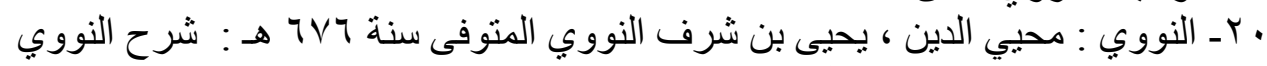

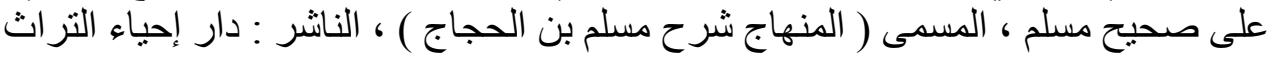

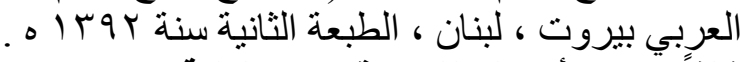

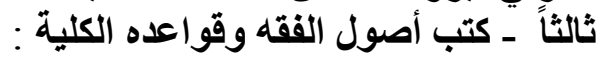

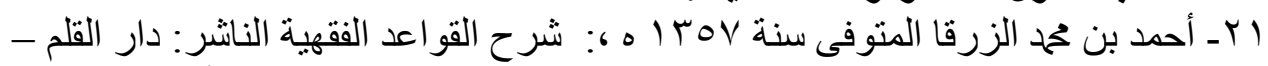

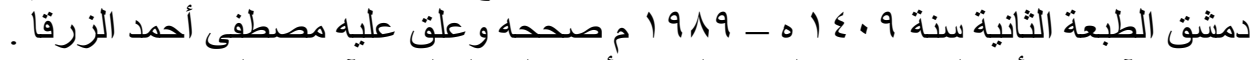

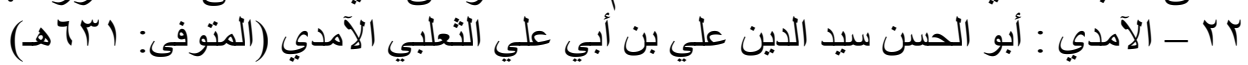

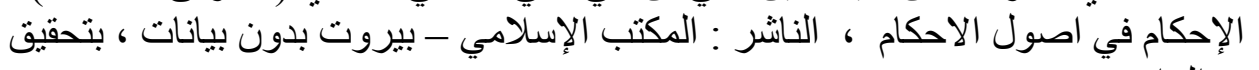

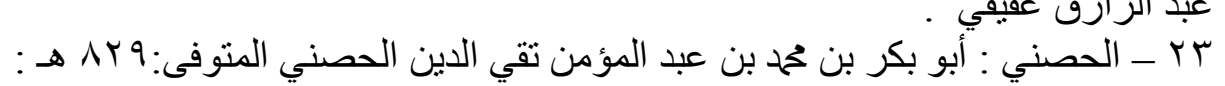

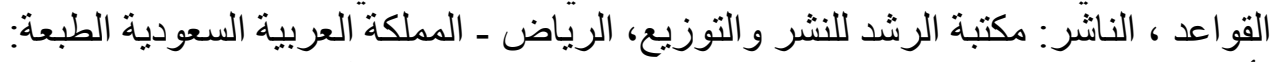

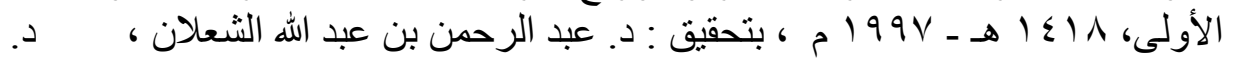

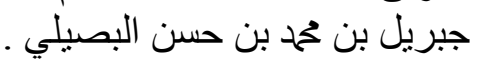

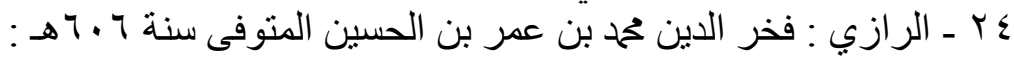

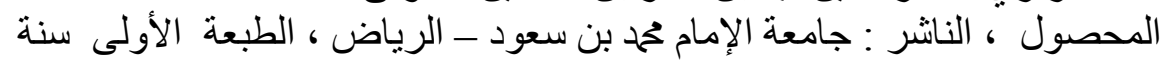

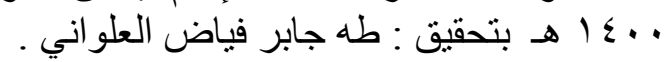

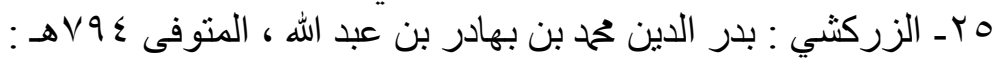

○人. مجلة بحوث كلية الآداب 


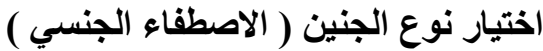

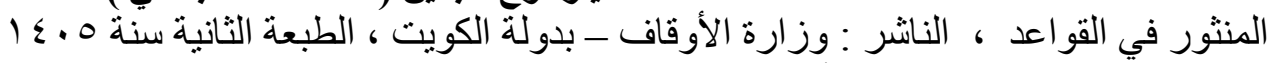
هـ بتحقيق : د / تيسير فائق أحمد .

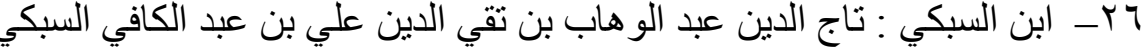

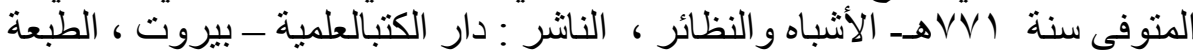

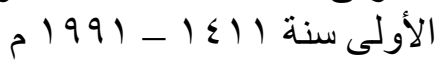

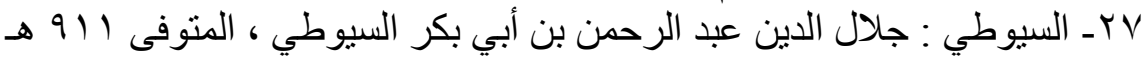

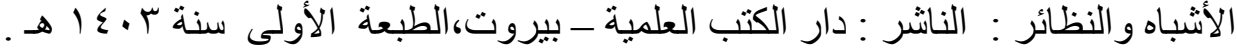

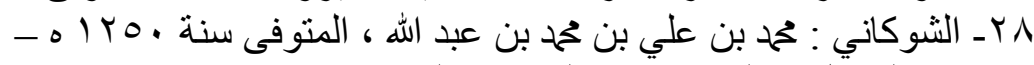

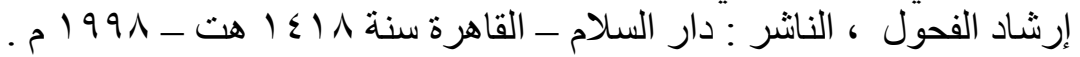

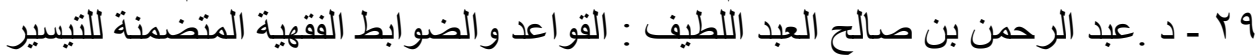

الناشر : عمادة البحث العلمي بالجامعة الإسلامية بالمدينة المنورة ، الطبعة الاولى سنة الطنة

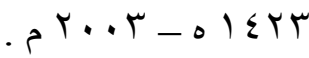

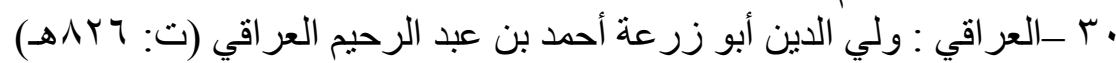

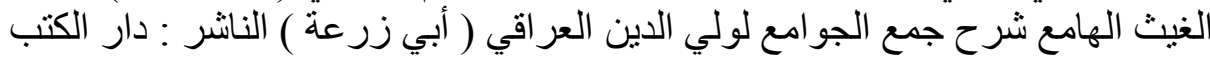

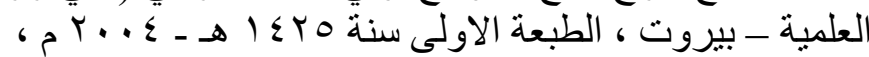

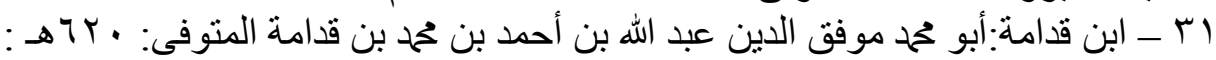

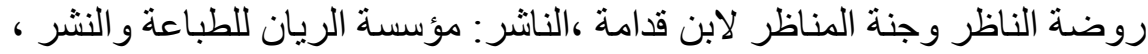

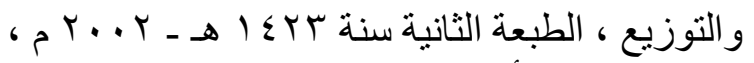

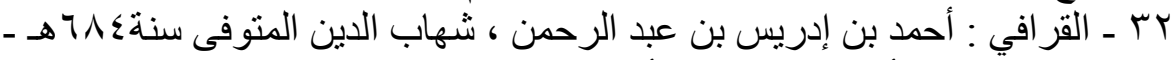

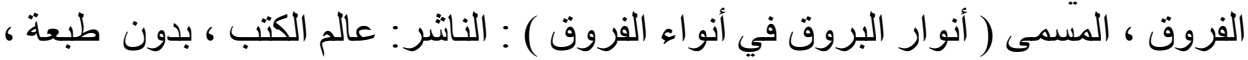

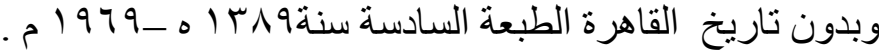

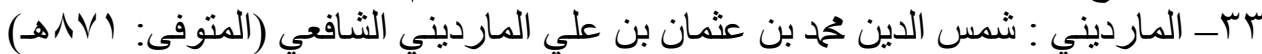

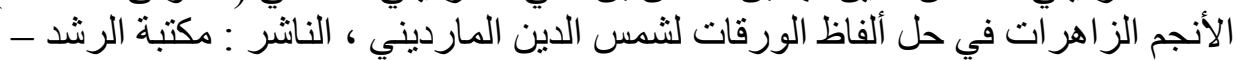

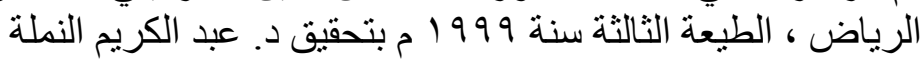

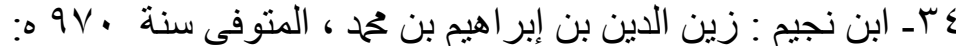

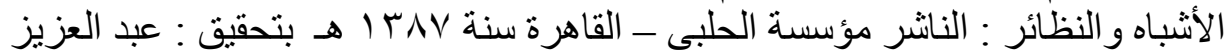

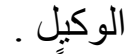

$$
\begin{aligned}
& \text { رابعاً ـ كتب المذاهب الفقهية : } \\
& \text { ( أ ) - كتب الفقه الحنفي : }
\end{aligned}
$$

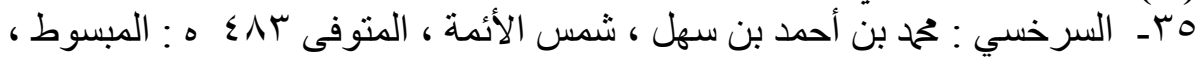

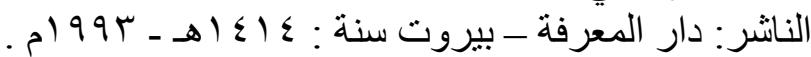

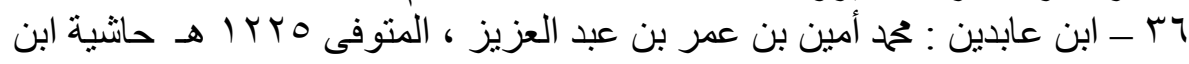

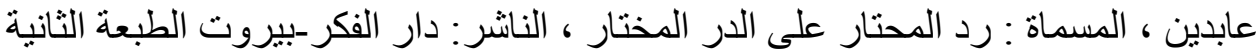

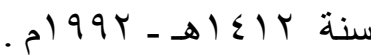


د الد / خالد محمد حسين إبراهيم

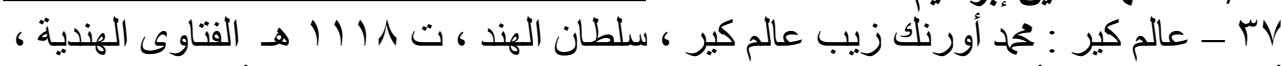

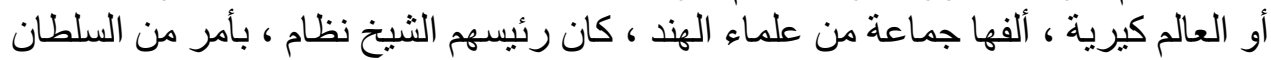

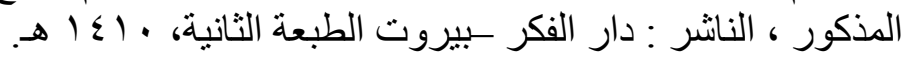

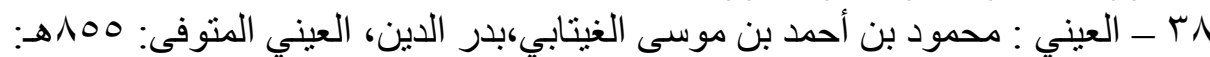

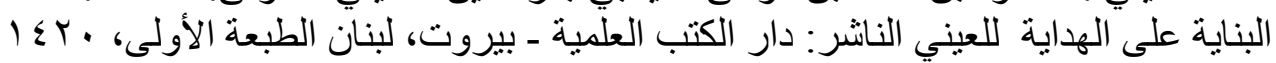

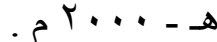

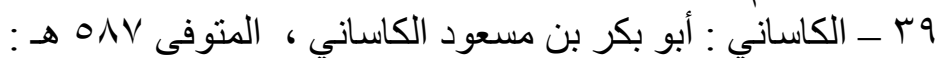

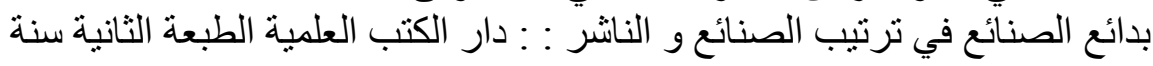

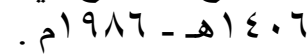

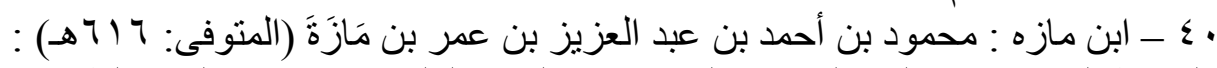

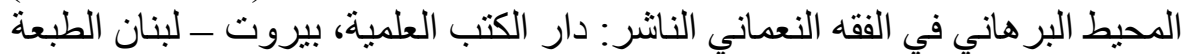

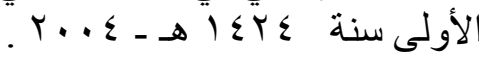

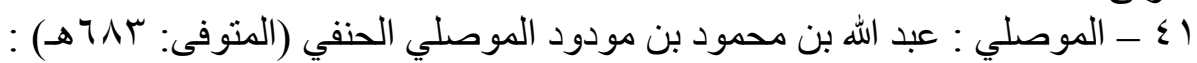

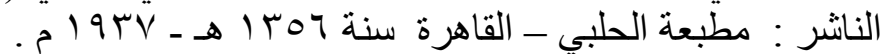

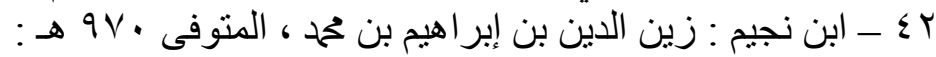

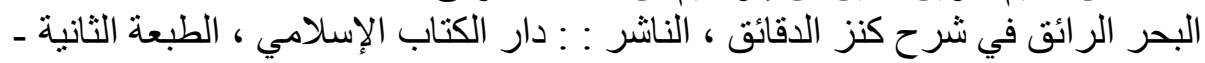
بدون تاريخ.

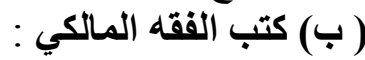

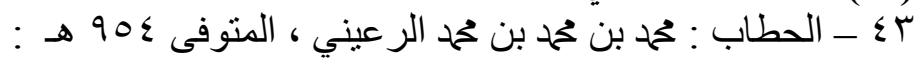

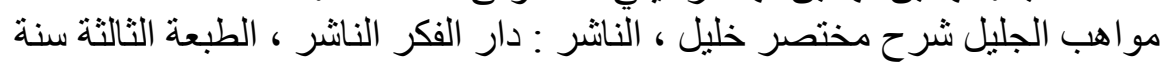

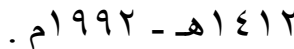

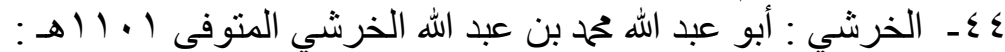

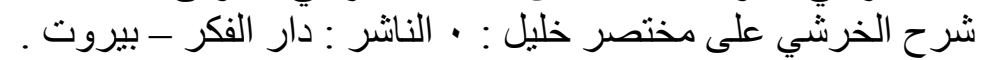

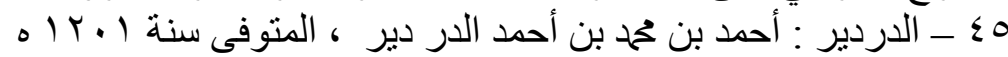

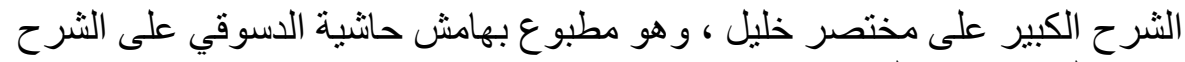
المذكور ، الناثنر : دار الفكر . الفير

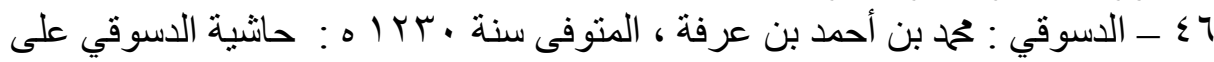

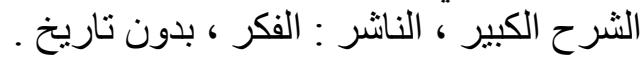

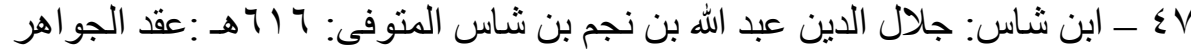

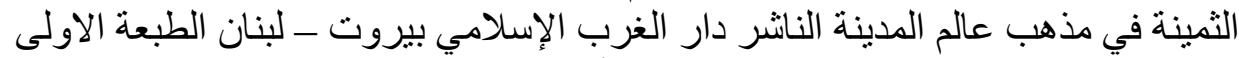

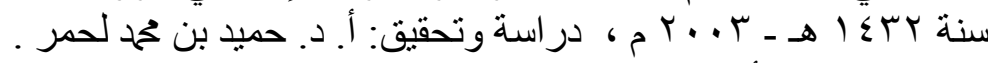

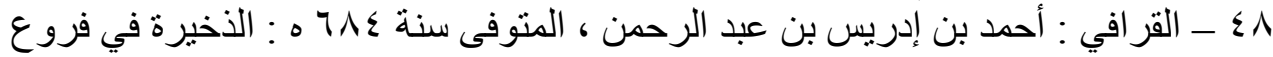

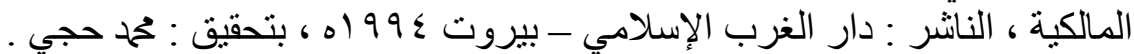

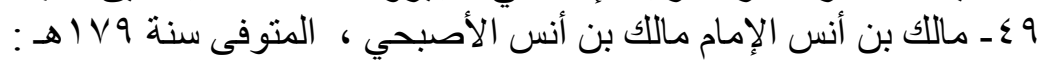

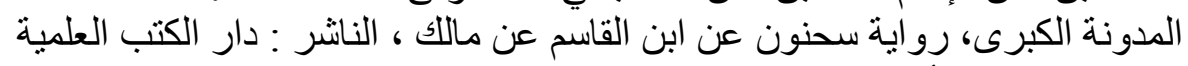

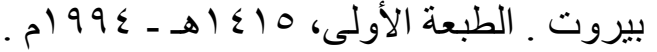

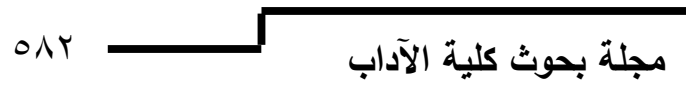




\section{اختيار نوع الجنين ( الاصطفاء الجنسي ) إنوفي )}

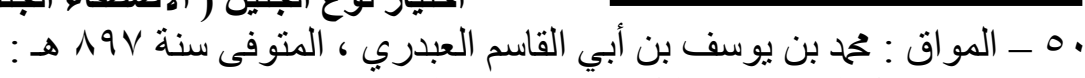

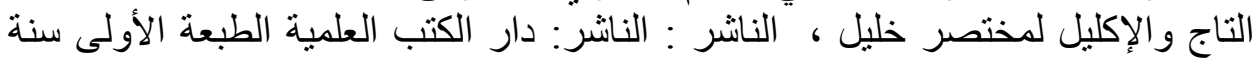

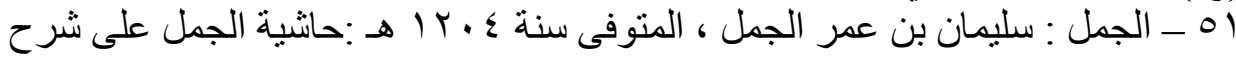

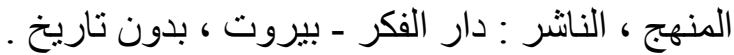

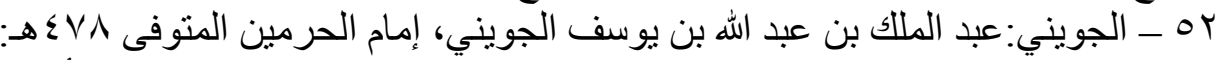

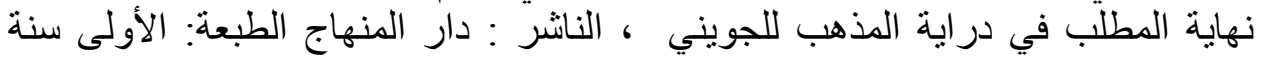

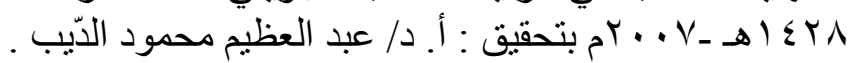

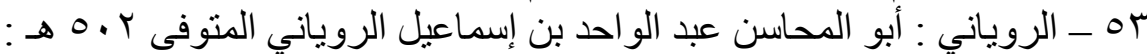

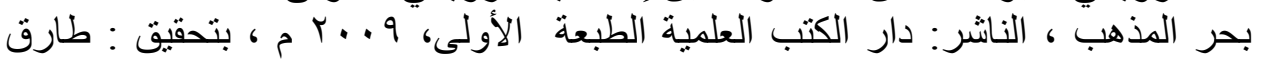

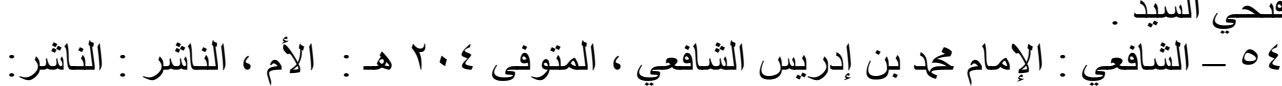

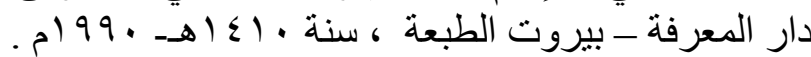

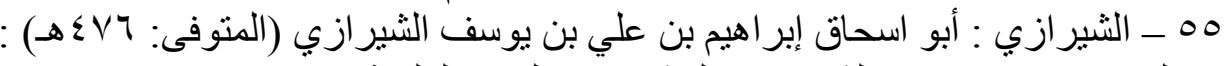

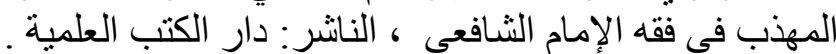

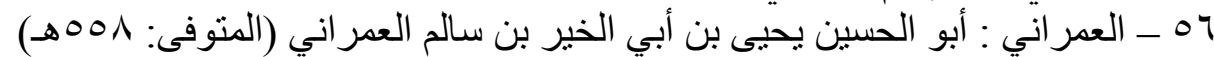

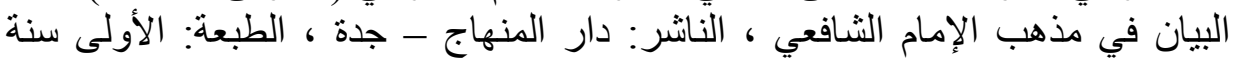

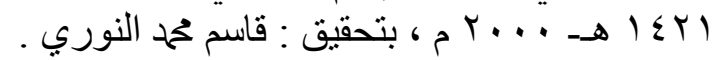
OV

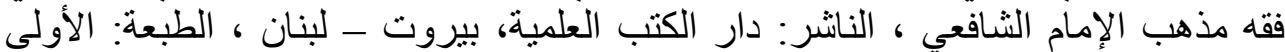

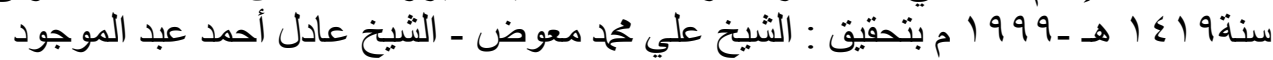

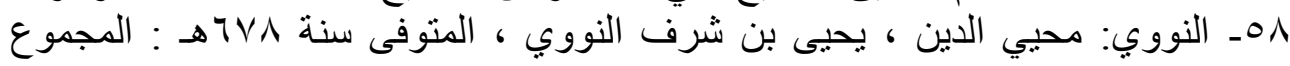

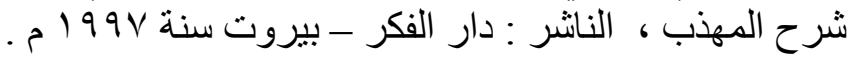

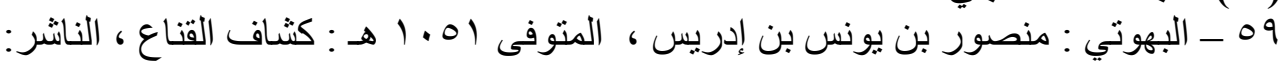
دار الكتب العلمية.

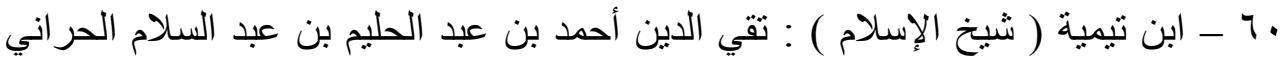

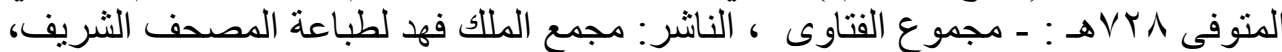

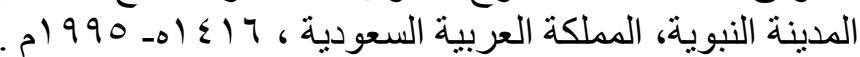

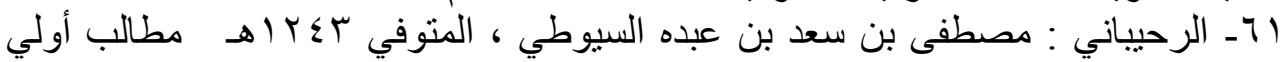

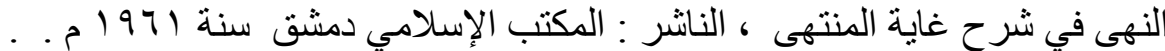




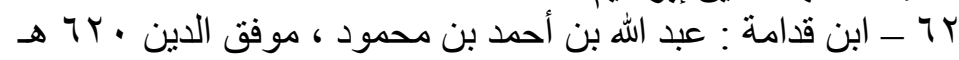

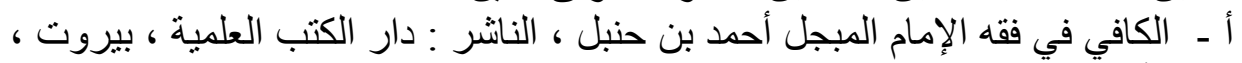

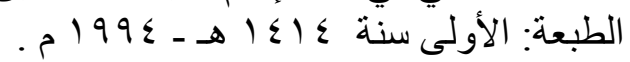

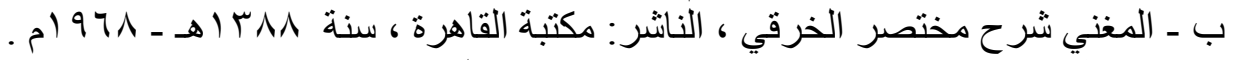

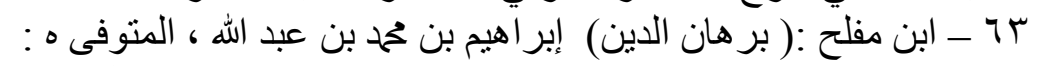
المبدع في شرح المقنع ، الناثر : دار الكت الكتب العلمية، بيروت ـ ـلبنان ، الطبعة: الأولى سنة

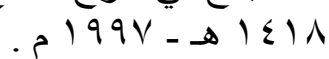

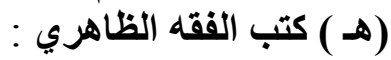

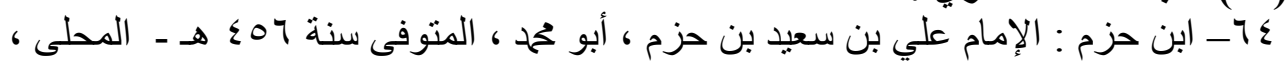

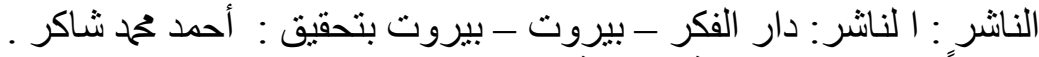

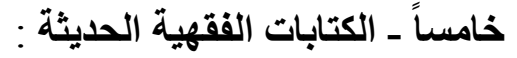

10 ـ د ـ ـ حسن عبد الغني أبو غدة : اختيار جنس الجنين ، والإنة وهو بحث منشور في مجلة

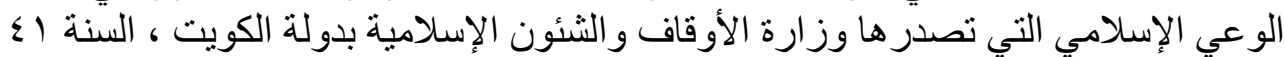

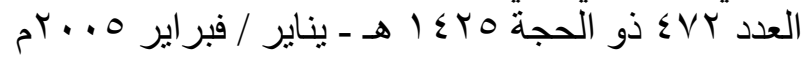

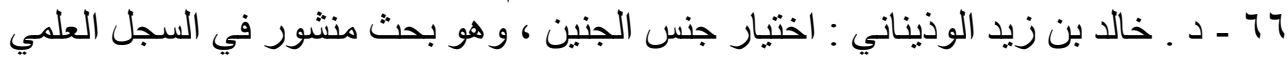

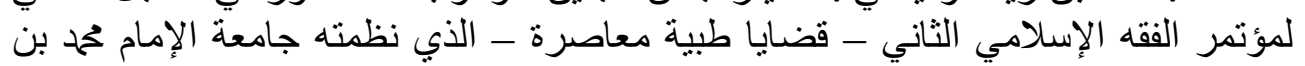

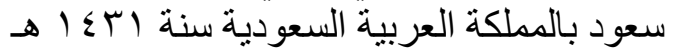

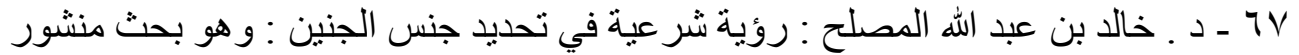

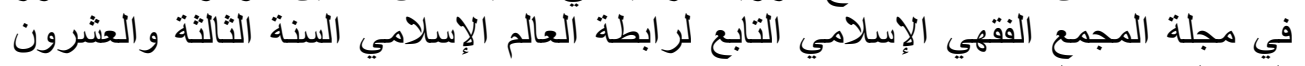

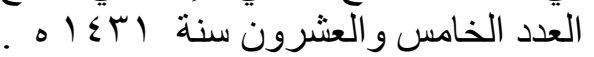

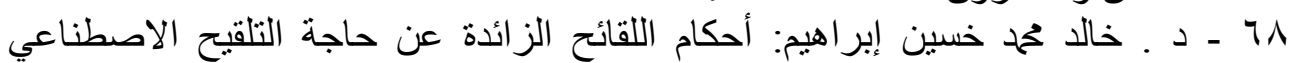

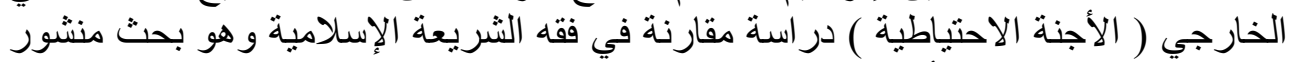

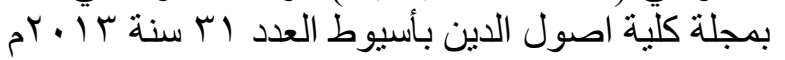

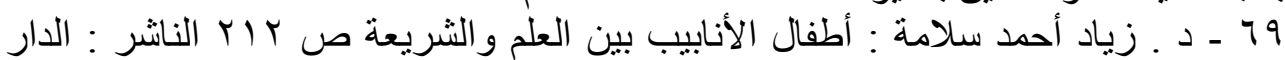

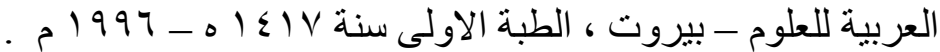

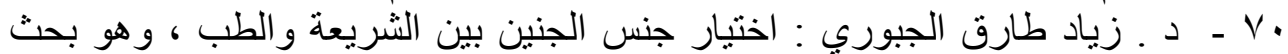

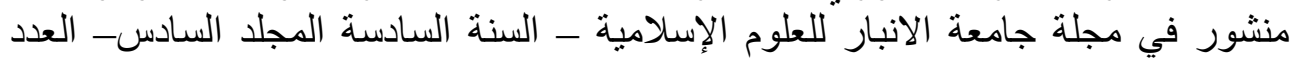

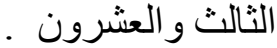

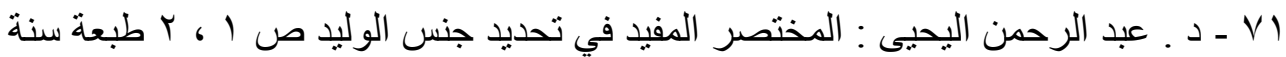
ه $1 \leqslant Y q$ في مجلة ـ _ ـ ـ عبد الفتاح إدريس : اختيار جنس الجنين من منظور إسلامي ، وهو مقال منشور

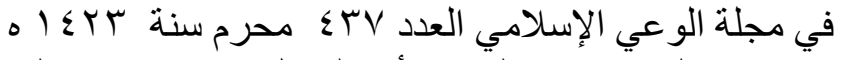

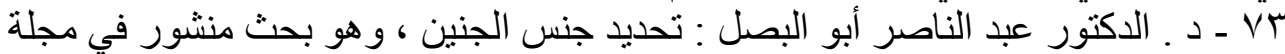

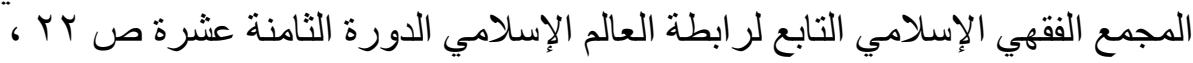




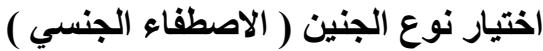

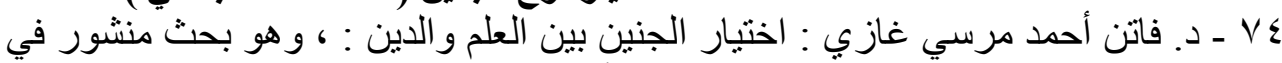

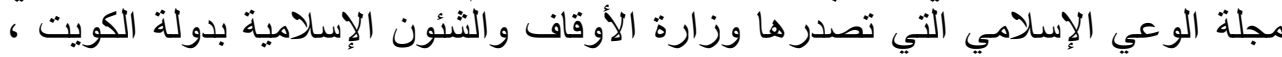

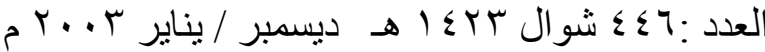

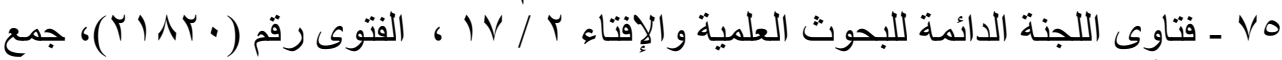

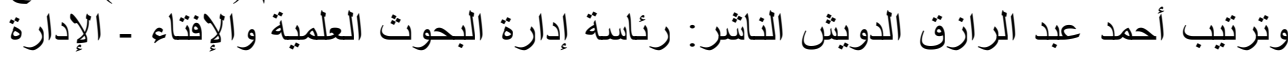

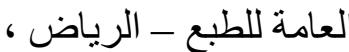

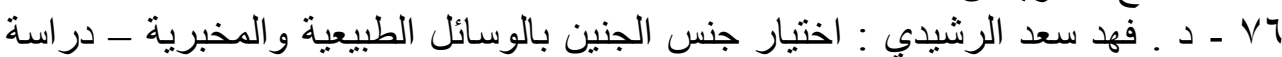

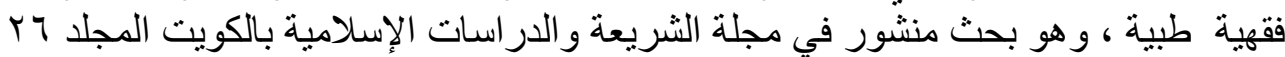

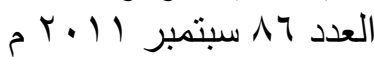

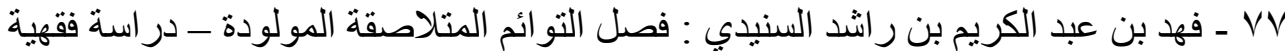
، وهو من إصدارات سلسلة دراسات عربية و إسلامية - مركز اللغات الاجنبية والترجمة التراتية

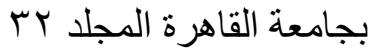

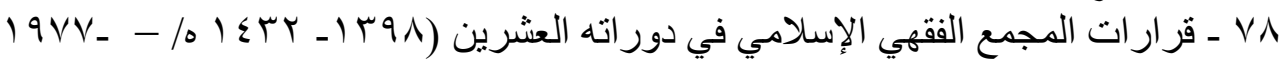

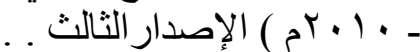

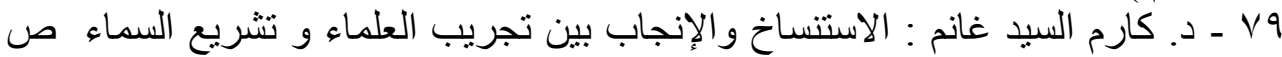

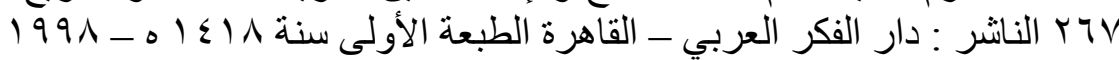

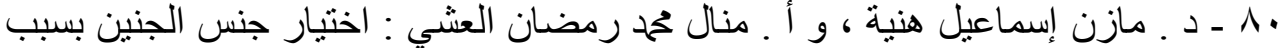
المرض الو راثي : وهو بحث منشور في مجلة الجامعة الإسلامية ( سلسلة الدراسات العات العان

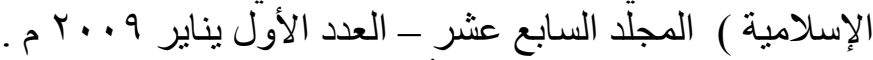

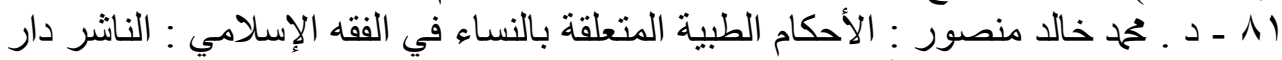

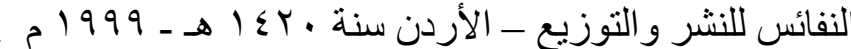

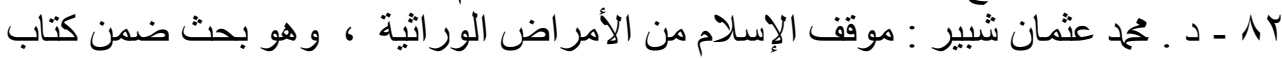

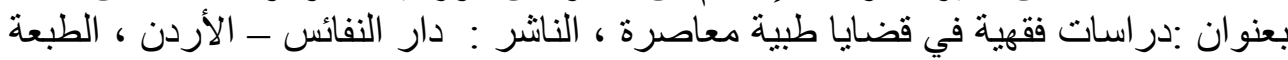

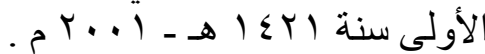

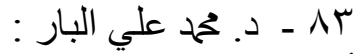

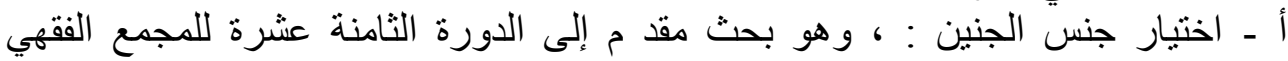

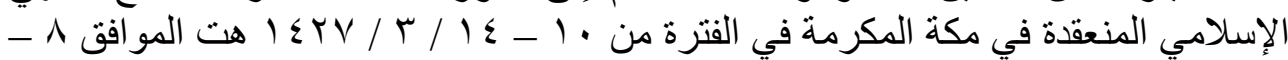

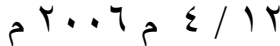
ب ـ أخلاقيات التلقيح الصناعي ، الناتشر : الدار السعودية للنشر والتوزيع الطبعة الأولى

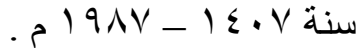
ج - خلق الإنسان بين الطب و القرآن ، الناشر : الدار السعودية ، الطبعة الرابعة سنة بـ19 19

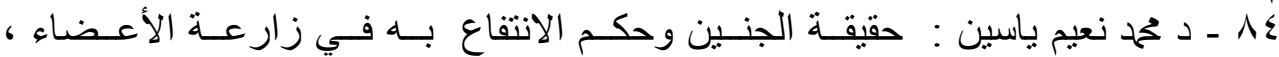

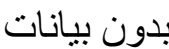

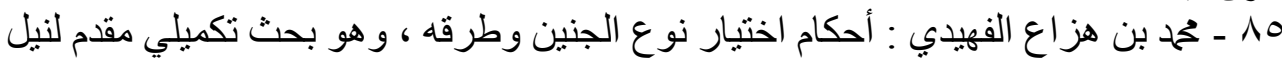

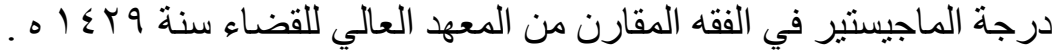


د / خالا محمه حسين إبراهيم

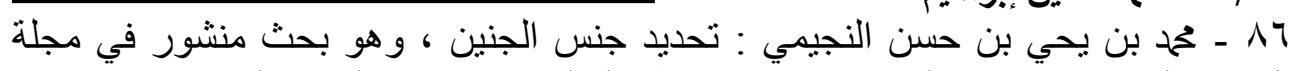

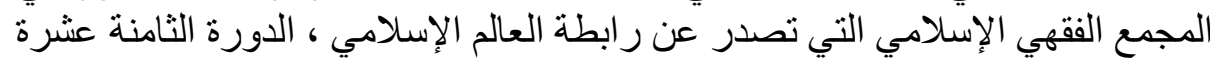

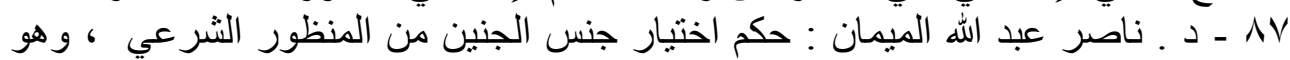

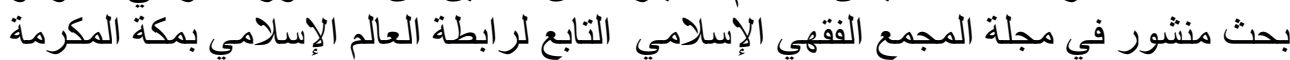

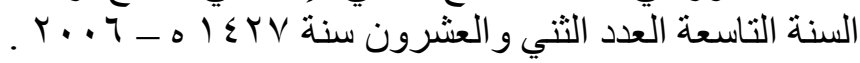

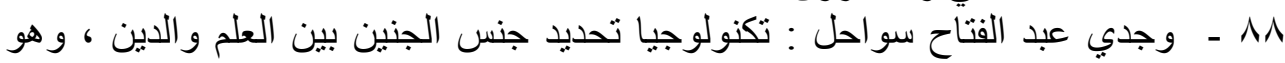

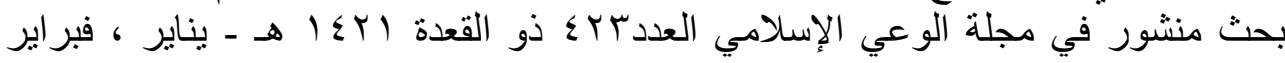

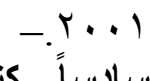

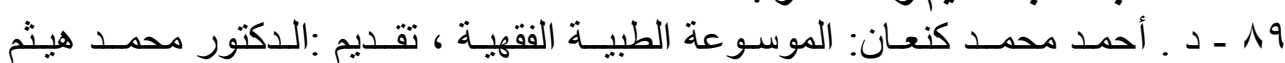

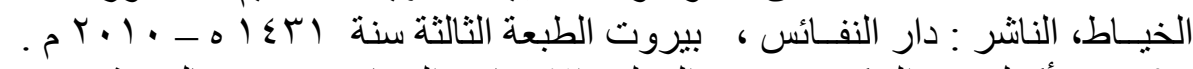

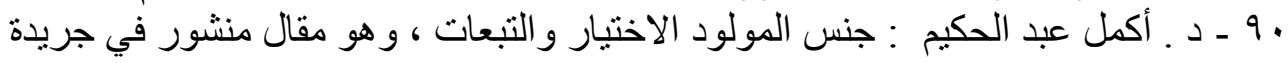

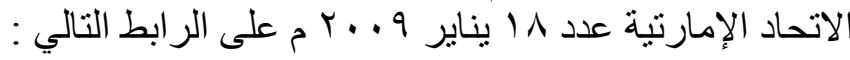
https://www.alittihad.ae/WejhatArticle/42649

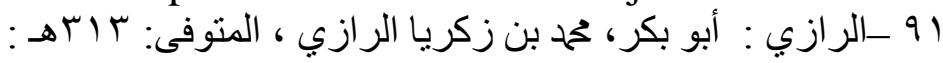

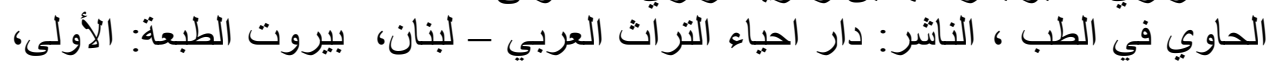

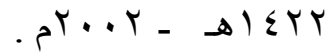

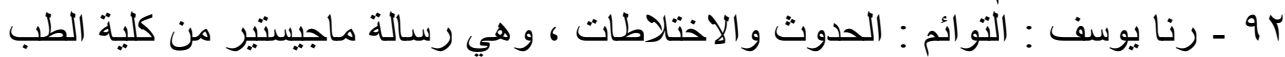

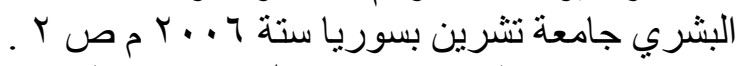

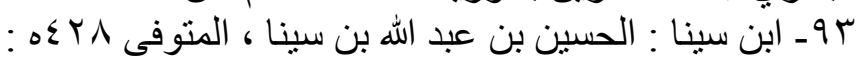

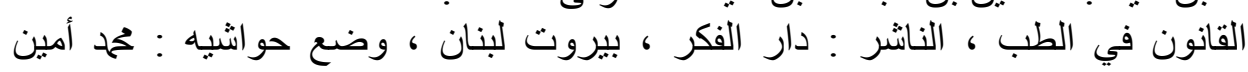
الضناوي . ع الضون ـ 9 ـ د. ـ عبد اللطيف ياسين : ولد أم بنت و هل يمكن اختيار الجنس المرغوب ، مطبعة دار

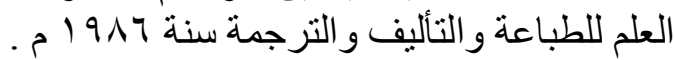

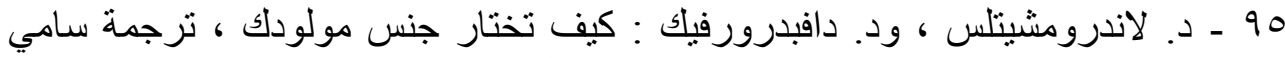

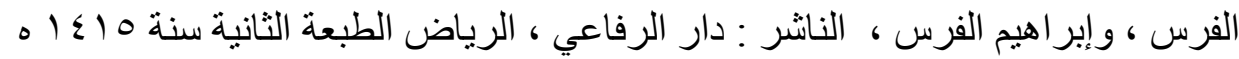

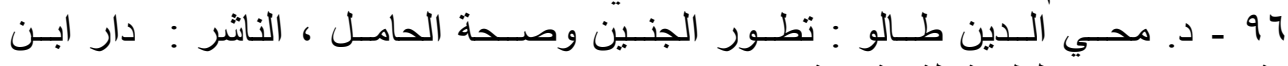

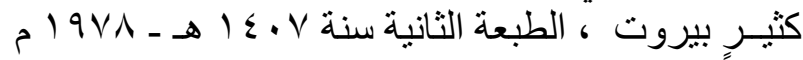

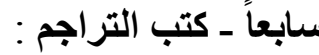
9V

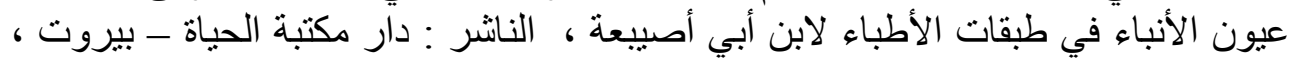

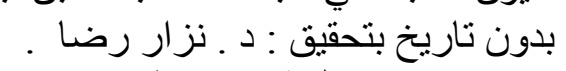
19 ـ ـ حاجي خليفة : مصطفى بن بن عبد الله العثماني ، المعروف بـ حاجي خليفة المتوفى $1.7 \mathrm{~V}$ سلم الوصول إلى طبقات الفحول لحاجي خليفة الناشر : مكتبة إرسيكا استانبول - تركيا

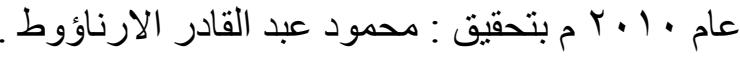




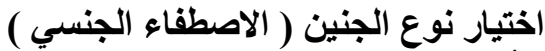

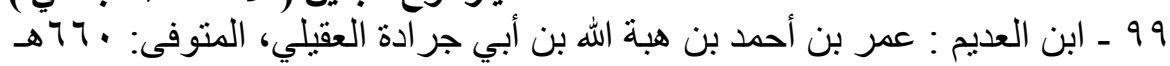

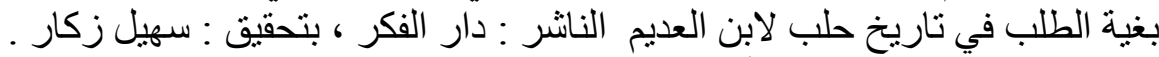

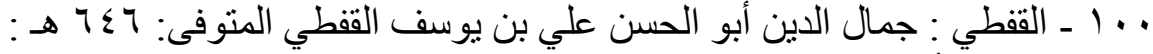

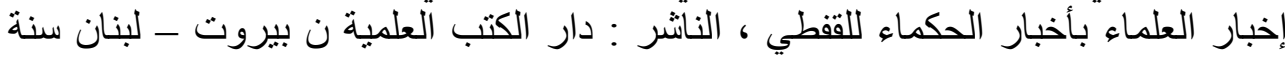

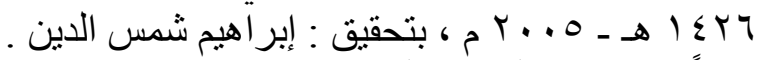

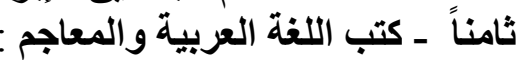

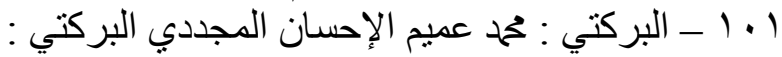

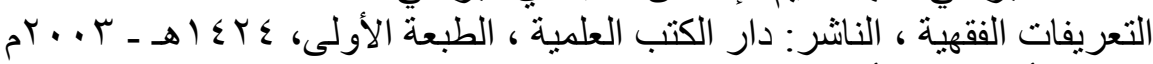

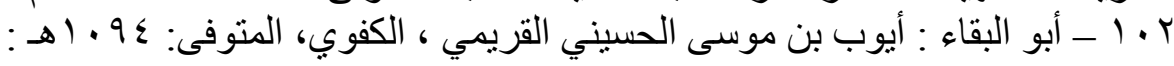

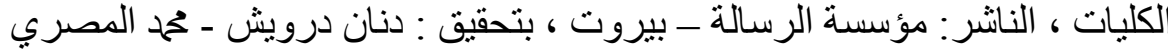

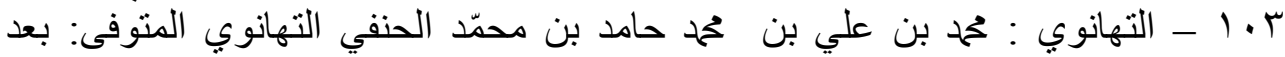

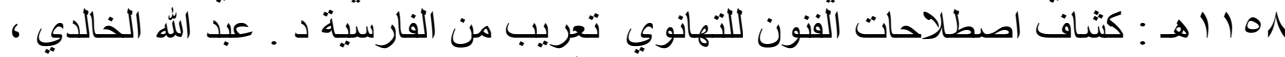

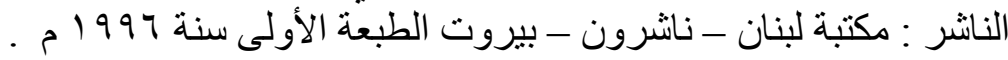

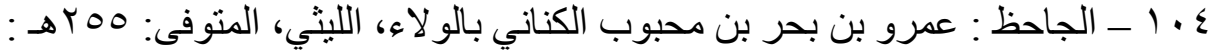

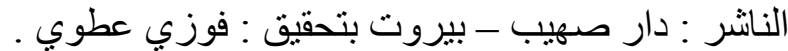

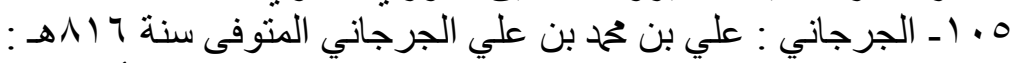

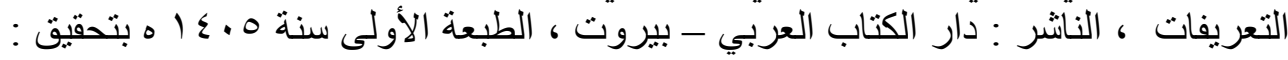

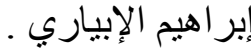

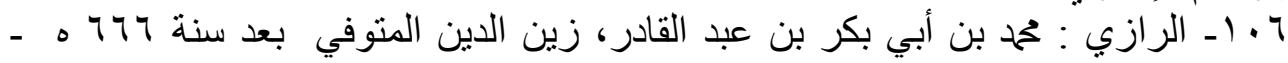

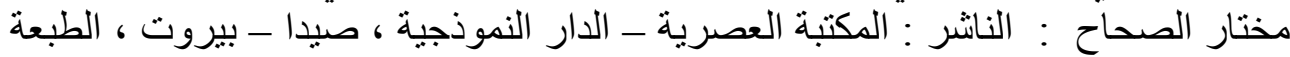

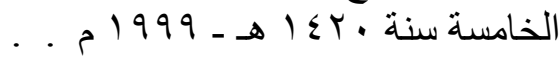

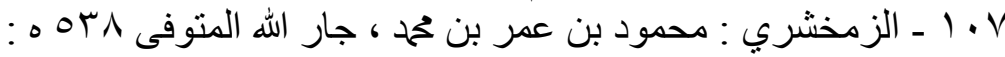

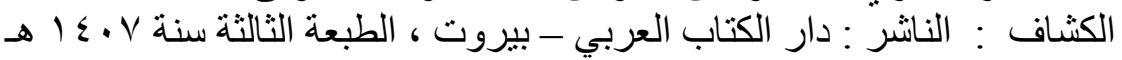

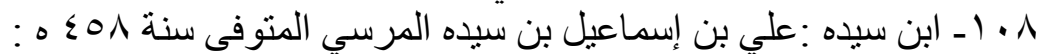

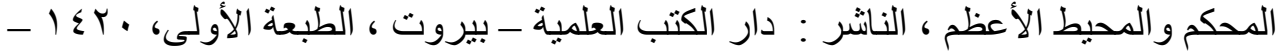

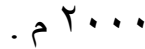

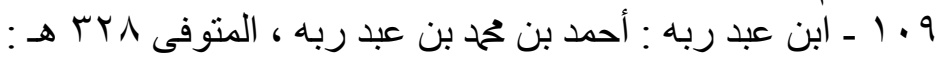

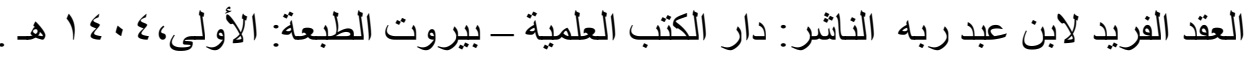

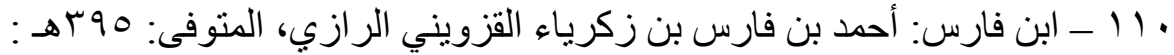

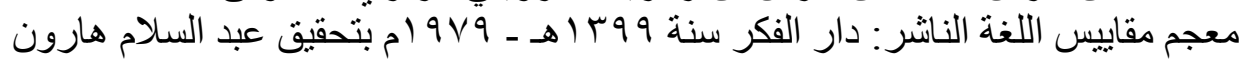

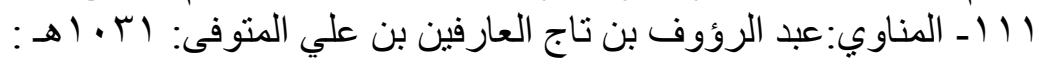

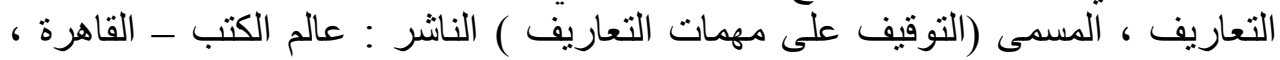

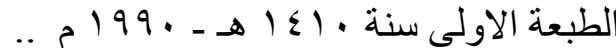

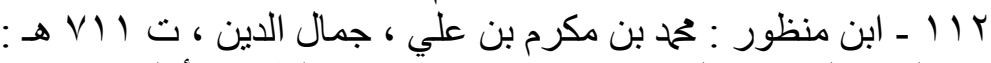

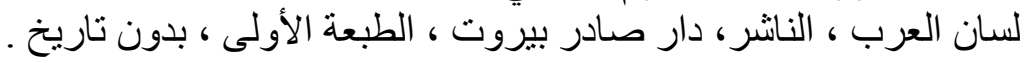


د / خالد محمد حسين إبرا هيم

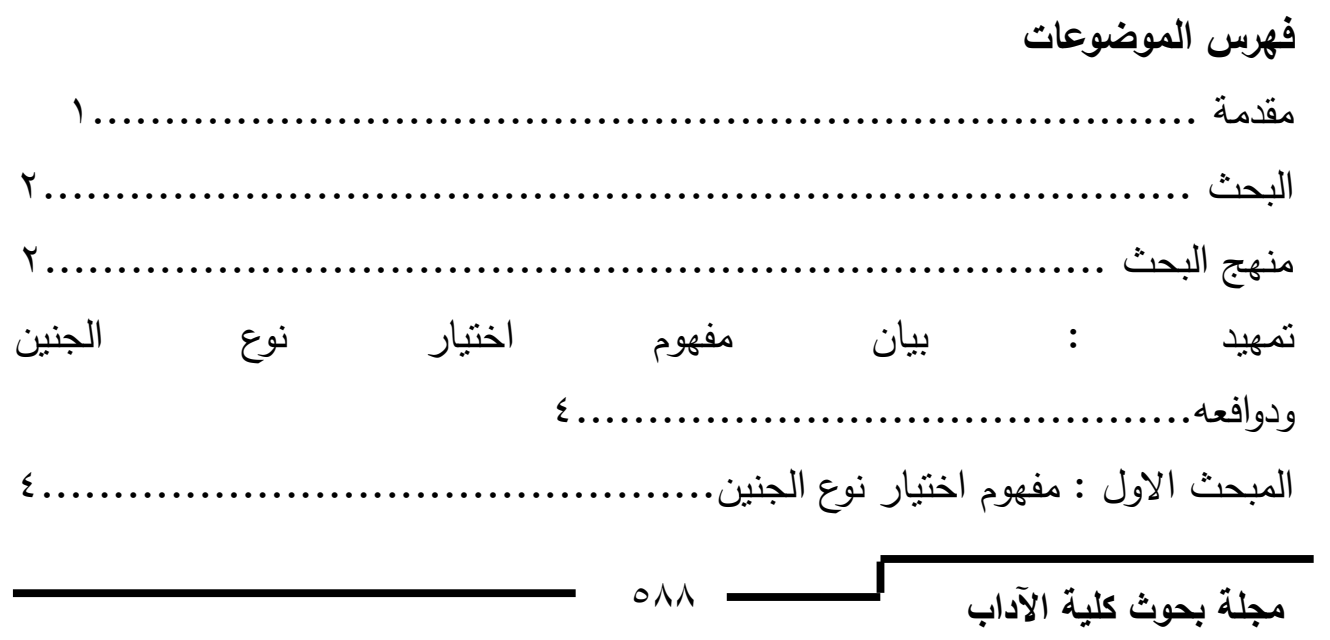


اختيار نوع الجنين ( الاصطفاء الجنسي )

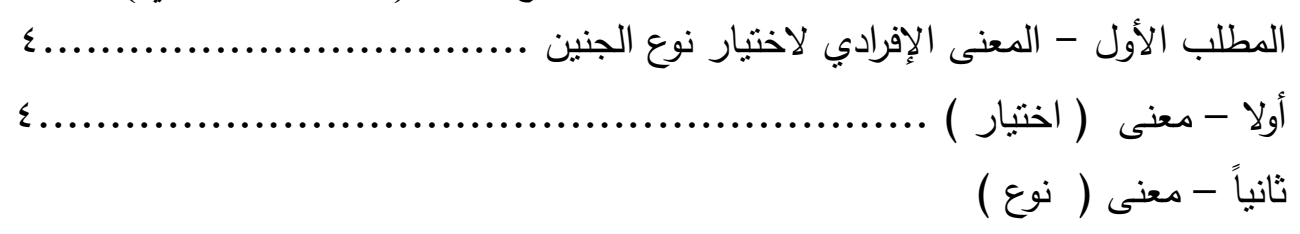

ثالثاً - معنى ( الجنين )

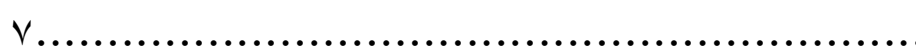

المطلب الثاني - التعريف الاصطلاحي( اللقبي ) لاختيار نوع الجنين ..........................

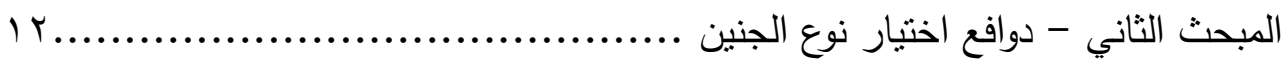
الفصل الأول - الوسائل القديمة لاختيار نوع الجنين وحكمها الثرعي....................... المبحث الأول - الوسائل القديمة لاختيار نوع الجنين

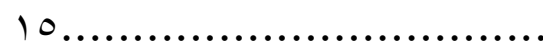
المطلب الأول -اختيار نوع الجنين عند اليونان........................................

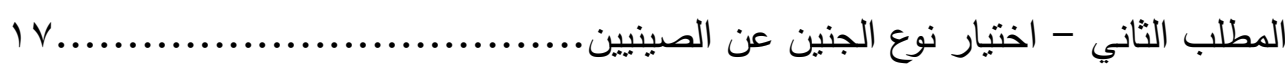

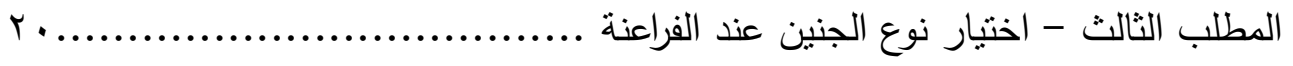

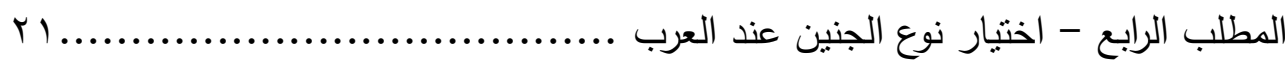
معرفة العرب أن نوع الجنين يرجع إلى الرجل .................................................

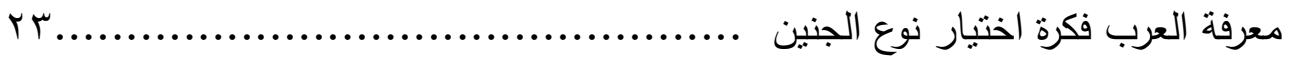
محاولة العرب معرفة نوع الجنين أثناء الحمل $r \leqslant$

المبحث الثاني - الحكم الثرعي للوسائل القديمة لاختيار نوع الجنين ............................. الفصل الثاني - الوسائل الحديثة لاختيار نوع الجنين وحكمها

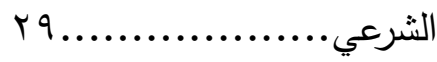

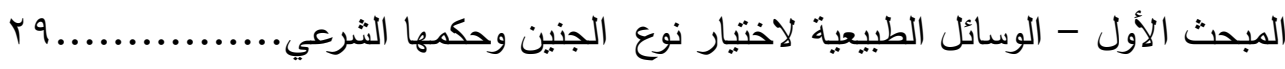

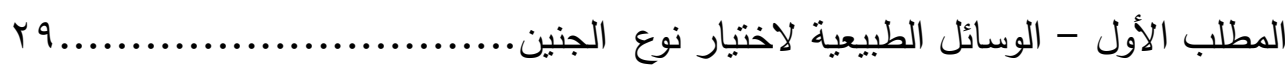


د / خالا محمد حسين إبراهيم

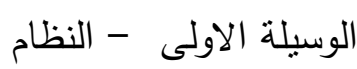

rq.

الغذائي

الوسيلة الثانية - توقيت الجماع بين الزوجين حسب وقت

التبوبض.............................

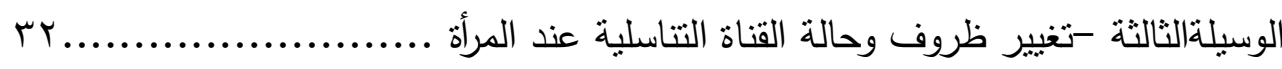
المطلب الثاني - الحكم الثرعي لاختيار نوع الجنين بالوسائل الطبيعية rT.

المبحث الثاني - الوسائل المعملية لاختيار نوع الجنين وحكمها الثرعي

rV.

المطلب الأول - الوسائل المعملية لاختيار نوع الجنين

rV.

الطريقة الأولى : التلقيح الاصطناعي الداخلي

rv.

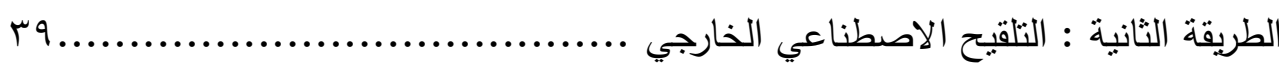
المطلب الثاني - الحكم الثرعي لاختبار نوع الجنين بالوسائل المعملية $\varepsilon$.

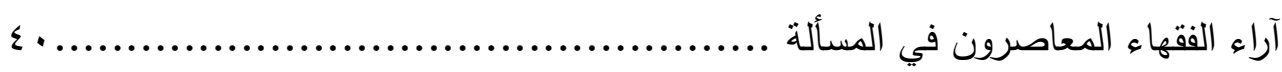

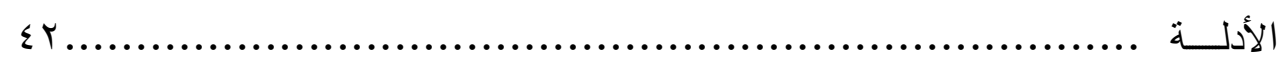

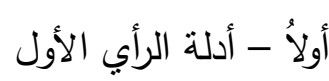
$\varepsilon r$

ثانياً - أدلة أصحاب الرأي الثاني $\leq 7$.

ثالثاً - أدلة أصحاب الرأي الثالث

$$
\text { or }
$$

or سبب الخلاف في المسألة 09. مجلة بحوث كلية الآداب 


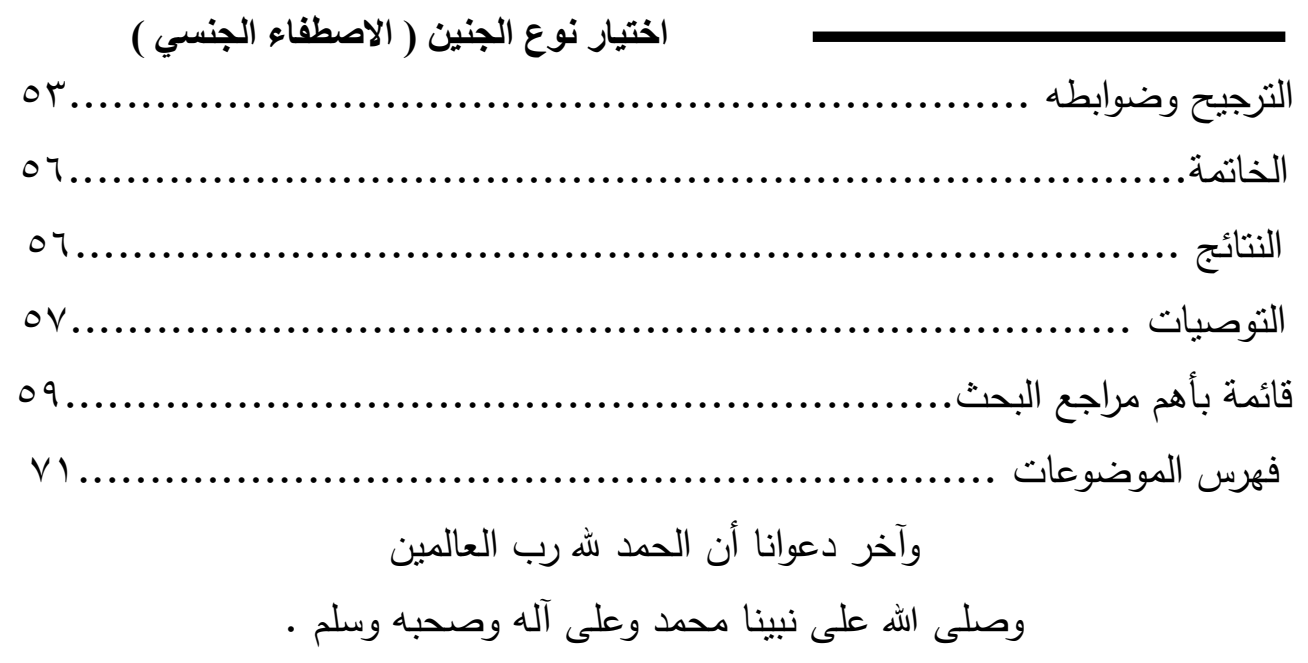

مجلة بحوث كلية الآداب 
د / خالد محم حسين إبراهيم

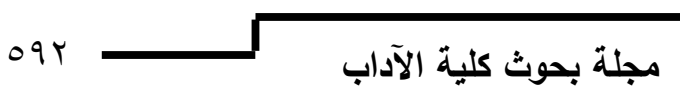

